\title{
Precise Synthesis of Side-Chain-Functionalized Linear Polysiloxanes by Organocatalytic Ring-Opening Polymerization of Monofunctional Cyclotrisiloxanes
}

Keita Fuchise, ${ }^{*}$ Kazuhiko Sato, and Masayasu Igarashi*

Interdisciplinary Research Center for Catalytic Chemistry, National Institute of Advanced Industrial Science and Technology (AIST), Central 5, 1-1-1 Higashi, Tsukuba, Ibaraki 305-8565, Japan

E-mail: k-fuchise@aist.go.jp (K.F.) and masayasu-igarashi@aist.go.jp (M.I)

\section{Supporting Information (SI)}

\section{Contents:}

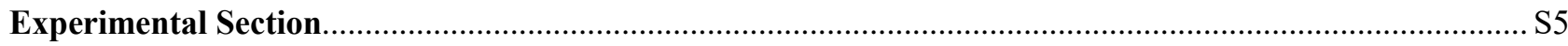

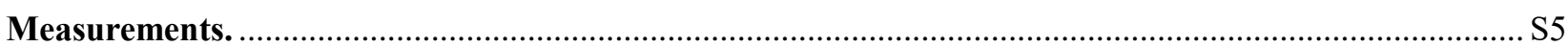

Matrix-assisted laser desorption ionization time-of-flight mass spectrometry (MALDI-TOF MS) ................. S5

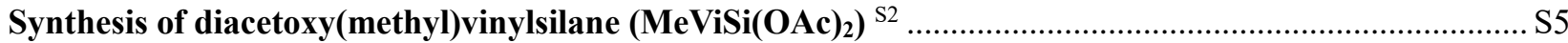

Synthesis of pentamethyl(vinyl)cyclotrisiloxane (VD2).......................................................................... S5

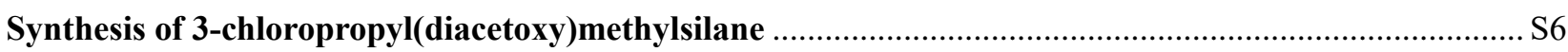

Synthesis of 3-chloropropylpentamethylcyclotrisiloxane (CIPD2) ……................................................ S6

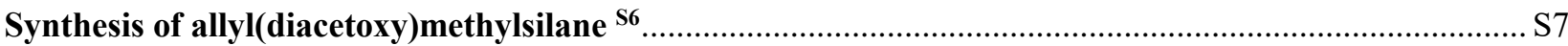

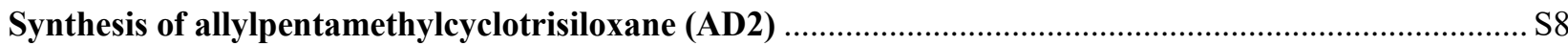

1,3-Trimethylene-2-methylguanidine hydroiodide (TMMG-HI) ................................................................. $\mathrm{S} 8$

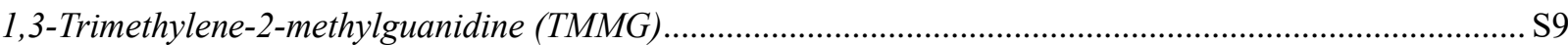

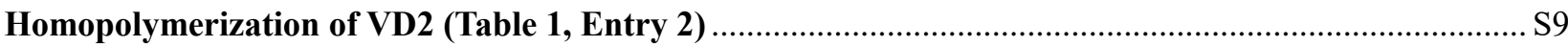

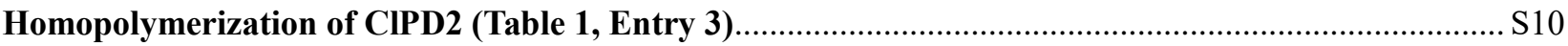

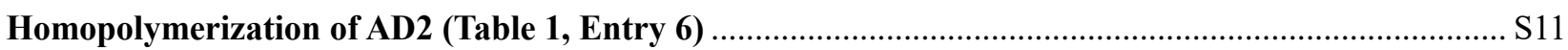

Statistical Copolymerization of two different cyclotrisiloxanes (Table 3) .............................................. S12

Statistical Copolymerization of VD2 and D3 (Table 3, Entry 1) .................................................................. S12

Statistical Copolymerization of ClPD2 and D3 (Table 3, entry 2) .............................................................. S13

Statistical Copolymerization of AD2 and D3 (Table 3, entry 3) ................................................................... 13

Statistical Copolymerization of VD2 and ClPD2 (Table 3, entry 4) ............................................................... $\mathrm{S} 14$

Statistical Copolymerization of AD2 and CIPD2 (Table 3, entry 5) .............................................................. S15

Two-stage Copolymerization of AD2 and D3 (Table 3, entry 7)................................................................. $\mathrm{S} 15$

Determination of the height of the shoulder/peak in the high-molar-mass region $\left(h_{c}\right)$ of the molar-mass

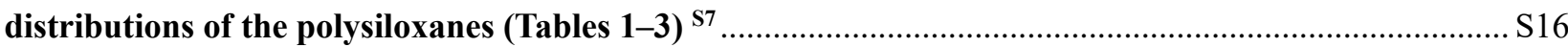

Figure S1. Determination of $h_{\mathrm{c}}(\mathrm{mol} \%)$ for polysiloxanes from their molar-mass distributions, which were estimated from SEC measurements using toluene as the eluent, narrowly dispersed polystyrene standards, and an RI detector.

Determination of number-average degree of polymerization $\left(<X_{\mathrm{n}}>\right)$ and $M_{\mathrm{n}, \mathrm{NMR}}$ of the polysiloxane using

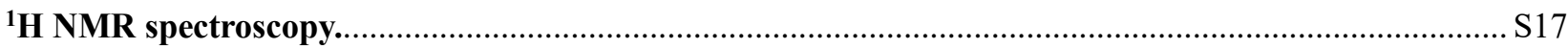

NMR and MALDI-TOF MS spectra and molar-mass distributions of the products .................................. S19 
Figure S2. Full ${ }^{1} \mathrm{H}$ and ${ }^{29} \mathrm{Si}\left\{{ }^{1} \mathrm{H}\right\}$ NMR spectra of $\mathrm{P}(\mathrm{DMS}-\mathrm{co}-\mathrm{MVS})$ end-functionalized with a (chloromethyl)dimethylsilyl group (Table 1, Entry 2, $M_{\mathrm{n}, \mathrm{NMR}}=6.51 \mathrm{kDa}, \bigoplus_{\mathrm{M}}=1.08_{5}$ ).

Figure S3. Full ${ }^{1} \mathrm{H}$ and ${ }^{29} \mathrm{Si}\left\{{ }^{1} \mathrm{H}\right\}$ NMR spectra of $\mathrm{P}(\mathrm{DMS}-\mathrm{co}-\mathrm{ClPMS})$ end-functionalized with a dimethylvinylsilyl group (Table 1, Entry $3, M_{\mathrm{n}, \mathrm{NMR}}=8.87 \mathrm{kDa}, \bigoplus_{\mathrm{M}}=1.09_{4}$ )

Figure S4. Full ${ }^{1} \mathrm{H}$ and ${ }^{29} \mathrm{Si}\left\{{ }^{1} \mathrm{H}\right\}$ NMR spectra of $\mathrm{P}(\mathrm{DMS}-\mathrm{co}-\mathrm{AMS})$ end-functionalized with a (chloromethyl)dimethylsilyl group (Table 1, Entry 6, $M_{\mathrm{n}, \mathrm{NMR}}=6.59 \mathrm{kDa}, \bigoplus_{\mathrm{M}}=1.11_{7}$ ). S22

Figure S5. Positive-ion MALDI-TOF MS spectra of the obtained $\alpha, \omega$-bis[(chloromethyl)dimethylsilyl]terminated $\mathrm{P}(\mathrm{DMS}-\mathrm{co}-\mathrm{MVS})$ (top, $M_{\mathrm{n}, \mathrm{NMR}}=6.51 \mathrm{kDa} ; \emptyset_{\mathrm{M}}=1.08_{5} ;$ Table 1 , entry 2), $\alpha, \omega-$ bis[dimethyl(vinyl)silyl]-terminated P(DMS-co-ClPMS) (middle, $M_{\mathrm{n}, \mathrm{NMR}}=8.87 \mathrm{kDa} ; \bigoplus_{\mathrm{M}}=1.09_{4}$; Table 1 , entry 3), and $\alpha, \omega$-bis[(chloromethyl)dimethylsilyl]-terminated P(DMS-co-AMS) (bottom, $M_{\mathrm{n}, \mathrm{NMR}}=6.59$ $\mathrm{kDa} ; \bigoplus_{\mathrm{M}}=1.11_{7}$; Table 1, entry 6) measured in linear mode using a trans-2-[3-(4-tert-butylphenyl)-2methyl-2-propenylidene]malononitrile (DCTB) matrix and silver trifluoroacetate as the cationization agent. The circles in the right spectrum show the theoretical $\mathrm{m} / \mathrm{z}$ values for the polymers with degrees of polymerization of $n$ and $m$. The circles with lower deviation from $n / m=2 / 1$ are displayed at higher positions

Figure S6. ${ }^{1} \mathrm{H}$ and ${ }^{29} \mathrm{Si}\left\{{ }^{1} \mathrm{H}\right\}$ NMR spectra and molar-mass distribution of $\mathrm{P}(\mathrm{DMS}-\mathrm{co}-\mathrm{VMS})$ end-functionalized with a trimethylsilyl group and a (chloromethyl)dimethylsilyl group (Table 2, Entry 2, $M_{\mathrm{n}, \mathrm{NMR}}=4.88 \mathrm{kDa}, \bigoplus_{\mathrm{M}}$ $\left.=1.11_{7}\right)$.

Figure S7. Full ${ }^{1} \mathrm{H}$ and ${ }^{29} \mathrm{Si}\left\{{ }^{1} \mathrm{H}\right\}$ NMR spectra of $\mathrm{P}(\mathrm{DMS}-\mathrm{co}-\mathrm{VMS})$ end-functionalized with a trimethylsilyl group and a (chloromethyl)dimethylsilyl group (Table 2, Entry 2, $M_{\mathrm{n}, \mathrm{NMR}}=4.88 \mathrm{kDa}, \bigoplus_{\mathrm{M}}=1.11_{7}$ ). S25

Figure S8. ${ }^{1} \mathrm{H}$ and ${ }^{29} \mathrm{Si}\left\{{ }^{1} \mathrm{H}\right\}$ NMR spectra and molar-mass distribution of P(DMS-co-CIPMS) endfunctionalized with a trimethylsilyl group and a dimethylvinylsilyl group (Table 2, Entry 3, $M_{\mathrm{n}, \mathrm{NMR}}=7.83 \mathrm{kDa}$, $\left.\bigoplus_{\mathrm{M}}=1.13_{2}\right)$.

Figure S9. Full ${ }^{1} \mathrm{H}$ and ${ }^{29} \mathrm{Si}\left\{{ }^{1} \mathrm{H}\right\}$ NMR spectra of $\mathrm{P}(\mathrm{DMS}-\mathrm{co}$-CIPMS) end-functionalized with a trimethylsilyl group and a dimethylvinylsilyl group (Table 2, Entry 3, $M_{\mathrm{n}, \mathrm{NMR}}=7.83 \mathrm{kDa}, \oslash_{\mathrm{M}}=1.13_{2}$ ) S27

Figure S10. ${ }^{1} \mathrm{H}$ and ${ }^{29} \mathrm{Si}\left\{{ }^{1} \mathrm{H}\right\}$ NMR spectra and molar-mass distribution of P(DMS-co-AMS) endfunctionalized with a trimethylsilyl group and a (chloromethyl)dimethylsilyl group (Table 2, Entry 6, $M_{\mathrm{n}, \mathrm{NMR}}$ $\left.=7.27 \mathrm{kDa}, \bigoplus_{\mathrm{M}}=1.13_{8}\right)$.

Figure S11. Full ${ }^{1} \mathrm{H}$ and ${ }^{29} \mathrm{Si}\left\{{ }^{1} \mathrm{H}\right\}$ NMR spectra of $\mathrm{P}(\mathrm{DMS}-\mathrm{co}$-AMS) end-functionalized with a trimethylsilyl group and a (chloromethyl)dimethylsilyl group (Table 2, Entry 6, $M_{\mathrm{n}, \mathrm{NMR}}=7.27 \mathrm{kDa}, \emptyset_{\mathrm{M}}=1.13_{8}$ ).

Figure S12. ${ }^{1} \mathrm{H}$ and ${ }^{29} \mathrm{Si}\left\{{ }^{1} \mathrm{H}\right\}$ NMR spectra and molar-mass distribution of P(DMS-co-MVS) endfunctionalized with a (chloromethyl)dimethylsilyl group (Table 3, Entry 1, $M_{\mathrm{n}, \mathrm{NMR}}=7.29 \mathrm{kDa}, \bigoplus_{\mathrm{M}}=1.12_{1}$ ).

Figure S13. Full ${ }^{1} \mathrm{H}$ and ${ }^{29} \mathrm{Si}\left\{{ }^{1} \mathrm{H}\right\}$ NMR spectra of $\mathrm{P}(\mathrm{DMS}-\mathrm{co}-\mathrm{MVS})$ end-functionalized with a (chloromethyl)dimethylsilyl group (Table 3, Entry 1, $M_{\mathrm{n}, \mathrm{NMR}}=7.29 \mathrm{kDa}, \bigoplus_{\mathrm{M}}=1.12_{1}$ ).

Figure S14. Comparison of ${ }^{1} \mathrm{H}$ and ${ }^{29} \mathrm{Si}\left\{{ }^{1} \mathrm{H}\right\}$ NMR spectra of $\mathrm{P}(\mathrm{DMS}-\mathrm{co}-\mathrm{MVS})$ synthesized with different procedures (measured in $\mathrm{CDCl}_{3}$ ). (a) $\mathrm{P}(\mathrm{DMS}-\mathrm{co}$-MVS) obtained from copolymerization of VD2 and D3 (Table 3, Entry $1, m / n=69.2 / 14.1, M_{\mathrm{n}, \mathrm{NMR}}=7.29 \mathrm{kDa}, \bigoplus_{\mathrm{M}}=1.12_{1}$ ), (b) the homopolymerization of VD2 (Table 1, Entry $2, m / n=53.3 / 27.0, M_{\mathrm{n}, \mathrm{NMR}}=6.51 \mathrm{kDa}, \nexists_{\mathrm{M}}=1.085$ ), (c) the copolymerization of 1,3,5-trimethyl-1,3,5trivinylcyclotrisiloxane (V3) and D3 with the semi-batch method (Table 4, Entry $12, m / n=52 / 26, M_{\mathrm{n}, \mathrm{NMR}}=$ 
$\left.6.34 \mathrm{kDa}, D_{\mathrm{M}}=1.13\right),{ }^{\mathrm{S} 1}$ and (d) the copolymerization of $\mathrm{V} 3$ and $\mathrm{D} 3$ with the premix method $(\mathrm{m} / \mathrm{n}=78 / 79$, $\left.M_{\mathrm{n}, \mathrm{NMR}}=12.9 \mathrm{kDa}, \bigoplus_{\mathrm{M}}=1.37\right) .{ }^{\mathrm{S} 1}$ The polymerizations (c) and (d) were described in our previous article. ${ }^{\mathrm{S} 1}$

Figure S15. ${ }^{1} \mathrm{H}$ and ${ }^{29} \mathrm{Si}\left\{{ }^{1} \mathrm{H}\right\}$ NMR spectra and molar-mass distribution of P(DMS-co-ClPMS) endfunctionalized with a dimethylvinylsilyl group (Table 3, Entry 2, $M_{\mathrm{n}, \mathrm{NMR}}=7.34 \mathrm{kDa}, \emptyset_{\mathrm{M}}=1.11_{3}$ )...... S33

Figure S16. Full ${ }^{1} \mathrm{H}$ and ${ }^{29} \mathrm{Si}\left\{{ }^{1} \mathrm{H}\right\}$ NMR spectra of $\mathrm{P}(\mathrm{DMS}-\mathrm{co}-\mathrm{ClPMS})$ end-functionalized with a dimethylvinylsilyl group (Table 3, Entry 2, $M_{\mathrm{n}, \mathrm{NMR}}=7.34 \mathrm{kDa}, \bigoplus_{\mathrm{M}}=1.11_{3}$ )......

Figure S17. ${ }^{1} \mathrm{H}$ and ${ }^{29} \mathrm{Si}\left\{{ }^{1} \mathrm{H}\right\}$ NMR spectra and molar-mass distribution of P(DMS-co-AMS) endfunctionalized with a (chloromethyl)dimethylsilyl group (Table 3, Entry 3, $M_{\mathrm{n}, \mathrm{NMR}}=6.57 \mathrm{kDa}, \bigoplus_{\mathrm{M}}=1.10_{9}$ ).

Figure S18. Full ${ }^{1} \mathrm{H}$ and ${ }^{29} \mathrm{Si}\left\{{ }^{1} \mathrm{H}\right\}$ NMR spectra of $\mathrm{P}(\mathrm{DMS}-$-co-AMS) end-functionalized with a (chloromethyl)dimethylsilyl group (Table 3, Entry 3, $M_{\mathrm{n}, \mathrm{NMR}}=6.57 \mathrm{kDa}, \bigoplus_{\mathrm{M}}=1.10_{9}$ ). S36

Figure S19. ${ }^{1} \mathrm{H}$ and ${ }^{29} \mathrm{Si}\left\{{ }^{1} \mathrm{H}\right\}$ NMR spectra and molar-mass distribution of P(DMS-co-AMS) endfunctionalized with a (chloromethyl)dimethylsilyl group (Table 3, Entry $6, M_{\mathrm{n}, \mathrm{NMR}}=5.95 \mathrm{kDa}, \bigoplus_{\mathrm{M}}=1.11_{3}$ ).

Figure S20. Full ${ }^{1} \mathrm{H}$ and ${ }^{29} \mathrm{Si}\left\{{ }^{1} \mathrm{H}\right\}$ NMR spectra and molar-mass distribution of P(DMS-co-AMS) endfunctionalized with a (chloromethyl)dimethylsilyl group (Table 3, Entry $6, M_{\mathrm{n}, \mathrm{NMR}}=5.95 \mathrm{kDa}, \emptyset_{\mathrm{M}}=1.11_{3}$ ).

Figure S21. ${ }^{1} \mathrm{H}$ and ${ }^{29} \mathrm{Si}\left\{{ }^{1} \mathrm{H}\right\}$ NMR spectra and molar-mass distribution of P(DMS-co-MVS-co-CIPMS) endfunctionalized with a (chloromethyl)dimethylsilyl group (Table 3, Entry 4, $M_{\mathrm{n}, \mathrm{NMR}}=6.75 \mathrm{kDa}, \bigoplus_{\mathrm{M}}=1.10_{2}$ ).

Figure S22. Full ${ }^{1} \mathrm{H}$ and ${ }^{29} \mathrm{Si}\left\{{ }^{1} \mathrm{H}\right\}$ NMR spectra of P(DMS-co-MVS-co-CIPMS) end-functionalized with a (chloromethyl)dimethylsilyl group (Table 3, Entry 4, $M_{\mathrm{n}, \mathrm{NMR}}=6.75 \mathrm{kDa}, \bigoplus_{\mathrm{M}}=1.10_{2}$ ). S40

Figure S23. ${ }^{1} \mathrm{H}$ and ${ }^{29} \mathrm{Si}\left\{{ }^{1} \mathrm{H}\right\}$ NMR spectra and molar-mass distribution of P(DMS-co-AMS-co-ClPMS) endfunctionalized with a (chloromethyl)dimethylsilyl group (Table 3, Entry $5, M_{\mathrm{n}, \mathrm{NMR}}=7.47 \mathrm{kDa}, D_{\mathrm{M}}=1.13_{1}$ ).

Figure S24. Full ${ }^{1} \mathrm{H}$ and ${ }^{29} \mathrm{Si}\left\{{ }^{1} \mathrm{H}\right\}$ NMR spectra of P(DMS-co-AMS-co-CIPMS) end-functionalized with a (chloromethyl)dimethylsilyl group (Table 3, Entry 5, $M_{\mathrm{n}, \mathrm{NMR}}=7.47 \mathrm{kDa}, \bigoplus_{\mathrm{M}}=1.13_{1}$ ). S42

Figure S25. ${ }^{1} \mathrm{H}$ and ${ }^{29} \mathrm{Si}\left\{{ }^{1} \mathrm{H}\right\}$ NMR spectra and molar-mass distribution of triblock copolymer of P(DMS-coAMS $)_{\mathrm{A}}-b-\mathrm{P}(\mathrm{DMS}-c o-\mathrm{AMS})_{\mathrm{B}}-b-\mathrm{P}(\mathrm{DMS}-c o-\mathrm{AMS})_{\mathrm{A}}$ end-functionalized with (chloromethyl)dimethylsilyl groups (Table 3, Entry 7b, $M_{\mathrm{n}, \mathrm{NMR}}=6.21 \mathrm{kDa}, \emptyset_{\mathrm{M}}=1.09_{8}$ ).

Figure S26. Full ${ }^{1} \mathrm{H}$ and ${ }^{29} \mathrm{Si}\left\{{ }^{1} \mathrm{H}\right\}$ NMR spectra of triblock copolymer of P(DMS-co-AMS) $)_{\mathrm{A}}-b-\mathrm{P}(\mathrm{DMS}-c o-$ AMS $)_{\mathrm{B}}-b$-P(DMS-co-AMS) $)_{\mathrm{A}}$ end-functionalized with a (chloromethyl)dimethylsilyl group (Table 3, Entry 7b,

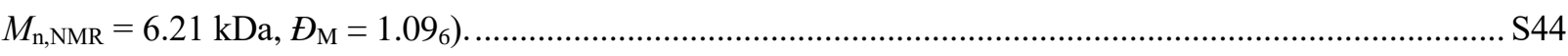

Kinetics of the polymerizations S45

Figure S27. First-order kinetic plots for the polymerizations of VD2 (left, Table 1, Entry 2), CIPD2 (center, Table 1, Entry 3), and AD2 (right, Table 1, Entry 6) using water as an initiator and guanidine bases as catalysts.

Figure S28. First-order kinetic plots for the polymerizations of VD2 (left, Table 2, Entry 2), CIPD2 (center, Table 2, Entry 3), and AD2 (right, Table 2, Entry 6) using $\mathrm{MeD} 4 \mathrm{OH}$ or $\mathrm{Ph}_{3} \mathrm{SiOH}$ as an initiator and guanidine 
bases as catalysts.

Figure S29. First-order kinetic plots for the copolymerizations of D3 and FnD2, i.e. VD2 (left, Table 3, Entry 1), CIPD2 (center, Table 3, Entry 2), and AD2 (right, Table 3, Entry 3) using water as an initiator and guanidine bases as catalysts. . 446

Figure S30. First-order kinetic plots for the copolymerizations of VD2 and CIPD2 (left, Table 3, Entry 4) as well as AD2 and CIPD2 (Table 3, Entry 5) using water as an initiator and guanidine bases as catalysts...... S46 Figure S31. First-order kinetic plots for the copolymerizations of D3 and AD2 conducted using the premix method with $[\mathrm{AD} 2]_{0} /[\mathrm{D} 3]_{0} /\left[\mathrm{H}_{2} \mathrm{O}\right]_{0} /[\mathrm{TMMG}]_{0}=7.5 / 17.5 / 1 / 0.25$ (left, Table 3, Entry 6) as well as the copolymerizations of D3 and AD2 by the two-stage method (right, Table 3, Entry 7). S46

Figure S32. Comparison of ${ }^{29} \mathrm{Si}\left\{{ }^{1} \mathrm{H}\right\}$ NMR spectra of P(DMS-co-MVS) synthesized with different procedures shown in Table 4 (measured in $\mathrm{CDCl}_{3}$ ).

Figure S33. Comparison of ${ }^{29} \mathrm{Si}\left\{{ }^{1} \mathrm{H}\right\}$ NMR spectra of P(DMS-co-ClPMS) synthesized with different procedures shown in Table 4 (measured in $\mathrm{CDCl}_{3}$ ).

Figure S34. Comparison of ${ }^{29} \mathrm{Si}\left\{{ }^{1} \mathrm{H}\right\}$ NMR spectra of $\mathrm{P}(\mathrm{DMS}-\mathrm{co}-\mathrm{AMS})$ synthesized with different procedures shown in Table 4 (measured in $\mathrm{CDCl}_{3}$ ).

Figure S35. Comparison of the regio-selective propagation and the statistical propagation in the ROP of monofunctional cyclotrisiloxanes.

Scheme S1. Possible and plausible elementary reactions in the polymerization of cyclotrisiloxanes using a water or a silanol as an initiator and a strong organic base as a catalyst. S50

Method to simulate the monomeric unit sequences and chain-length distributions of the side-chainfunctionalized polysiloxanes S51 $P(D M S$-co-MVS) S55

Figure S36. Simulated results for the sequence of monomeric units and distribution of chain length of P(DMSco-MVS) synthesized with different methods. The parameters used for each polymer are indicated in the figures. The first, second, and sixth data are also shown in Figure 1. S55 $P(D M S$-co-ClPMS $)$ S56

Figure S37. Simulated results for the sequence of monomeric units and distribution of chain length of P(DMSco-CIPMS) synthesized with different methods. The parameters used for each polymer are indicated in the figures. S56 $P(D M S-c o-A M S)$. S57

Figure S38. Simulated results for the sequence of monomeric units and distribution of chain length of P(DMSco-AMS) synthesized with different methods. The parameters used for each polymer are indicated in the figures.

Figure S39. Simulated results for the sequence of monomeric units and distribution of chain length of P(DMSco-MVS-co-ClPMS) and P(DMS-co-AMS-co-CIPMS) synthesized with different methods. The parameters used for each polymer are indicated in the figures. 


\section{Experimental Section}

Measurements.

Matrix-assisted laser desorption ionization time-of-flight mass spectrometry (MALDI-TOF MS)

MALDI-TOF MS of the obtained polymers was performed using a Bruker autoflex ${ }^{\mathrm{TM}}$ speed TOF/TOF system with a Smartbeam laser (Bruker Daltonics). Spectra were acquired in the positive linear mode by accumulating 200 to 2000 laser shots at a $19 \mathrm{kV}$ acceleration voltage. External calibration was performed using Tosoh TSKgel ${ }^{\circledR}$ standard Polystyrene TS-502 $\left(M_{\mathrm{w}}=2.63 \mathrm{~kg} \mathrm{~mol}^{-1}, \bigoplus_{\mathrm{M}}=1.05\right)$ and TS-521 $\left(M_{\mathrm{w}}=5.06 \mathrm{~kg} \mathrm{~mol}^{-1}, \bigoplus_{\mathrm{M}}=1.02\right)$. In a typical measurement, a solution of the external standard was prepared by mixing TS-502 $\left(12.5 \mu \mathrm{L}, 10 \mathrm{mg} \mathrm{mL}^{-1}\right.$ in THF), TS-521 (12.5 $\mu \mathrm{L}, 10 \mathrm{mg} \mathrm{mL}^{-1}$ in THF), the matrix (DCTB, $50 \mathrm{mg} \mathrm{mL}^{-1}, 20 \mu \mathrm{L}$ ), and the cationization agent (TFAAg, $\left.2.2 \mathrm{mg} \mathrm{mL}^{-1}, 45 \mu \mathrm{L}\right)$. Solution of the samples were prepared by mixing polysiloxane $\left(30 \mathrm{mg} \mathrm{mL}^{-1}\right.$ in THF, $10 \mu \mathrm{L}$ ), the matrix (DCTB, $50 \mathrm{mg} \mathrm{mL}^{-1}, 20 \mu \mathrm{L}$ ), and the cationization agent (TFAAg, $2.2 \mathrm{mg} \mathrm{mL}^{-1}, 45 \mu \mathrm{L}$ ). Approximately $10 \mu \mathrm{L}$ of the obtained mixture was spotted on a ground steel target plate and dried prior to measurements.

\section{Synthesis of diacetoxy(methyl)vinylsilane $\left(\mathrm{MeViSi}(\mathrm{OAc})_{2}\right)^{\mathrm{s} 2}$}

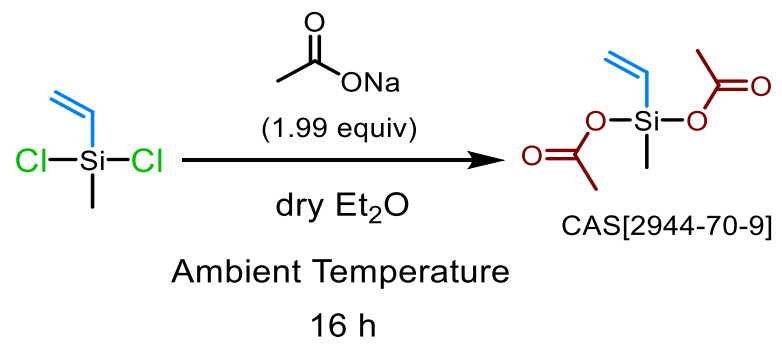

$\mathrm{MeViSiCl}_{2}(26.00 \mathrm{~g}, 184.3 \mathrm{mmol})$ was added to a mixture of AcONa (30.02 g, $\left.366.0 \mathrm{mmol}\right)$ and dry $\mathrm{Et}_{2} \mathrm{O}(184$ $\mathrm{mL})$. After $16 \mathrm{~h}$, the solution was filtered through a glass filter. The filtrate was concentrated to obtain $\mathrm{MeViSi}(\mathrm{OAc})_{2}$ as a colorless liquid. Yield: $24.78 \mathrm{~g}(131.6 \mathrm{mmol}, 71.4 \%)$.

${ }^{1} \mathrm{H}$ NMR (600 MHz, $\left.\mathrm{CDCl}_{3}\right): \delta 6.24-6.13\left(\mathrm{~m}, 2 \mathrm{H},=\mathrm{CH}\right.$-Si and $\left.H_{2} \mathrm{C}=\mathrm{CH}-\right), 6.05(\mathrm{dd}, J=4.7 \mathrm{~Hz}$ and $19.2 \mathrm{~Hz}, 1 \mathrm{H}$, $\left.\mathrm{H}_{2} \mathrm{C}=\mathrm{CH}-\right), 2.12\left(\mathrm{~s}, 6 \mathrm{H}, \mathrm{H}_{3} \mathrm{CCO}\right), 0.60\left(\mathrm{~s}, 3 \mathrm{H}, \mathrm{SiCH}_{3}\right) .{ }^{13} \mathrm{C}\left\{{ }^{1} \mathrm{H}\right\} \mathrm{NMR}\left(151 \mathrm{MHz}, \mathrm{CDCl}_{3}\right): \delta 170.70\left(\mathrm{H}_{3} \mathrm{CCO}\right)$, $137.58\left(\mathrm{H}_{2} \mathrm{C}=\right), 130.71(=\mathrm{CH}-\mathrm{Si}), 22.56\left(\mathrm{H}_{3} \mathrm{CCO}\right),-3.50\left(\mathrm{SiCH}_{3}\right) .{ }^{29} \mathrm{Si}\left\{{ }^{1} \mathrm{H}\right\} \mathrm{NMR}\left(119 \mathrm{MHz}, \mathrm{CDCl}_{3}\right): \delta-12.42$.

\section{Synthesis of pentamethyl(vinyl)cyclotrisiloxane (VD2)}

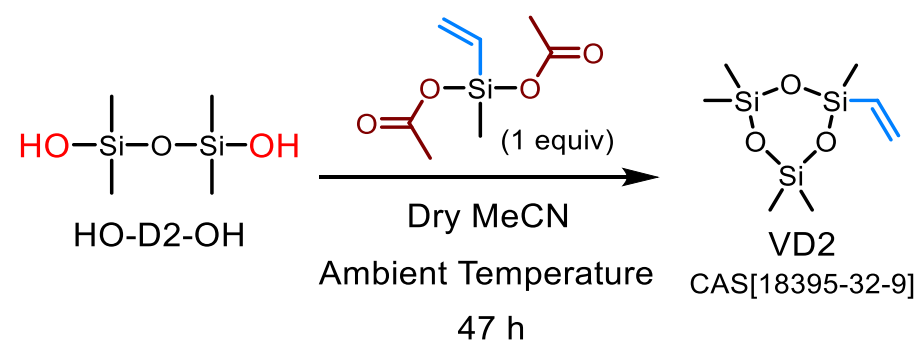

$\mathrm{MeViSi}(\mathrm{OAc})_{2}(8.03 \mathrm{~g}, 42.6 \mathrm{mmol})$ in dry $\mathrm{MeCN}$ (40 mL) was dropwise added to a solution of HO-D2-OH (7.09 $\mathrm{g}, 42.6 \mathrm{mmol})$ in dry $\mathrm{MeCN}(173 \mathrm{~mL})$ at ambient temperature. The reaction mixture was stirred for $47 \mathrm{~h}$. Imidazole 
$(17.40 \mathrm{~g}, 255.8 \mathrm{mmol})$ was added to the reaction mixture. The $\mathrm{MeCN}$ phase was extracted with hexane $(50 \mathrm{~mL} \times$

4). The separated hexane phase was washed with water $(200 \mathrm{~mL} \times 3)$, dried over $\mathrm{Na}_{2} \mathrm{SO}_{4}$, filtered, and concentrated at $110 \mathrm{hPa}$. The residue was distilled under reduced pressure to give VD2 as a colorless liquid. Yield: $4.12 \mathrm{~g}$ (17.6 mmol, $41.3 \%)$.

M.p. $20-23^{\circ} \mathrm{C}$. B.p. $46-47.5^{\circ} \mathrm{C} / 28.5 \mathrm{mmHg}$ (Lit. $\left.85^{\circ} \mathrm{C} / 80 \mathrm{mmHg}\right) .{ }^{\mathrm{S} 3}$ (Lit. $45-50{ }^{\circ} \mathrm{C} / 14 \mathrm{mmHg}$ ). ${ }^{\mathrm{S}} \quad{ }^{1} \mathrm{H}$ NMR $\left(600 \mathrm{MHz}, \mathrm{CDCl}_{3}\right): \delta$ 6.09-6.00 (m, 2H, $\left.\mathrm{H}_{2} \mathrm{C}=\mathrm{CH}-\right), 5.88(\mathrm{dd}, 1 \mathrm{H}, \mathrm{J}=7.1 \mathrm{~Hz}, 17.0 \mathrm{~Hz},=\mathrm{CH}-\mathrm{Si}), 0.24(\mathrm{~s}, 3 \mathrm{H}$, $\mathrm{SiMeVi}), 0.19_{0}$ (s, 6H, SiMe $), 0.17_{6}(\mathrm{~s}, 6 \mathrm{H}, \mathrm{SiMe}) .{ }^{13} \mathrm{C}\left\{{ }^{1} \mathrm{H}\right\} \mathrm{NMR}\left(151 \mathrm{MHz}, \mathrm{CDCl}_{3}\right): \delta 135.88$ (=CH-Si), 134.03 $\left(\mathrm{H}_{2} \mathrm{C}=\right), 0.95(\mathrm{SiMe}), 0.87(\mathrm{SiMe}),-0.77(\mathrm{SiMe}) .{ }^{29} \mathrm{Si}\left\{{ }^{1} \mathrm{H}\right\} \mathrm{NMR}\left(119 \mathrm{MHz}, \mathrm{CDCl}_{3}\right): \delta-7.71\left(\mathrm{SiMe}_{2}\right),-23.29$ (SiMe). HRMS (APCI, in $\mathrm{MeOH}$ ) calcd for $\left[\mathrm{C}_{7} \mathrm{H}_{19} \mathrm{O}_{3} \mathrm{Si}_{3}\right]^{+}[\mathrm{M}+\mathrm{H}]^{+} 235.0637$, found 235.0636.

\section{Synthesis of 3-chloropropyl(diacetoxy)methylsilane}

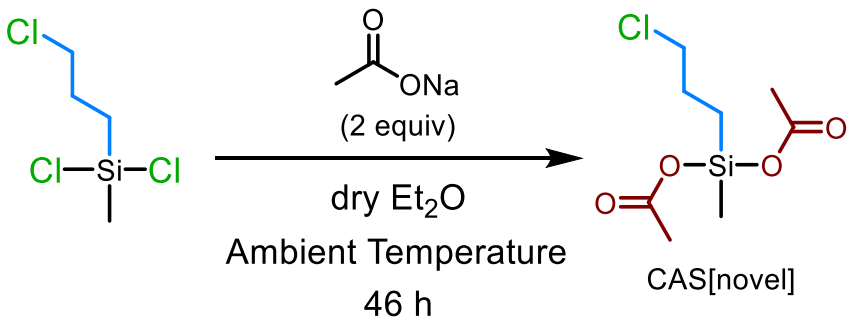

3-Chloropropyl(dichloro)methylsilane $(10.00 \mathrm{~g}, 52.21 \mathrm{mmol})$ was added to a mixture of AcONa $(8.57 \mathrm{~g}, 104$ $\mathrm{mmol})$ and dry $\mathrm{Et}_{2} \mathrm{O}(52 \mathrm{~mL})$ under an argon atmosphere. The reaction mixture was stirred for $46 \mathrm{~h}$ at ambient temperature and filtered through a glass filter. The filtrate was concentrated under reduced pressure (at $9 \mathrm{mmHg}$ ) to obtain the target compound (10.81 g, $45.28 \mathrm{mmol}, y .86 .7 \%)$ as a colorless liquid.

${ }^{1} \mathrm{H}$ NMR (600 MHz, $\left.\mathrm{CDCl}_{3}\right): \delta 3.52\left(\mathrm{t}, 2 \mathrm{H}, J=6.7 \mathrm{~Hz}, \mathrm{ClCH}_{2}\right), 2.12\left(\mathrm{~s}, 6 \mathrm{H}, \mathrm{COCH}_{3}\right), 1.93-1.87(\mathrm{~m}, 2 \mathrm{H}$, $\left.\mathrm{ClCH}_{2} \mathrm{CH}_{2}\right), 1.12-1.06\left(\mathrm{~m}, 2 \mathrm{H}, \mathrm{CH}_{2} \mathrm{Si}\right), 0.52\left(\mathrm{~s}, 3 \mathrm{H}, \mathrm{SiCH}_{3}\right) .{ }^{13} \mathrm{C}\left\{{ }^{1} \mathrm{H}\right\} \mathrm{NMR}\left(151 \mathrm{MHz}, \mathrm{CDCl}_{3}\right): \delta 170.84\left(\mathrm{H}_{3} \mathrm{CCO}\right)$, $47.02\left(\mathrm{ClCH}_{2}-\right), 25.68\left(\mathrm{ClCH}_{2} \mathrm{CH}_{2}-\right), 22.53\left(\mathrm{H}_{3} \mathrm{CCO}\right), 12.38\left(\mathrm{CH}_{2} \mathrm{Si}\right),-2.83\left(\mathrm{SiCH}_{3}\right) .{ }^{29} \mathrm{Si}\left\{{ }^{1} \mathrm{H}\right\} \mathrm{NMR}(119 \mathrm{MHz}$, $\left.\mathrm{CDCl}_{3}\right): \delta 3.40$.

\section{Synthesis of 3-chloropropylpentamethylcyclotrisiloxane (CIPD2)}

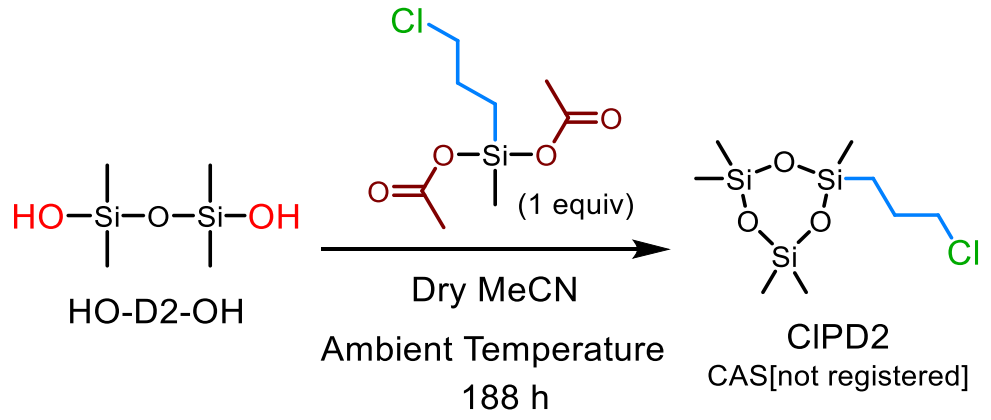

3-chloropropyl(diacetoxy)methylsilane $(8.38 \mathrm{~g}, 35.1 \mathrm{mmol})$ was added to a solution of HO-D2-OH (5.84 g, 35.1 $\mathrm{mmol})$ in dry $\mathrm{MeCN}(230 \mathrm{~mL})$ at ambient temperature. The reaction mixture was stirred for $188 \mathrm{~h}$. Imidazole (14.4 
$\mathrm{g}, 211 \mathrm{mmol})$ was added to the reaction mixture. The $\mathrm{MeCN}$ phase was extracted with hexane $(125 \mathrm{~mL} \times 5)$. The separated hexane phase was washed with water $(160 \mathrm{~mL} \times 3)$, dried over $\mathrm{Na}_{2} \mathrm{SO}_{4}$, filtered, and concentrated at 110 $\mathrm{hPa}$. The residue was distilled under reduced pressure to give CIPD2 as a colorless liquid. Yield: $6.71 \mathrm{~g}$ (23.5 mmol, $67.1 \%)$.

M.p. 6-8 ${ }^{\circ} \mathrm{C}$. B.p. $91-92.5^{\circ} \mathrm{C} / 15 \mathrm{mmHg}$ (Lit. $95^{\circ} \mathrm{C} / 10 \mathrm{mmHg}$ ). ${ }^{\mathrm{S}}{ }^{1} \mathrm{H}$ NMR $\left(600 \mathrm{MHz}, \mathrm{CDCl}_{3}\right): \delta 3.53$ (t, $2 \mathrm{H}$, $\left.J=6.9 \mathrm{~Hz}, \mathrm{ClCH}_{2}\right), 1.89-1.81\left(\mathrm{~m}, 2 \mathrm{H}, \mathrm{ClCH}_{2} \mathrm{CH}_{2}\right), 0.75-0.68\left(\mathrm{~m}, 2 \mathrm{H}, \mathrm{CH}_{2} \mathrm{Si}\right), 0.178\left(\mathrm{~s}, 6 \mathrm{H},-\mathrm{Si}\left(\mathrm{CH}_{3}\right) \mathrm{CH}_{3}-\mathrm{O}-\right.$ $\left.\mathrm{Si}\left(\mathrm{CH}_{3}\right) \mathrm{CH}_{3}-\right), 0.175$ (s, 6H, -Si( $\left.\left.\mathrm{CH}_{3}\right) \mathrm{CH}_{3}-\mathrm{O}-\mathrm{Si}\left(\mathrm{CH}_{3}\right) \mathrm{CH}_{3}-\right), 0.171$ (s, $\left.3 \mathrm{H}, \mathrm{Si}\left(\mathrm{CH}_{2} \mathrm{CH}_{2} \mathrm{CH}_{2} \mathrm{Cl}\right) \mathrm{CH}_{3}\right) .{ }^{13} \mathrm{C}\left\{{ }^{1} \mathrm{H}\right\} \mathrm{NMR}$

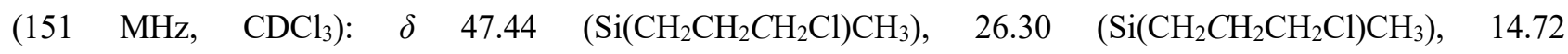
$\left(\mathrm{Si}\left(\mathrm{CH}_{2} \mathrm{CH}_{2} \mathrm{CH}_{2} \mathrm{Cl}\right) \mathrm{CH}_{3}\right), \quad 0.95 \quad\left(-\mathrm{Si}\left(\mathrm{CH}_{3}\right) \mathrm{CH}_{3}-\mathrm{O}-\mathrm{Si}\left(\mathrm{CH}_{3}\right) \mathrm{CH}_{3}-\right), \quad 0.87 \quad\left(-\mathrm{Si}\left(\mathrm{CH}_{3}\right) \mathrm{CH}_{3}-\mathrm{O}-\mathrm{Si}\left(\mathrm{CH}_{3}\right) \mathrm{CH}_{3}-\right), \quad-0.48$

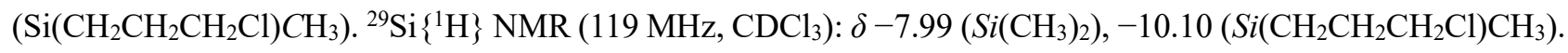
HRMS (APCI, in $\mathrm{MeOH}$ ) calcd for $\left[\mathrm{C}_{8} \mathrm{H}_{22} \mathrm{O}_{3} \mathrm{Si}_{3} \mathrm{Cl}\right]^{+}[\mathrm{M}+\mathrm{H}]^{+}$285.0560, found 285.0558.

The titled compound was once synthesized from 1,3-dihydroxy-1,1,3,3-tetramethyldisiloxane and 3chloropropyl(dichloro)methylsilane, although the yield is not explicitly written. ${ }^{\mathrm{S} 5}$

\section{Synthesis of allyl(diacetoxy)methylsilane ${ }^{\mathrm{S6}}$}
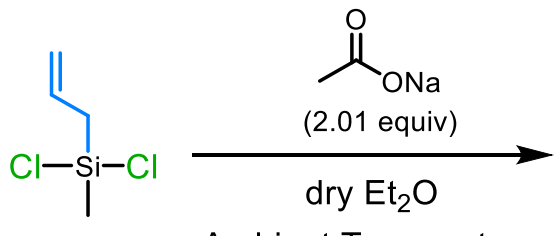

Ambient Temperature

$281 \mathrm{~h}$

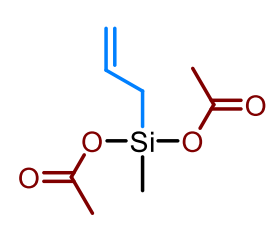

CAS[18387-85-4]

Allyl(dichloro)methylsilane (5.35 g, $34.5 \mathrm{mmol})$ was added to a mixture of AcONa (5.69 g, $69.4 \mathrm{mmol})$ and dry $\mathrm{Et}_{2} \mathrm{O}(34.5 \mathrm{~mL})$ under an argon atmosphere at ambient temperature. The reaction mixture was stirred for $281 \mathrm{~h}$ and filtered through a glass filter. The filtrate was concentrated under reduced pressure (at $9 \mathrm{mmHg}$ ) to obtain the target compound (6.53 g, $32.3 \mathrm{mmol}, y .93 .6 \%)$ as a colorless liquid.

${ }^{1} \mathrm{H}$ NMR $\left(600 \mathrm{MHz}, \mathrm{CDCl}_{3}\right): \delta$ 5.81-5.70 (m, 1H, $\left.\mathrm{H}_{2} \mathrm{C}=\mathrm{CH}-\right)$, 5.04-4.99 (m, $\left.1 \mathrm{H}, \mathrm{H}_{2} \mathrm{C}=\mathrm{CH}-\right), 5.00-4.96(\mathrm{~m}, 1 \mathrm{H}$, $\left.\mathrm{H}_{2} \mathrm{C}=\mathrm{CH}-\right), 2.11$ (s, 6H, $\left.\mathrm{H}_{3} \mathrm{CCO}\right), 2.01-1.95\left(\mathrm{~m}, 2 \mathrm{H}, \mathrm{SiCH}{ }_{2}\right), 0.51$ (s, 3H, SiMe). ${ }^{13} \mathrm{C}\left\{{ }^{1} \mathrm{H}\right\} \mathrm{NMR}\left(151 \mathrm{MHz}, \mathrm{CDCl}_{3}\right)$ : $\delta 170.73(\mathrm{CO}), 130.63$ (allyl), 116.21 (allyl), $22.49\left(\mathrm{CH}_{3} \mathrm{CO}\right), 21.81\left(\mathrm{SiCH}_{2}\right),-3.29(\mathrm{SiMe}) .{ }^{29} \mathrm{Si}\left\{{ }^{1} \mathrm{H}\right\} \mathrm{NMR}(119$ $\left.\mathrm{MHz}, \mathrm{CDCl}_{3}\right): \delta-0.85$. 


\section{Synthesis of allylpentamethylcyclotrisiloxane (AD2)}

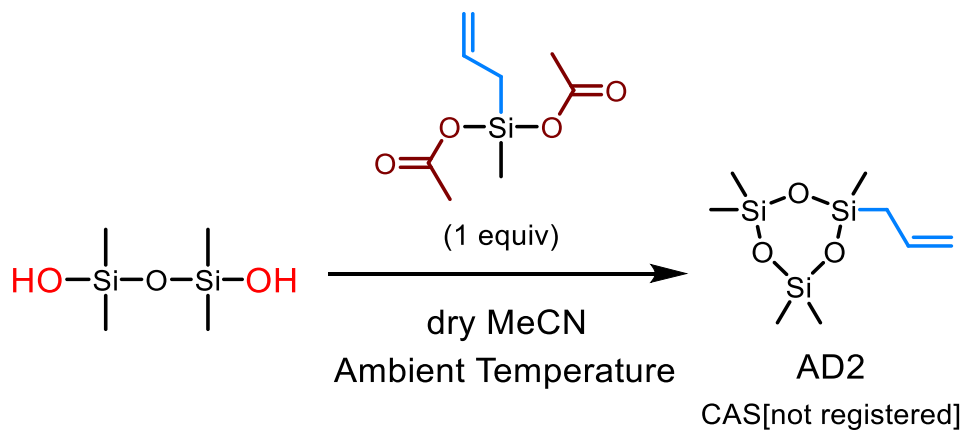

Diacetoxy(allyl)methylsilane $(10.35 \mathrm{~g}, 51.17 \mathrm{mmol})$ was added to a solution of HO-D2-OH $(8.51 \mathrm{~g}, 51.2 \mathrm{mmol})$ in dry $\mathrm{MeCN}(350 \mathrm{~mL})$ at ambient temperature. The reaction mixture was stirred for $235 \mathrm{~h}$. Imidazole $(21.8 \mathrm{~g}, 320$ mmol) was added to the reaction mixture. The $\mathrm{MeCN}$ phase was extracted with hexane $(180 \mathrm{~mL} \times 4)$. The separated hexane phase was washed with water $(230 \mathrm{~mL} \times 3)$, dried over $\mathrm{Na}_{2} \mathrm{SO}_{4}$, filtered, and concentrated at $110 \mathrm{hPa}$. The residue was distilled under reduced pressure to give a mixture of AD2 (90.6wt\%) and octamethylcyclotetrasiloxane (D4, 9.4wt\%) as a colorless liquid. Total yield: $5.88 \mathrm{~g}$. Yield of AD2: $5.33 \mathrm{~g} \mathrm{(21.4} \mathrm{mmol,} \mathrm{41.9 \% ).} \mathrm{D4} \mathrm{was} \mathrm{generated}$ from two molecules of HO-D2-OH during the reaction. AD2 was not able to be perfectly separated from D4, because the boiling points of the two compounds are almost the same. The product was used for the polymerizations without further purifications.

M.p. $\quad-23-(-36){ }^{\circ} \mathrm{C}$. B.p. $63-64.5^{\circ} \mathrm{C} / 19 \mathrm{mmHg} .{ }^{1} \mathrm{H} \mathrm{NMR}\left(600 \mathrm{MHz}, \mathrm{CDCl}_{3}\right): \delta 5.85-5.75\left(\mathrm{~m}, 1 \mathrm{H}, \mathrm{H}_{2} \mathrm{C}=\mathrm{CH}-\right)$, 4.97-4.92 (m, 1H, $\left.H_{2} \mathrm{C}=\mathrm{CH}-\right)$, 4.94-4.91 (m, 1H, $\left.H_{2} \mathrm{C}=\mathrm{CH}-\right)$, 1.63-1.60 (m, 2H, SiCH2), 0.173 (s, 3H, SiMe), 0.173 (s, 6H, SiMeOSiMe), 0.169 (s, 6H, SiMeOSiMe). ${ }^{13} \mathrm{C}\left\{{ }^{1} \mathrm{H}\right\} \mathrm{NMR}\left(151 \mathrm{MHz}, \mathrm{CDCl}_{3}\right.$ ): $\delta 132.78$ (Allyl), 114.51 (Allyl), $25.06\left(\mathrm{SiCH}_{2}\right), 0.95$ (SiMeOSiMe), $0.88(\mathrm{SiMeOSiMe}),-0.90(\mathrm{SiMe}) .{ }^{29} \mathrm{Si}\left\{{ }^{1} \mathrm{H}\right\} \mathrm{NMR}\left(119 \mathrm{MHz}, \mathrm{CDCl}_{3}\right): \delta-8.05$ $\left(\mathrm{SiMe}_{2} \mathrm{OSi} \mathrm{Me}_{2}\right),-13.88$ (SiAllylMe). HRMS (APCI, in $\left.\mathrm{MeOH}\right)$ calcd for $\left[\mathrm{C}_{9} \mathrm{H}_{24} \mathrm{O}_{4} \mathrm{Si}_{3}\right]+[\mathrm{M}+\mathrm{MeOH}]+280.0977$, found 280.0973. $([\mathrm{M}+\mathrm{MeOH}]+)$

\section{1,3-Trimethylene-2-methylguanidine hydroiodide (TMMG-HI)}

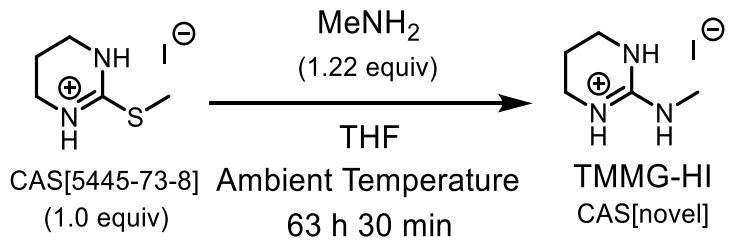

Methylamine (4.19 g, $2.0 \mathrm{~mol} \mathrm{~L}{ }^{-1}(7.0 \mathrm{wt} \%)$ in THF, $\left.9.44 \mathrm{mmol}\right)$ was added to a suspension of 2-methylthio1,4,5,6-tetrahydropyrimidine hydroiodide $(2.00 \mathrm{~g}, 7.75 \mathrm{mmol})$ in THF $(7.0 \mathrm{~mL}$, stabilizer-free $)$ at ambient temperature. After 63 h 30 min of reaction, the reaction mixture was concentrated in vacuo. The residue was washed with $\mathrm{Et}_{2} \mathrm{O}(50 \mathrm{~mL}$ in total) at ambient temperature under air and dried in vacuo to give TMMG-HI as a white solid. Yield: $1.87 \mathrm{~g}(\sim 100 \%)$.

M.p. $65^{\circ} \mathrm{C} .{ }^{1} \mathrm{H}$ NMR (600 MHz, DMSO-d $): \delta 7.71$ (br s, $2 \mathrm{H},-\mathrm{N} H\left(\mathrm{CH}_{2}\right)_{3} \mathrm{~N} H$-), 7.14 (br s, $\left.1 \mathrm{H}, \mathrm{N} H \mathrm{CH}_{3}\right), 3.24(\mathrm{t}$, $\left.J=5.7 \mathrm{~Hz}, 4 \mathrm{H}, \mathrm{NCH}_{2} \mathrm{CH}_{2} \mathrm{CH}_{2} \mathrm{~N}\right), 2.68\left(\mathrm{~s}, 3 \mathrm{H},-\mathrm{CH}_{3}\right), 1.81$ (quintet, $\left.J=5.8 \mathrm{~Hz}, 2 \mathrm{H}, \mathrm{NCH}_{2} \mathrm{CH}_{2} \mathrm{CH}_{2} \mathrm{~N}\right) .{ }^{13} \mathrm{C}\left\{{ }^{1} \mathrm{H}\right\}$ 
NMR (151 MHz, DMSO-d $\left.d_{6}\right): \delta \quad 153.14 \quad\left(\mathrm{CNCH}_{3}\right), 37.95 \quad\left(\mathrm{NHCH}_{2} \mathrm{CH}_{2} \mathrm{CH}_{2} \mathrm{NH}\right), 27.25 \quad\left(-\mathrm{CH}_{3}\right), \quad 19.59$

$\left(\mathrm{NHCH}_{2} \mathrm{CH}_{2} \mathrm{CH}_{2} \mathrm{NH}\right)$. HRMS (ESI) calcd for $\left[\mathrm{C}_{5} \mathrm{H}_{12} \mathrm{~N}_{3}\right]^{+}[\mathrm{M}-\mathrm{I}]^{+}$114.1026, found 114.1022; calcd for [I] $[\mathrm{M}-\mathrm{TMEG}-\mathrm{H}]^{-}$126.9050, found 126.9047.

\section{1,3-Trimethylene-2-methylguanidine (TMMG)}

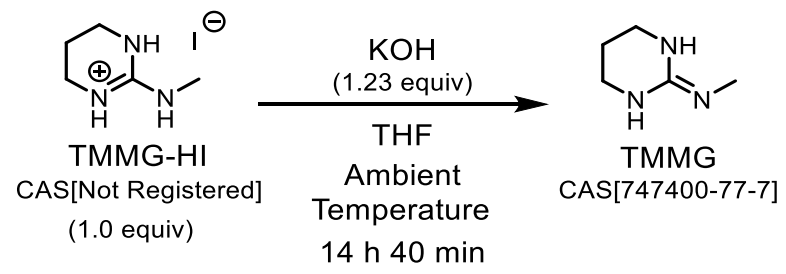

KOH (259 mg, $4.62 \mathrm{mmol})$ was added to a solution of TMMG-HI (0.90 g, $3.7 \mathrm{mmol})$ in THF $(9.1 \mathrm{~mL}$, stabilizer free) at ambient temperature. After $14 \mathrm{~h} 40 \mathrm{~min}$, the reaction mixture was filtered using a SARTORIUS syringe filter (Mini Sarto SRP, pore size $=0.2 \mu \mathrm{m}$ ). The filtrate was concentrated under reduced pressure and dissolved in dry toluene $(6 \mathrm{~mL})$. The solution was concentrated under reduced pressure. The residue was dissolved in THF (5.0 $\mathrm{mL}$ ) and filtered using another SARTORIUS syringe filter (Mini Sarto SRP, pore size $=0.2 \mu \mathrm{m}$ ). The filtrate was concentrated under reduced pressure to obtain TMMG as a pale-yellow solid. The product was dissolved in dry THF to prepare a stock solution of TMMG in THF $\left(60 \mathrm{mg} \mathrm{mL}^{-1}\right)$. Yield: $422 \mathrm{mg}(\sim 100 \%)$. Activated MS4 $\AA$ was added to dehydrate the solution.

TMMG: Hygroscopic. ${ }^{1} \mathrm{H}$ NMR (600 MHz, $\left.\mathrm{CDCl}_{3}\right): \delta 3.30$ (t, $J=5.8 \mathrm{~Hz}, 4 \mathrm{H}, \mathrm{NCH}_{2} \mathrm{CH}_{2} \mathrm{CH}_{2} \mathrm{~N}$ ), $2.72(\mathrm{~s}, 3 \mathrm{H},-$ $\left.\mathrm{CH}_{3}\right), 1.82-1.75\left(\mathrm{~m}, 2 \mathrm{H}, \mathrm{NCH}_{2} \mathrm{CH}_{2} \mathrm{CH}_{2} \mathrm{~N}\right) .{ }^{13} \mathrm{C}\left\{{ }^{1} \mathrm{H}\right\}$ NMR $\left(151 \mathrm{MHz}, \mathrm{CDCl}_{3}\right): \delta 153.24\left(\mathrm{CNCH}_{3}\right), 40.71$ $\left(\mathrm{NHCH}_{2} \mathrm{CH}_{2} \mathrm{CH}_{2} \mathrm{NH}\right), 28.25\left(\mathrm{NCH}_{3}\right), 21.68\left(\mathrm{NHCH}_{2} \mathrm{CH}_{2} \mathrm{CH}_{2} \mathrm{NH}\right)$. HRMS (ESI) calcd for $\left[\mathrm{C}_{5} \mathrm{H}_{12} \mathrm{~N}_{3}\right]^{+}[\mathrm{M}+\mathrm{H}]^{+}$ 114.1026, found 114.1021 .

\section{Homopolymerization of VD2 (Table 1, Entry 2)}
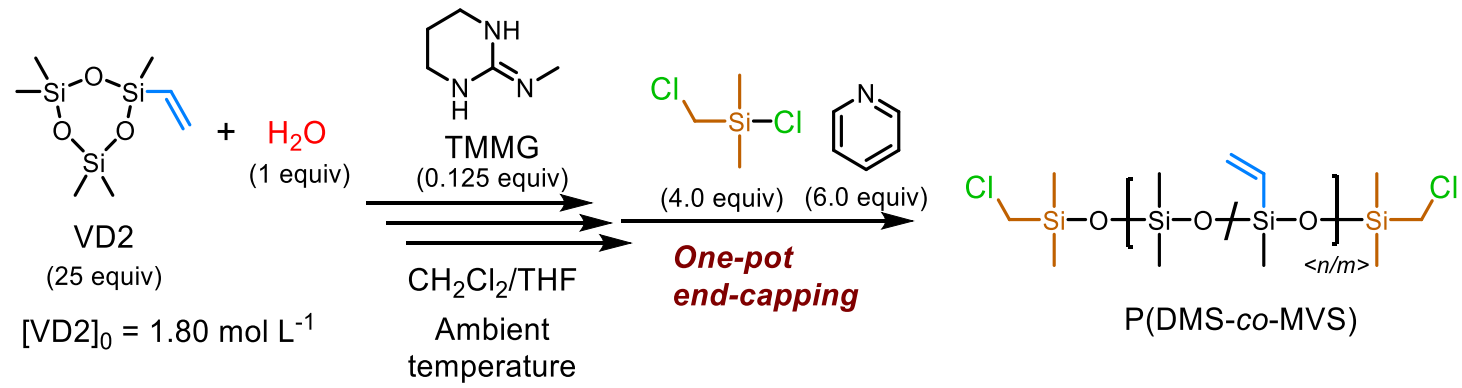

P(DMS-co-MVS)

Typically, polymerizations of VD2 were conducted using the following procedures. A THF solution of TMMG (60 mg mL $\mathrm{mL}^{-1}, 9.0 \mu \mathrm{L}, 4.8 \mu \mathrm{mol}, 0.125$ equiv) was added to a solution of VD2 (224 mg, $954 \mu \mathrm{mol}, 25$ equiv) and a THF solution of $\mathrm{H}_{2} \mathrm{O}\left(1 / 99\left(\mathrm{H}_{2} \mathrm{O} / \mathrm{THF}, \mathrm{v} / \mathrm{v}\right), 68.8 \mu \mathrm{L}, 38.2 \mu \mathrm{mol}, 1.0\right.$ equiv) in dry $\mathrm{CH}_{2} \mathrm{Cl}_{2}(461 \mu \mathrm{L})$ in a glass vial or a flask under an argon atmosphere to initiate the polymerization at ambient temperature $\left(24-26{ }^{\circ} \mathrm{C}\right)$. During the polymerization, an aliquot of the reaction mixture $(\sim 40 \mu \mathrm{L})$ was taken and mixed with a small amount of benzoic acid. The aliquot was analyzed by ${ }^{1} \mathrm{H}$ NMR to determine the conversion of the monomer and by SEC to analyze the molar-mass distribution of the crude product. The sampling was conducted four times in this polymerization. After $2 \mathrm{~h} 8 \mathrm{~min}$, dry pyridine $(18.5 \mu \mathrm{L}, 229 \mu \mathrm{mol}, 6.0$ equiv) was added as a hydrochloric acid scavenger, and 
$\left(\mathrm{ClCH}_{2}\right) \mathrm{SiMe}_{2} \mathrm{Cl}(20.1 \mu \mathrm{L}, 153 \mu \mathrm{mol}, 4.0$ equiv $)$ was added to end-cap the propagating polymers. The end-capping reaction was continued at least for $15 \mathrm{~min}$ and generally for longer than $12 \mathrm{~h}$ at ambient temperature to ensure quantitative end-capping. Then, the reaction mixture was concentrated under reduced pressure. The obtained oil was mixed/shaken with $\mathrm{MeCN}(3 \mathrm{~mL})$ and the upper layer was removed; the washing procedure with MeCN was repeated in total three times. The residue was diluted with toluene $(2 \mathrm{~mL})$ and concentrated in vacuo. The solvent remaining in the product was thoroughly removed in vacuo to obtain $\alpha, \omega$-bis[(chloromethyl)dimethylsilyl]terminated poly[dimethylsiloxane-co-methyl(vinyl)siloxane] (P(DMS-co-MVS)) (136.8 mg, 58.8\% yield, $M_{\mathrm{n}, \mathrm{NMR}}$ $\left.=6.51 \mathrm{kDa}(n / m=53.3 / 27.0), \bigoplus_{\mathrm{M}}=1.08_{5}\right)$ as a colorless liquid. ${ }^{1} \mathrm{H}$ NMR and ${ }^{29} \mathrm{Si}\left\{{ }^{1} \mathrm{H}\right\}$ NMR spectra of the product are shown in Figures 1 and S2. $T_{\mathrm{g}}$ was observed at $-124{ }^{\circ} \mathrm{C}$ for the product.

The polymerizations initiated by silanols (Table 2, Entry 1 and 2) were conducted with the same procedures using the silanols, such as $\mathrm{MeD} 4 \mathrm{OH}$ and $\mathrm{Ph}_{3} \mathrm{SiOH}$, instead of the THF solution of $\mathrm{H}_{2} \mathrm{O}$.

\section{Homopolymerization of CIPD2 (Table 1, Entry 3)}

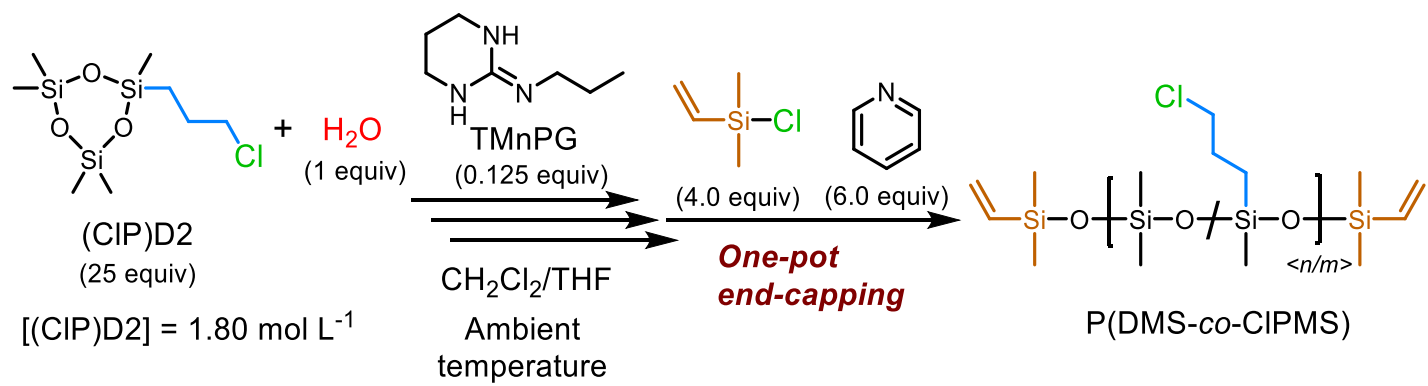

Typically, polymerizations of ClPD2 were conducted using the following procedures. A toluene solution of TMnPG (100 mg mL $-1,6.0 \mu \mathrm{L}, 4.2 \mu \mathrm{mol}, 0.125$ equiv) was added to a solution of ClPD2 (242 mg, $850 \mu \mathrm{mol}, 25$ equiv) and a THF solution of $\mathrm{H}_{2} \mathrm{O}\left(1 / 99\left(\mathrm{H}_{2} \mathrm{O} / \mathrm{THF}, \mathrm{v} / \mathrm{v}\right), 61.2 \mu \mathrm{L}, 34.0 \mu \mathrm{mol}, 1.0\right.$ equiv) in dry $\mathrm{CH}_{2} \mathrm{Cl}_{2}(411 \mu \mathrm{L})$ in a glass vial or a flask under an argon atmosphere to initiate the polymerization at ambient temperature $\left(24-26^{\circ} \mathrm{C}\right)$. During the polymerization, an aliquot of the reaction mixture $(\sim 40 \mu \mathrm{L})$ was taken and mixed with a small amount of benzoic acid. The aliquot was analyzed by ${ }^{1} \mathrm{H}$ NMR to determine the conversion of the monomer and by SEC to analyze the molar-mass distribution of the crude product. The sampling was conducted four times in this polymerization. After $4 \mathrm{~h} 49 \mathrm{~min}$, dry pyridine $(16.4 \mu \mathrm{L}, 204 \mu \mathrm{mol}, 6.0$ equiv) was added as a hydrochloric acid scavenger, and $\mathrm{Me}_{2} \mathrm{ViSiCl}(18.4 \mu \mathrm{L}, 136 \mu \mathrm{mol}, 4.0$ equiv) was added to end-cap the propagating polymers. The end-capping reaction was continued at least for $15 \mathrm{~min}$ and generally for longer than $12 \mathrm{~h}$ at ambient temperature to ensure quantitative end-capping. Then, the reaction mixture was concentrated under reduced pressure. The obtained oil was mixed/shaken with $\mathrm{MeCN}(3 \mathrm{~mL})$ and the upper layer was removed; the washing procedure with $\mathrm{MeCN}$ was repeated in total three times. The residue was diluted with toluene $(2 \mathrm{~mL})$ and concentrated in vacuo. The solvent remaining in the product was thoroughly removed in vacuo to obtain $\alpha, \omega$-bis[dimethyl(vinyl) silyl]terminated poly[dimethylsiloxane-co-(3-chloropropyl)methylsiloxane] (P(DMS-co-ClPMS)) (191.1 mg, 77.1\% yield, $\left.M_{\mathrm{n}, \mathrm{NMR}}=8.68 \mathrm{kDa}(n / m=59.7 / 29.7), \bigoplus_{\mathrm{M}}=1.089\right)$ as a colorless liquid. ${ }^{1} \mathrm{H} \mathrm{NMR}$ and ${ }^{29} \mathrm{Si}\left\{{ }^{1} \mathrm{H}\right\} \mathrm{NMR}$ spectra of the product are shown in Figures 1 and S3. $T_{\mathrm{g}}$ was observed at $-117^{\circ} \mathrm{C}$ for the product. 
The polymerizations initiated by silanols (Table 2, Entry 3-5) were conducted with the same procedures using the silanols, such as $\mathrm{MeD} 4 \mathrm{OH}, \mathrm{Ph}_{3} \mathrm{SiOH}$, and $\mathrm{Me}_{3} \mathrm{SiOH}$, instead of the THF solution of $\mathrm{H}_{2} \mathrm{O}$.

\section{Homopolymerization of AD2 (Table 1, Entry 6)}

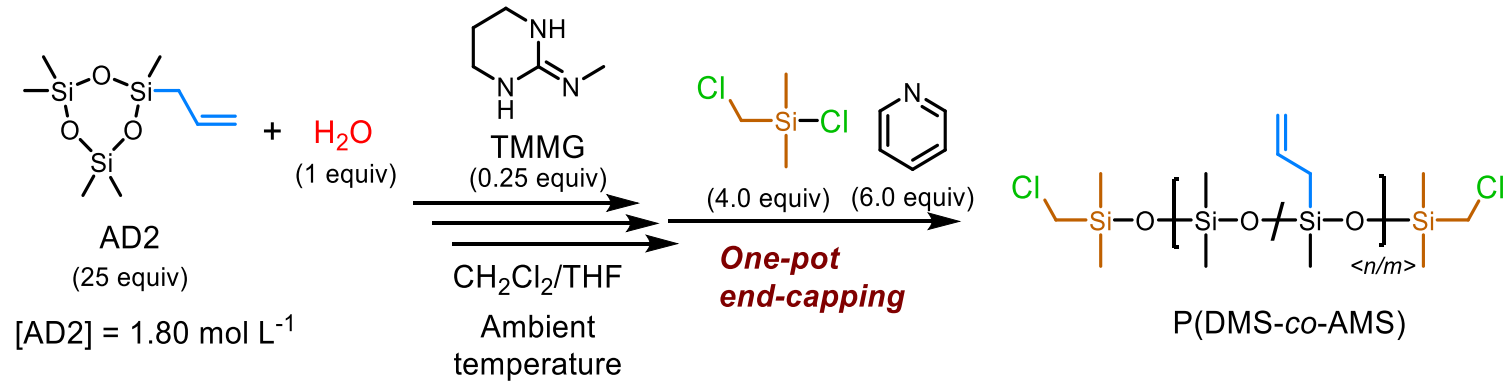

Typically, polymerizations of AD2 were conducted using the following procedures. A THF solution of TMMG (60 mg mL ${ }^{-1}, 18.0 \mu \mathrm{L}, 9.54 \mu \mathrm{mol}, 0.25$ equiv) was added to a solution of AD2 (262 mg, $954 \mu \mathrm{mol}-\mathrm{AD} 2,25$ equiv, purity 90.6wt\%) and a THF solution of $\mathrm{H}_{2} \mathrm{O}\left(1 / 99\left(\mathrm{H}_{2} \mathrm{O} / \mathrm{THF}, \mathrm{v} / \mathrm{v}\right), 68.8 \mu \mathrm{L}, 38.2 \mu \mathrm{mol}, 1.0\right.$ equiv) in dry $\mathrm{CH}_{2} \mathrm{Cl}_{2}$ $(461 \mu \mathrm{L})$ in a glass vial or a flask under an argon atmosphere to initiate the polymerization at ambient temperature (24-26 $\left.{ }^{\circ} \mathrm{C}\right)$. During the polymerization, an aliquot of the reaction mixture $(\sim 40 \mu \mathrm{L})$ was taken and mixed with a small amount of benzoic acid. The aliquot was analyzed by ${ }^{1} \mathrm{H}$ NMR to determine the conversion of the monomer and by SEC to analyze the molar-mass distribution of the crude product. The sampling was conducted four times in this polymerization. After $2 \mathrm{~h} 51 \mathrm{~min}$, dry pyridine $(18.5 \mu \mathrm{L}, 229 \mu \mathrm{mol}, 6.0$ equiv) was added as a hydrochloric acid scavenger, and $\left(\mathrm{ClCH}_{2}\right) \mathrm{Me}_{2} \mathrm{SiCl}(20.1 \mu \mathrm{L}, 153 \mu \mathrm{mol}, 4.0$ equiv $)$ was added to end-cap the propagating polymers. The end-capping reaction was continued at least for $15 \mathrm{~min}$ and generally for longer than $12 \mathrm{~h}$ at ambient temperature to ensure quantitative end-capping. Then, the reaction mixture was concentrated under reduced pressure. The obtained oil was mixed/shaken with $\mathrm{MeCN}(3 \mathrm{~mL})$ and the upper layer was removed; the washing procedure with $\mathrm{MeCN}$ was repeated in total four times. The residue was diluted with toluene $(2 \mathrm{~mL})$ and concentrated in vacuo. The solvent remaining in the product was thoroughly removed in vacuo to obtain $\alpha, \omega-$ bis(chloromethyldimethylsilyl)-terminated poly[dimethylsiloxane-co-allyl(methyl)siloxane] (P(DMS-co-AMS)) $\left(156.5 \mathrm{mg}, 63.6 \%\right.$ yield, $\left.M_{\mathrm{n}, \mathrm{NMR}}=6.59 \mathrm{kDa}(n / m=51.8 / 25.1), \emptyset_{\mathrm{M}}=1.11_{7}\right)$ as a colorless liquid. ${ }^{1} \mathrm{H}$ NMR and ${ }^{29} \mathrm{Si}\left\{{ }^{1} \mathrm{H}\right\}$ NMR spectra of the product are shown in Figures 1 and S4. $T_{\mathrm{g}}$ was observed at $-120{ }^{\circ} \mathrm{C}$ for the product.

The polymerizations initiated by silanols (Table 2, Entry 6 and 7) were conducted with the same procedures using the silanols, such as MeD4OH and $\mathrm{Ph}_{3} \mathrm{SiOH}$, instead of the THF solution of $\mathrm{H}_{2} \mathrm{O}$. 


\section{Statistical Copolymerization of two different cyclotrisiloxanes (Table 3)}

Typically, statistical copolymerizations of monofunctional pentamethylcyclotrisiloxane and D3 were conducted using the following procedures.

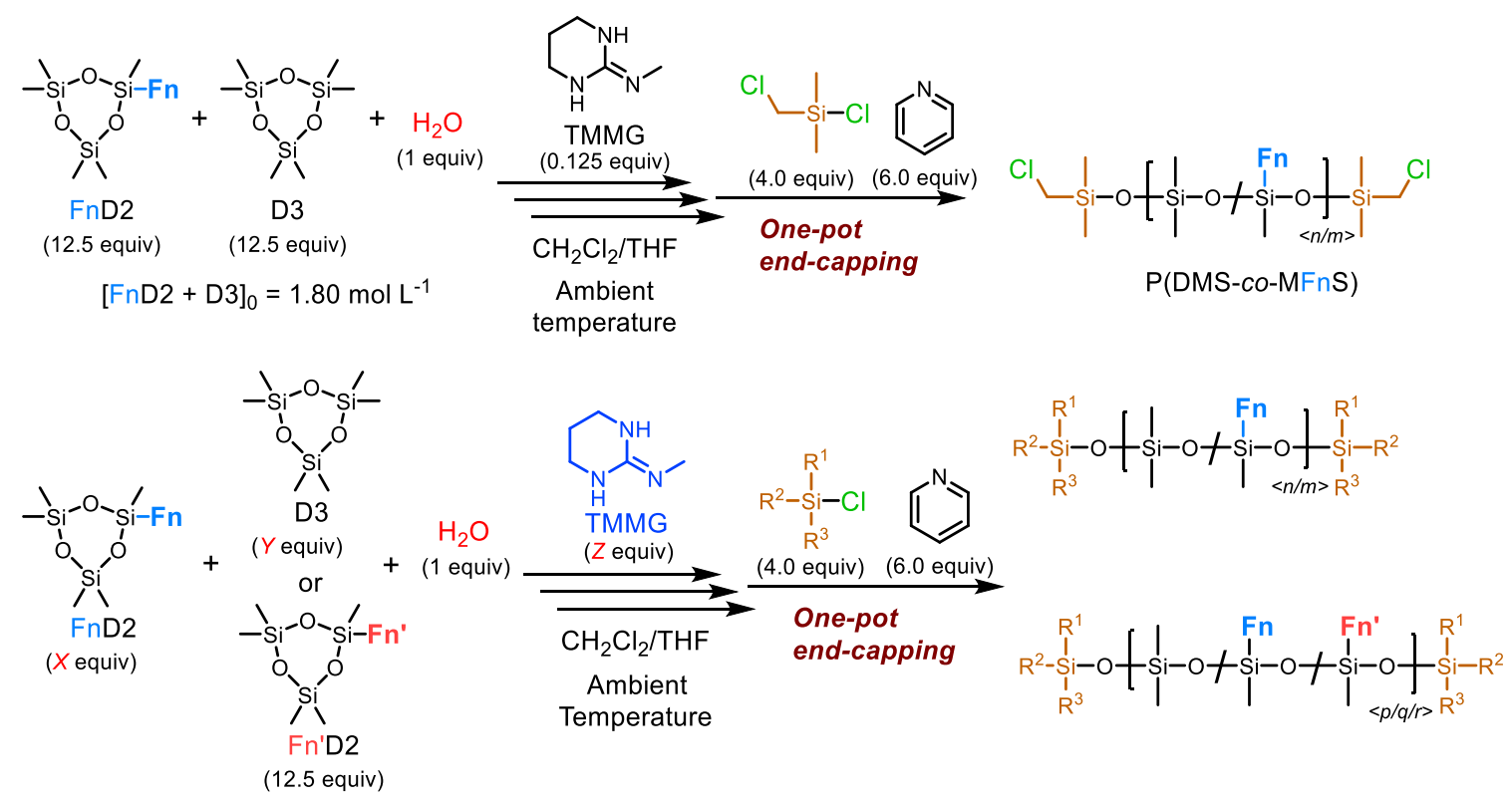

Statistical Copolymerization of VD2 and D3 (Table 3, Entry 1)

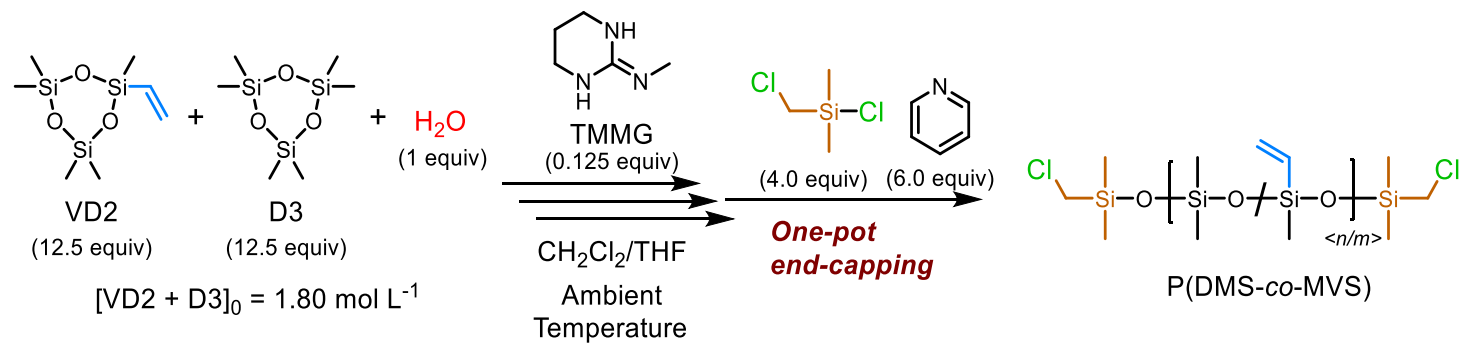

A THF solution of TMMG (60 mg mL $\mathrm{m}^{-1}, 11.0 \mu \mathrm{L}, 5.83 \mu \mathrm{mol}, 0.125$ equiv) was added to a solution of VD2 (137 mg, $583 \mu \mathrm{mol}, 12.5$ equiv), D3 (130 mg, $583 \mu \mathrm{mol}, 12.5$ equiv), and a THF solution of $\mathrm{H}_{2} \mathrm{O}\left(1 / 99\left(\mathrm{H}_{2} \mathrm{O} / \mathrm{THF}, \mathrm{v} / \mathrm{v}\right)\right.$, $84.1 \mu \mathrm{L}, 46.7 \mu \mathrm{mol}, 1.0$ equiv) in dry $\mathrm{CH}_{2} \mathrm{Cl}_{2}(564 \mu \mathrm{L})$ in a glass vial or a flask under an argon atmosphere to initiate the polymerization at ambient temperature $\left(24-26^{\circ} \mathrm{C}\right)$. During the polymerization, an aliquot of the reaction mixture $(\sim 40 \mu \mathrm{L})$ was taken and mixed with a small amount of benzoic acid. The aliquot was analyzed by ${ }^{1} \mathrm{H}$ NMR to determine the conversion of the monomer and by SEC to analyze the molar-mass distribution of the crude product. The sampling was conducted six times in this polymerization. After $4 \mathrm{~h} 15 \mathrm{~min}$, dry pyridine $(22.6 \mu \mathrm{L}, 280 \mu \mathrm{mol}$, 6.0 equiv) was added as a hydrochloric acid scavenger, and $\left(\mathrm{ClCH}_{2}\right) \mathrm{SiMe}_{2} \mathrm{Cl}(24.6 \mu \mathrm{L}, 187 \mu \mathrm{mol}, 4.0$ equiv) was added to end-cap the propagating polymers. The end-capping reaction was continued at least for $15 \mathrm{~min}$ and generally for longer than $12 \mathrm{~h}$ at ambient temperature to ensure quantitative end-capping. Then, the reaction mixture was concentrated under reduced pressure. The obtained oil was mixed/shaken with $\mathrm{MeCN}(3 \mathrm{~mL})$ and the upper layer was removed; the washing procedure with $\mathrm{MeCN}$ was repeated in total six times. The residue was diluted with toluene $(2 \mathrm{~mL})$ and concentrated in vacuo. The solvent remaining in the product was thoroughly removed in vacuo to obtain $\alpha, \omega$-bis(chloromethyldimethylsilyl)-terminated poly[dimethylsiloxane-co-methyl(vinyl)siloxane] $(\mathrm{P}(\mathrm{DMS}-\mathrm{co}-\mathrm{MVS}))\left(180.4 \mathrm{mg}, 65.1 \%\right.$ yield, $\left.M_{\mathrm{n}, \mathrm{NMR}}=7.29 \mathrm{kDa}(n / m=69.2 / 14.1), \bigoplus_{\mathrm{M}}=1.135\right)$ as a colorless liquid. 
${ }^{1} \mathrm{H}$ NMR and ${ }^{29} \mathrm{Si}\left\{{ }^{1} \mathrm{H}\right\}$ NMR spectra of the product are shown in Figures $\mathrm{S} 12$ and S13. $T_{\mathrm{g}}$ was observed at $-124{ }^{\circ} \mathrm{C}$ for the product.

Statistical Copolymerization of ClPD2 and D3 (Table 3, entry 2)

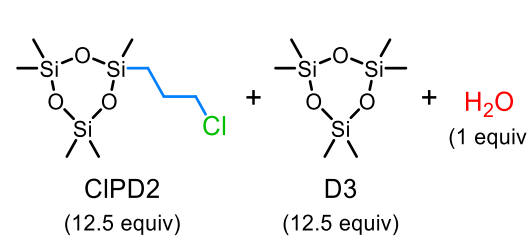

$[\mathrm{CIPD} 2+\mathrm{D} 3]_{0}=1.80 \mathrm{~mol} \mathrm{~L}^{-1}$
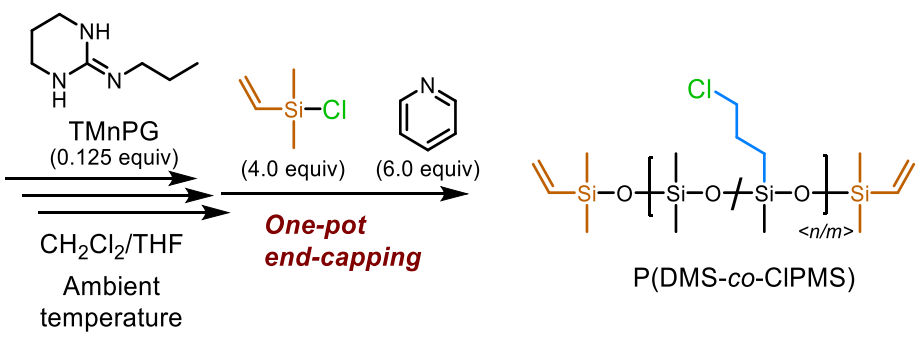

A toluene solution of TMnPG (100 mg mL $\mathrm{mL}^{-1}, 8.0 \mu \mathrm{L}, 5.7 \mu \mathrm{mol}, 0.12_{5}$ equiv) was added to a solution of ClPD2 (161.4 mg, $566 \mu \mathrm{mol}, 12.5$ equiv), D3 (126 mg, $566 \mu \mathrm{mol}, 12.5$ equiv), and a THF solution of $\mathrm{H}_{2} \mathrm{O}\left(1 / 99\left(\mathrm{H}_{2} \mathrm{O} / \mathrm{THF}\right.\right.$, $\mathrm{v} / \mathrm{v}), 81.6 \mu \mathrm{L}, 45.3 \mu \mathrm{mol}, 1.0$ equiv) in dry $\mathrm{CH}_{2} \mathrm{Cl}_{2}(547 \mu \mathrm{L})$ in a glass vial or a flask under an argon atmosphere to initiate the polymerization at ambient temperature $\left(24-26^{\circ} \mathrm{C}\right)$. During the polymerization, an aliquot of the reaction mixture $(\sim 40 \mu \mathrm{L})$ was taken and mixed with a small amount of benzoic acid. The aliquot was analyzed by ${ }^{1} \mathrm{H}$ NMR to determine the conversion of the monomer and by SEC to analyze the molar-mass distribution of the crude product. The sampling was conducted five times in this polymerization. After $4 \mathrm{~h} 52 \mathrm{~min}$, dry pyridine $(22.6 \mu \mathrm{L}, 280 \mu \mathrm{mol}$, 6.0 equiv) was added as a hydrochloric acid scavenger, and $\mathrm{ViSiMe}_{2} \mathrm{Cl}(24.5 \mu \mathrm{L}, 181 \mu \mathrm{mol}, 4.0$ equiv) was added to end-cap the propagating polymers. The end-capping reaction was continued at least for $15 \mathrm{~min}$ and generally for longer than $12 \mathrm{~h}$ at ambient temperature to ensure quantitative end-capping. Then, the reaction mixture was concentrated under reduced pressure. The obtained oil was mixed/shaken with $\mathrm{MeCN}(3 \mathrm{~mL})$ and the upper layer was removed; the washing procedure with $\mathrm{MeCN}$ was repeated in total six times. The residue was diluted with toluene $(2 \mathrm{~mL})$ and concentrated in vacuo. The solvent remaining in the product was thoroughly removed in vacuo to obtain $\alpha, \omega$-bis[dimethyl(vinyl)silyl]-terminated poly[dimethylsiloxane-co-(3-chloropropyl)methylsiloxane] $(\mathrm{P}(\mathrm{DMS}-\mathrm{co}-\mathrm{ClPMS}))\left(180.4 \mathrm{mg}, 65.1 \%\right.$ yield, $\left.M_{\mathrm{n}, \mathrm{NMR}}=7.34 \mathrm{kDa}(n / m=70.3 / 14.2), \bigoplus_{\mathrm{M}}=1.10_{2}\right)$ as a colorless liquid. ${ }^{1} \mathrm{H}$ NMR and ${ }^{29} \mathrm{Si}\left\{{ }^{1} \mathrm{H}\right\}$ NMR spectra of the product are shown in Figures $\mathrm{S} 15$ and $\mathrm{S} 16 . T_{\mathrm{g}}$ was observed at

$-115^{\circ} \mathrm{C}$ for the product.

Statistical Copolymerization of AD2 and D3 (Table 3, entry 3)

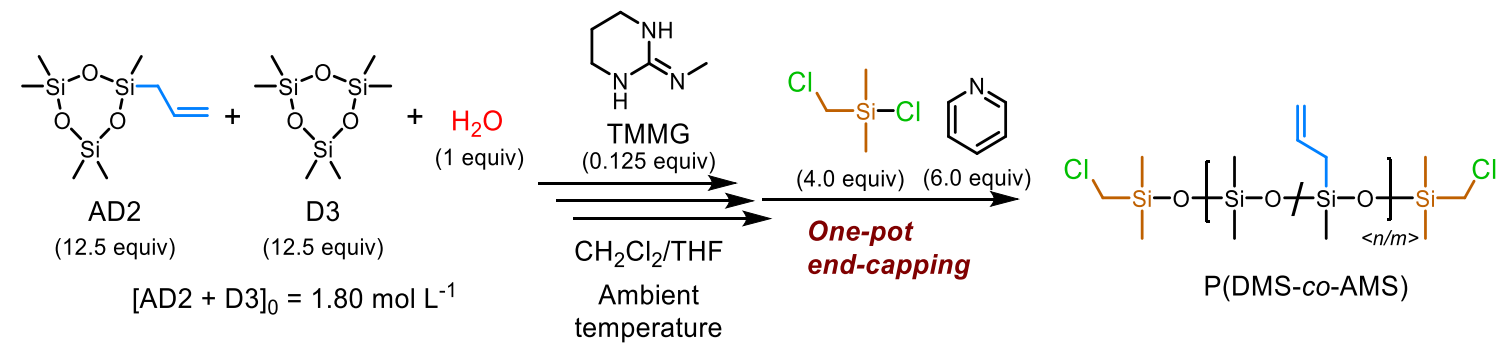

A THF solution of TMMG ( $60 \mathrm{mg} \mathrm{mL}^{-1}, 11.0 \mu \mathrm{L}, 5.83 \mu \mathrm{mol}, 0.125$ equiv) was added to a solution of AD2 (160 mg, $583 \mu$ mol-AD2, 25 equiv, purity 90.6wt\%), D3 (130 mg, $583 \mu$ mol, 12.5 equiv), and a THF solution of $\mathrm{H}_{2} \mathrm{O}$ $\left(1 / 99\left(\mathrm{H}_{2} \mathrm{O} / \mathrm{THF}, \mathrm{v} / \mathrm{v}\right), 84.1 \mu \mathrm{L}, 46.7 \mu \mathrm{mol}, 1.0\right.$ equiv) in dry $\mathrm{CH}_{2} \mathrm{Cl}_{2}(564 \mu \mathrm{L})$ in a glass vial or a flask under an 
argon atmosphere to initiate the polymerization at ambient temperature $\left(24-26^{\circ} \mathrm{C}\right)$. During the polymerization, an aliquot of the reaction mixture $(\sim 40 \mu \mathrm{L})$ was taken and mixed with a small amount of benzoic acid. The aliquot was analyzed by ${ }^{1} \mathrm{H}$ NMR to determine the conversion of the monomer and by SEC to analyze the molar-mass distribution of the crude product. The sampling was conducted four times in this polymerization. After $3 \mathrm{~h} 40 \mathrm{~min}$, dry pyridine ( $22.6 \mu \mathrm{L}, 280 \mu \mathrm{mol}, 6.0$ equiv) was added as a hydrochloric acid scavenger, and $\left(\mathrm{ClCH}_{2}\right) \mathrm{SiMe}_{2} \mathrm{Cl}(24.6$ $\mu \mathrm{L}, 187 \mu \mathrm{mol}, 4.0$ equiv) was added to end-cap the propagating polymers. The end-capping reaction was continued at least for $15 \mathrm{~min}$ and generally for longer than $12 \mathrm{~h}$ at ambient temperature to ensure quantitative end-capping. Then, the reaction mixture was concentrated under reduced pressure. The obtained oil was mixed/shaken with $\mathrm{MeCN}(3 \mathrm{~mL})$ and the upper layer was removed; the washing procedure with $\mathrm{MeCN}$ was repeated in total four times. The residue was diluted with toluene $(2 \mathrm{~mL})$ and concentrated in vacuo. The solvent remaining in the product was thoroughly removed in vacuo to obtain $\alpha, \omega$-bis(chloromethyldimethylsilyl)-terminated poly[dimethylsiloxane-coallyl(methyl)siloxane] (P(DMS-co-AMS)) $\left(173.3 \mathrm{mg}, 60.7 \%\right.$ yield, $M_{\mathrm{n}, \mathrm{NMR}}=6.57 \mathrm{kDa}(n / m=68.0 / 13.0), \emptyset_{\mathrm{M}}=$ $1.13_{2}$ ) as a colorless liquid. ${ }^{1} \mathrm{H}$ NMR and ${ }^{29} \mathrm{Si}\left\{{ }^{1} \mathrm{H}\right\}$ NMR spectra of the product are shown in Figures $\mathrm{S} 17$ and $\mathrm{S} 18$. $T_{\mathrm{g}}$ was observed at $-121^{\circ} \mathrm{C}$ for the product.

The statistical copolymerization of AD2 (17.5 equiv) and D3 (7.5 equiv) (Table 3, Entry 6) was conducted with the same procedures. $T_{\mathrm{g}}$ was observed at $-122{ }^{\circ} \mathrm{C}$ for the product.

Statistical Copolymerization of VD2 and ClPD2 (Table 3, entry 4)

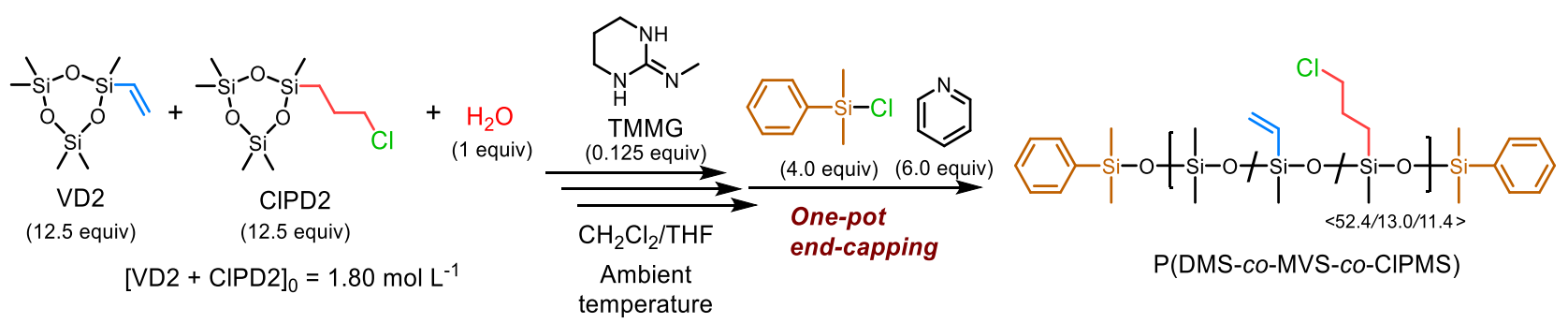

A THF solution of TMMG ( $60 \mathrm{mg} \mathrm{mL}^{-1}, 10.0 \mu \mathrm{L}, 5.30 \mu \mathrm{mol}, 0.125$ equiv) was added to a solution of VD2 (124 $\mathrm{mg}, 530 \mu \mathrm{mol}, 12.5$ equiv), ClPD2 (151 mg, $530 \mu \mathrm{mol}, 12.5$ equiv), and a THF solution of $\mathrm{H}_{2} \mathrm{O}\left(1 / 99\left(\mathrm{H}_{2} \mathrm{O} / \mathrm{THF}\right.\right.$, $\mathrm{v} / \mathrm{v}), 76.4 \mu \mathrm{L}, 42.4 \mu \mathrm{mol}, 1.0$ equiv) in dry $\mathrm{CH}_{2} \mathrm{Cl}_{2}(513 \mu \mathrm{L})$ in a glass vial or a flask under an argon atmosphere to initiate the polymerization at ambient temperature $\left(24-26^{\circ} \mathrm{C}\right)$. During the polymerization, an aliquot of the reaction mixture $(\sim 40 \mu \mathrm{L})$ was taken and mixed with a small amount of benzoic acid. The aliquot was analyzed by ${ }^{1} \mathrm{H}$ NMR to determine the conversion of the monomer and by SEC to analyze the molar-mass distribution of the crude product. The sampling was conducted four times in this polymerization. After $3 \mathrm{~h} 5 \mathrm{~min}$, dry pyridine $(20.5 \mu \mathrm{L}, 254 \mu \mathrm{mol}$, 6.0 equiv) was added as a hydrochloric acid scavenger, and $\mathrm{Me}_{2} \mathrm{PhSiCl}(28.1 \mu \mathrm{L}, 170 \mu \mathrm{mol}, 4.0$ equiv) was added to end-cap the propagating polymers. The end-capping reaction was continued at least for $15 \mathrm{~min}$ and generally for longer than $12 \mathrm{~h}$ at ambient temperature to ensure quantitative end-capping. Then, the reaction mixture was concentrated under reduced pressure. The obtained oil was mixed/shaken with $\mathrm{MeCN}(3 \mathrm{~mL})$ and the upper layer was removed; the washing procedure with $\mathrm{MeCN}$ was repeated in total eight times. The residue was diluted with toluene $(2 \mathrm{~mL})$ and concentrated in vacuo. The solvent remaining in the product was thoroughly removed in vacuo 
to obtain $\alpha, \omega$-bis[dimethyl(phenyl)silyl]-terminated poly[dimethylsiloxane-co-methyl(vinyl)siloxane-co-3chloropropyl (methyl)siloxane] (P(DMS-co-MVS-co-ClPMS)) $\left(147.4 \mathrm{mg}, 51.3 \%\right.$ yield, $M_{\mathrm{n}, \mathrm{NMR}}=6.75 \mathrm{kDa}(\mathrm{n} / \mathrm{m} / \mathrm{l}$ $\left.=52.4 / 13.0 / 11.4), \bigoplus_{\mathrm{M}}=1.13_{1}\right)$ as a colorless liquid. ${ }^{1} \mathrm{H}$ NMR and ${ }^{29} \mathrm{Si}\left\{{ }^{1} \mathrm{H}\right\}$ NMR spectra of the product are shown in Figures S21 and S22.

Statistical Copolymerization of AD2 and ClPD2 (Table 3, entry 5)

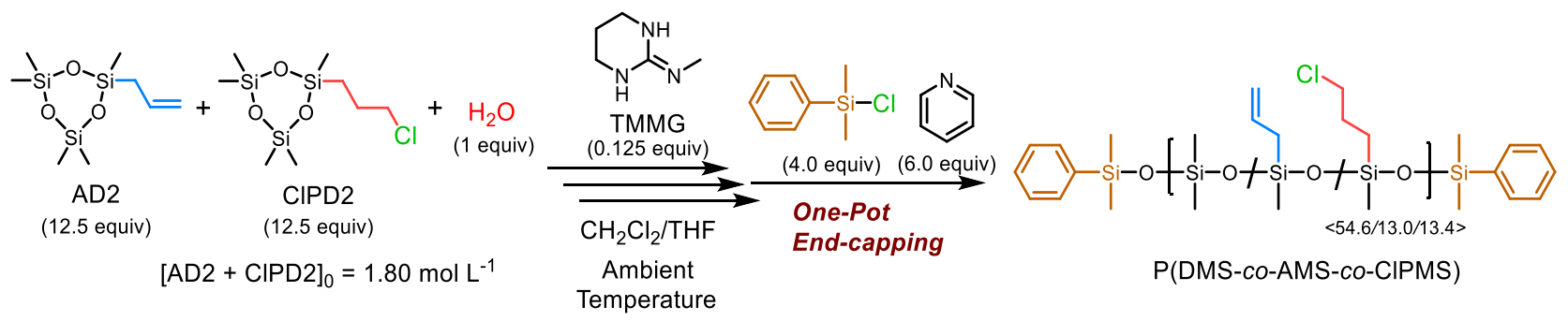

A THF solution of TMMG ( $60 \mathrm{mg} \mathrm{mL}^{-1}, 10.0 \mu \mathrm{L}, 5.30 \mu \mathrm{mol}, 0.125$ equiv) was added to a solution of AD2 (146 $\mathrm{mg}, 530 \mu \mathrm{mol}-\mathrm{AD} 2,12.5$ equiv, purity $90.6 \mathrm{wt} \%)$, ClPD2 (151 mg, $530 \mu \mathrm{mol}, 12.5$ equiv), and a THF solution of $\mathrm{H}_{2} \mathrm{O}\left(1 / 99\left(\mathrm{H}_{2} \mathrm{O} / \mathrm{THF}, \mathrm{v} / \mathrm{v}\right), 76.4 \mu \mathrm{L}, 42.4 \mu \mathrm{mol}, 1.0\right.$ equiv) in dry $\mathrm{CH}_{2} \mathrm{Cl}_{2}(513 \mu \mathrm{L})$ in a glass vial or a flask under an argon atmosphere to initiate the polymerization at ambient temperature $\left(24-26^{\circ} \mathrm{C}\right)$. During the polymerization, an aliquot of the reaction mixture $(\sim 40 \mu \mathrm{L})$ was taken and mixed with a small amount of benzoic acid. The aliquot was analyzed by ${ }^{1} \mathrm{H}$ NMR to determine the conversion of the monomer and by SEC to analyze the molar-mass distribution of the crude product. The sampling was conducted four times in this polymerization. After $6 \mathrm{~h} 56 \mathrm{~min}$, dry pyridine ( $20.5 \mu \mathrm{L}, 254 \mu \mathrm{mol}, 6.0$ equiv) was added as a hydrochloric acid scavenger, and $\mathrm{Me}_{2} \mathrm{PhSiCl}(28.1 \mu \mathrm{L}$, $170 \mu \mathrm{mol}, 4.0$ equiv) was added to end-cap the propagating polymers. The end-capping reaction was continued at least for $15 \mathrm{~min}$ and generally for longer than $12 \mathrm{~h}$ at ambient temperature to ensure quantitative end-capping. Then, the reaction mixture was concentrated under reduced pressure. The obtained oil was mixed/shaken with MeCN (3 $\mathrm{mL}$ ) and the upper layer was removed; the washing procedure with $\mathrm{MeCN}$ was repeated in total four times. The residue was diluted with toluene $(2 \mathrm{~mL})$ and concentrated in vacuo. The solvent remaining in the product was thoroughly removed in vacuo to obtain $\alpha, \omega$-bis[dimethyl(phenyl)silyl]-terminated poly[dimethylsiloxane-coallyl(methyl)siloxane-co-3-chloropropyl (methyl)siloxane] (P(DMS-co-AMS-co-ClPMS)) (174.8 mg, 59.2\% yield, $\left.M_{\mathrm{n}, \mathrm{NMR}}=7.47 \mathrm{kDa}(n / m / l=54.6 / 13.0 / 13.4), \bigoplus_{\mathrm{M}}=1.16_{2}\right)$ as a colorless liquid. ${ }^{1} \mathrm{H} \mathrm{NMR}$ and ${ }^{29} \mathrm{Si}\left\{{ }^{1} \mathrm{H}\right\} \mathrm{NMR}$ spectra of the product are shown in Figures S23 and S24.

Two-stage Copolymerization of AD2 and D3 (Table 3, entry 7)

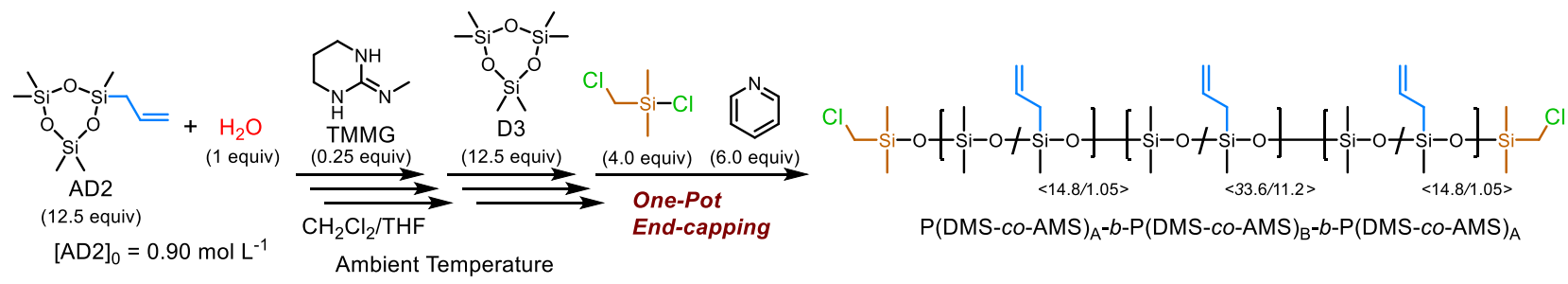

A THF solution of TMMG ( $60 \mathrm{mg} \mathrm{mL}^{-1}, 11.0 \mu \mathrm{L}, 5.83 \mu \mathrm{mol}, 0.125$ equiv) was added to a solution of AD2 (160 mg, $583 \mu$ mol-AD2, 12.5 equiv, purity 90.6wt\%) and a THF solution of $\mathrm{H}_{2} \mathrm{O}\left(1 / 99\left(\mathrm{H}_{2} \mathrm{O} / \mathrm{THF}, \mathrm{v} / \mathrm{v}\right), 84.1 \mu \mathrm{L}, 46.7\right.$ $\mu$ mol, 1.0 equiv) in dry $\mathrm{CH}_{2} \mathrm{Cl}_{2}(564 \mu \mathrm{L})$ in a glass vial or a flask under an argon atmosphere to initiate the polymerization at ambient temperature $\left(24-26^{\circ} \mathrm{C}\right)$. During the polymerization, an aliquot of the reaction mixture 
$(\sim 40 \mu \mathrm{L})$ was taken and mixed with a small amount of benzoic acid. The aliquot was analyzed by ${ }^{1} \mathrm{H}$ NMR to determine the conversion of the monomer and by SEC to analyze the molar-mass distribution of the crude product. During the first-stage of the polymerization, $11.8 \mathrm{wt} \%$ of the reaction mixture was taken to check the progress of the polymerization. After $1 \mathrm{~h} 38 \mathrm{~min}, \mathrm{D} 3(114 \mathrm{mg}, 512 \mu \mathrm{mol}, 12.5$ equiv) was added to the reaction mixture. The secondstage of the polymerization was continue for $1 \mathrm{~h} 40 \mathrm{~min}$. The sampling was conducted four times in the entire polymerization. Dry pyridine ( $22.6 \mu \mathrm{L}, 280 \mu \mathrm{mol}, 6.0$ equiv) was added as a hydrochloric acid scavenger, and $\left(\mathrm{ClCH}_{2}\right) \mathrm{SiMe}_{2} \mathrm{Cl}(24.6 \mu \mathrm{L}, 187 \mu \mathrm{mol}, 4.0$ equiv) was added to end-cap the propagating polymers. The end-capping reaction was continued at least for $15 \mathrm{~min}$ and generally for longer than $12 \mathrm{~h}$ at ambient temperature to ensure quantitative end-capping. Then, the reaction mixture was concentrated under reduced pressure. The obtained oil was mixed/shaken with $\mathrm{MeCN}(3 \mathrm{~mL})$ and the upper layer was removed; the washing procedure with $\mathrm{MeCN}$ was repeated in total four times. The residue was diluted with toluene $(2 \mathrm{~mL})$ and concentrated in vacuo. The solvent remaining in the product was thoroughly removed in vacuo to obtain $\alpha, \omega$-bis(chloromethyldimethylsilyl)-terminated triblock poly[dimethylsiloxane-co-allyl(methyl)siloxane] (P(DMS-co-AMS) $)_{\mathrm{A}}-b-\mathrm{P}(\mathrm{DMS}-c o-\mathrm{AMS})_{\mathrm{B}}-b-\mathrm{P}(\mathrm{DMS}-c o-$ AMS) $)_{\mathrm{A}}\left(167.1 \mathrm{mg}, 58.5 \%\right.$ yield, $M_{\mathrm{n}, \mathrm{NMR}}=5.95 \mathrm{kDa}$ (Block A: $n / m=14.8 / 1.05$; Block B: $\left.n / m=33.6 / 11.2\right), \emptyset_{\mathrm{M}}=$ $\left.1.11_{3}\right)$ as a colorless liquid. ${ }^{1} \mathrm{H}$ NMR and ${ }^{29} \mathrm{Si}\left\{{ }^{1} \mathrm{H}\right\}$ NMR spectra of the product are shown in Figures S25 and S26.

$T_{\mathrm{g}}$ was observed at $-121^{\circ} \mathrm{C}$ for the product.

\section{Determination of the height of the shoulder/peak in the high-molar-mass region $\left(h_{c}\right)$ of the molar-mass distributions of the polysiloxanes (Tables 1-3) ${ }^{\mathrm{S} 7}$}

A shoulder/peak was observed in the high-molar-mass region of the molar-mass distributions of the polysiloxanes obtained in this study. The chromatograms obtained by SEC were converted into graphs of the molar-mass distribution. The molar mass of standard polystyrenes $\left(M_{\mathrm{PS}}\right)$ calculated from the elution time was used as the $x$-axis. The observed RI value ( $\Delta n)$ divided by $M$ PS was used for the $y$-axis. The $y$-axis of the resulting curve was normalized so that the highest point of the molar-mass distribution was $100 \mathrm{~mol} \%$. The $h_{\mathrm{c}}$ value was determined as shown in the following example.

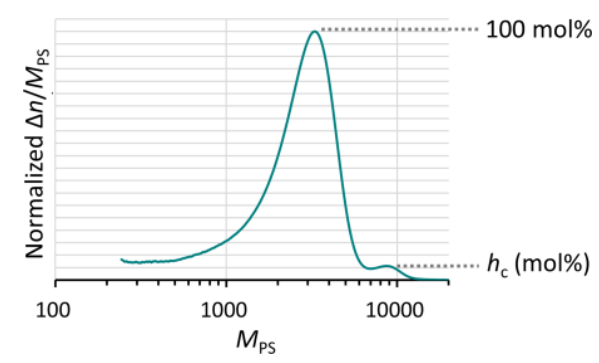

Figure S1. Determination of $h_{\mathrm{c}}(\mathrm{mol} \%)$ for polysiloxanes from their molar-mass distributions, which were estimated from SEC measurements using toluene as the eluent, narrowly dispersed polystyrene standards, and an RI detector.

The apparent rate coefficient of condensation $\left(k_{c}\right.$,app $)$ for a given polymerization was calculated by dividing the $h_{\mathrm{c}}(\mathrm{mol} \%)$ value by the polymerization time (h) 
Determination of number-average degree of polymerization $\left(<X_{n}>\right)$ and $M_{n, N M R}$ of the polysiloxane using ${ }^{1} \mathrm{H}$ NMR spectroscopy.

The $M_{\mathrm{n}}\left(M_{\mathrm{n}, \mathrm{NMR}}\right)$ values of the synthesized polysiloxanes were determined using ${ }^{1} \mathrm{H}$ NMR spectroscopy.

Index ' $\mathrm{Y}$ ' for $<X_{\mathrm{n}, \mathrm{Y}}>$ are defined as:

$\mathrm{D}=$ dimethylsiloxane units;

$\mathrm{V}=$ methyl(vinyl)siloxane units;

$\mathrm{ClP}=$ 3-chloropropyl(methyl)siloxane units;

$\mathrm{A}=$ allyl(methyl) siloxane units.

The integral values of peak $\mathrm{x}$ in ${ }^{1} \mathrm{H}$ NMR spectra are written as $I_{\mathrm{x}}$.

For P(DMS-co-MVS) with $\alpha, \omega$-bis[(chloromethyl)dimethylsilyl] groups (Table 1 and 3): The peaks in Figure 1 were used for the calculation.

$$
\begin{aligned}
& <X_{\mathrm{n}, \mathrm{D}}>=\left(I_{\mathrm{a}} / 6\right) /\left(I_{\mathrm{g}} / 4\right) \\
& <X_{\mathrm{n}, \mathrm{V}}>=\left(I_{\mathrm{b}} / 3\right) /\left(I_{\mathrm{g}} / 4\right) \\
& M_{\mathrm{n}, \mathrm{NMR}}=74.154<X_{\mathrm{n}, \mathrm{D}}>+86.165<X_{\mathrm{n}, \mathrm{V}}>+231.26
\end{aligned}
$$

For P(DMS-co-MVS) with $\alpha$-trimethylsilyl- $\omega$-(chloromethyl)dimethylsilyl groups (molar mass of terminal groups $\left.=M_{\text {terminal }}=196.82\right)$ and $\alpha$-triphenylsilyl- $\omega$-(chloromethyl)dimethylsilyl groups $\left(M_{\text {terminal }}=383.03\right)($ Table 2$)$ : The peaks in Figure S6 were used for the calculation.

$$
\begin{aligned}
& <X_{\mathrm{n}, \mathrm{D}}>=\left(I_{\mathrm{a}} / 6\right) /\left(I_{\mathrm{g}} / 2\right) \\
& <X_{\mathrm{n}, \mathrm{V}}>=\left(I_{\mathrm{b}} / 3\right) /\left(I_{\mathrm{g}} / 2\right) \\
& M_{\mathrm{n}, \mathrm{NMR}}=74.154<X_{\mathrm{n}, \mathrm{D}}>+86.165<X_{\mathrm{n}, \mathrm{V}}>+M_{\text {terminal }}
\end{aligned}
$$

For P(DMS-co-ClPMS) with $\alpha, \omega$-bis[dimethyl(vinyl)silyl] groups (Table 1 and 3): The peaks in Figure 1 were used for the calculation.

$$
\begin{aligned}
& <X_{\mathrm{n}, \mathrm{D}}>=\left(\left(I_{\mathrm{a}+\mathrm{b}}-3 I_{\mathrm{c}} / 2\right) / 6\right) /\left(\left(I_{\mathrm{g}}+I_{\mathrm{i}}+I_{\mathrm{h}}\right) / 6\right) \\
& <X_{\mathrm{n}, \mathrm{ClP}}>=\left(I_{\mathrm{c}} / 2\right) /\left(\left(I_{\mathrm{g}}+I_{\mathrm{i}}+I_{\mathrm{h}}\right) / 6\right) \\
& M_{\mathrm{n}, \mathrm{NMR}}=74.154<X_{\mathrm{n}, \mathrm{D}}>+136.65<X_{\mathrm{n}, \mathrm{ClP}}>+186.40
\end{aligned}
$$

For P(DMS-co-ClPMS) with $\alpha$-trimethylsilyl- $\omega$-[dimethyl(vinyl)silyl] groups (molar mass of terminal groups = $\left.M_{\text {terminal }}=174.39\right)$ and $\alpha$-triphenylsilyl- $\omega$-[dimethyl(vinyl)silyl groups $\left(M_{\text {terminal }}=360.60\right)($ Table 2$)$ : The peaks in Figure S8 were used for the calculation.

$$
\begin{aligned}
& <X_{\mathrm{n}, \mathrm{D}}>=\left(\left(I_{\mathrm{a}+\mathrm{b}+\mathrm{m}+\mathrm{k}+\mathrm{j}}-3 I_{\mathrm{c}} / 2\right) / 6\right) /\left(\left(I_{\mathrm{g}}+I_{\mathrm{i}}+I_{\mathrm{h}}\right) / 3\right) \\
& <X_{\mathrm{n}, \mathrm{ClP}}>=\left(I_{\mathrm{c}} / 2\right) /\left(\left(I_{\mathrm{g}}+I_{\mathrm{i}}+I_{\mathrm{h}}\right) / 3\right) \\
& M_{\mathrm{n}, \mathrm{NMR}}=74.154<X_{\mathrm{n}, \mathrm{D}}>+136.65<X_{\mathrm{n}, \mathrm{ClP}}>+M_{\text {terminal }}
\end{aligned}
$$


For P(DMS-co-AMS) with $\alpha, \omega$-bis[(chloromethyl)dimethylsilyl] groups (Table 1 and 3): The peaks in Figure 1 were used for the calculation.

$$
\begin{aligned}
& <X_{\mathrm{n}, \mathrm{D}}>=\left(\left(I_{\mathrm{a}+\mathrm{b}}-3 I_{\mathrm{e}+\mathrm{f}} / 2\right) / 6\right) /\left(I_{\mathrm{h}} / 4\right) \\
& <X_{\mathrm{n}, \mathrm{A}}>=\left(I_{\mathrm{e}+\mathrm{f}} / 2\right) /\left(I_{\mathrm{h}} / 4\right) \\
& M_{\mathrm{n}, \mathrm{NMR}}=74.154<X_{\mathrm{n}, \mathrm{D}}>+100.19<X_{\mathrm{n}, \mathrm{A}}>+231.26
\end{aligned}
$$

For P(DMS-co-AMS) with $\alpha$-trimethylsilyl- $\omega$-(chloromethyl)dimethylsilyl groups (molar mass of terminal groups $\left.=M_{\text {terminal }}=196.82\right)$ and $\alpha$-triphenylsilyl- $\omega$ - $($ chloromethyl $)$ dimethylsilyl groups $\left(M_{\text {terminal }}=383.03\right)($ Table 2$)$ : The peaks in Figure S10 were used for the calculation.

$$
\begin{aligned}
& <X_{\mathrm{n}, \mathrm{D}}>=\left(I_{\mathrm{a}+\mathrm{b}+\mathrm{j}+\mathrm{i}+\mathrm{k}} / 6\right) /\left(I_{\mathrm{h}} / 2\right) \\
& <X_{\mathrm{n}, \mathrm{A}}>=\left(I_{\mathrm{e}+\mathrm{f}} / 2\right) /\left(I_{\mathrm{h}} / 4\right) \\
& M_{\mathrm{n}, \mathrm{NMR}}=74.154<X_{\mathrm{n}, \mathrm{D}}>+100.19<X_{\mathrm{n}, \mathrm{A}}>+M_{\text {terminal }}
\end{aligned}
$$

For P(DMS-co-MVS-co-ClPMS) with $\alpha, \omega$-bis[dimethyl(phenyl)silyl] groups (Table 3): The peaks in Figure S21 were used for the calculation.

$$
\begin{aligned}
& <X_{\mathrm{n}, \mathrm{D}}>=\left(\left(I_{\mathrm{a}+\mathrm{f}}-3 I_{\mathrm{g}} / 2\right) / 6\right) /\left(I_{\mathrm{k}} / 12\right) \\
& <X_{\mathrm{n}, \mathrm{V}}>=\left(I_{\mathrm{c}+\mathrm{d}+\mathrm{e}} / 3\right) /\left(I_{\mathrm{k}} / 12\right) \\
& <X_{\mathrm{n}, \mathrm{ClP}}>=\left(I_{\mathrm{h}} / 2\right) /\left(I_{\mathrm{k}} / 12\right) \\
& M_{\mathrm{n}, \mathrm{NMR}}=74.154<X_{\mathrm{n}, \mathrm{D}}>+86.165<X_{\mathrm{n}, \mathrm{V}}>+136.65<X_{\mathrm{n}, \mathrm{ClP}}>+286.52
\end{aligned}
$$

For P(DMS-co-AMS-co-CIPMS) with $\alpha, \omega$-bis[dimethyl(phenyl)silyl] groups (Table 3): The peaks in Figure S23 were used for the calculation.

$$
\begin{aligned}
& <X_{\mathrm{n}, \mathrm{D}}>=\left(\left(I_{\mathrm{a}+\mathrm{b}+\mathrm{g}}-3 I_{\mathrm{e}+\mathrm{f}} / 2-3 I_{\mathrm{h}} / 2\right) / 6\right) /\left(I_{\mathrm{k}} / 12\right) \\
& <X_{\mathrm{n}, \mathrm{A}}>=\left(I_{\mathrm{e}+\mathrm{f}} / 2\right) /\left(I_{\mathrm{k}} / 12\right) \\
& <X_{\mathrm{n}, \mathrm{ClP}}>=\left(I_{\mathrm{h}} / 2\right) /\left(I_{\mathrm{k}} / 12\right) \\
& M_{\mathrm{n}, \mathrm{NMR}}=74.154<X_{\mathrm{n}, \mathrm{D}}>+100.19<X_{\mathrm{n}, \mathrm{A}}>+136.65<X_{\mathrm{n}, \mathrm{ClP}}>+286.52
\end{aligned}
$$


NMR and MALDI-TOF MS spectra and molar-mass distributions of the products

The symbols, 'O० spectra indicate the six possible triads of monomeric units, i.e. FnDFn/DDFn/DDD and FnFnFn/DFnFn/DFnD.
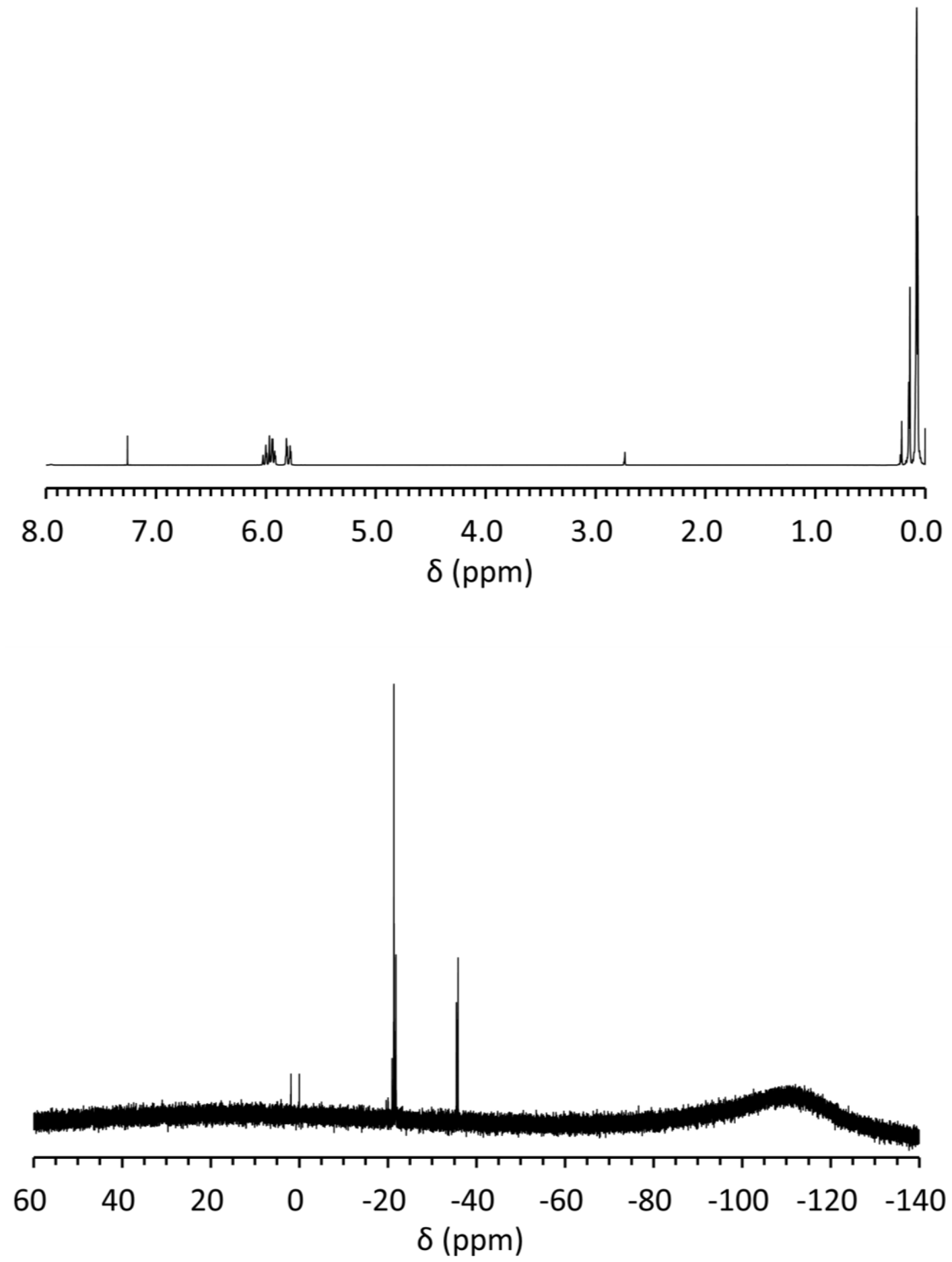

Figure S2. Full ${ }^{1} \mathrm{H}$ and ${ }^{29} \mathrm{Si}\left\{{ }^{1} \mathrm{H}\right\} \quad \mathrm{NMR}$ spectra of $\mathrm{P}(\mathrm{DMS}-\mathrm{co}-\mathrm{MVS})$ end-functionalized with 
(chloromethyl)dimethylsilyl groups (Table 1, Entry 2, $M_{\mathrm{n}, \mathrm{NMR}}=6.51 \mathrm{kDa}, \bigoplus_{\mathrm{M}}=1.08_{5}$ ). 

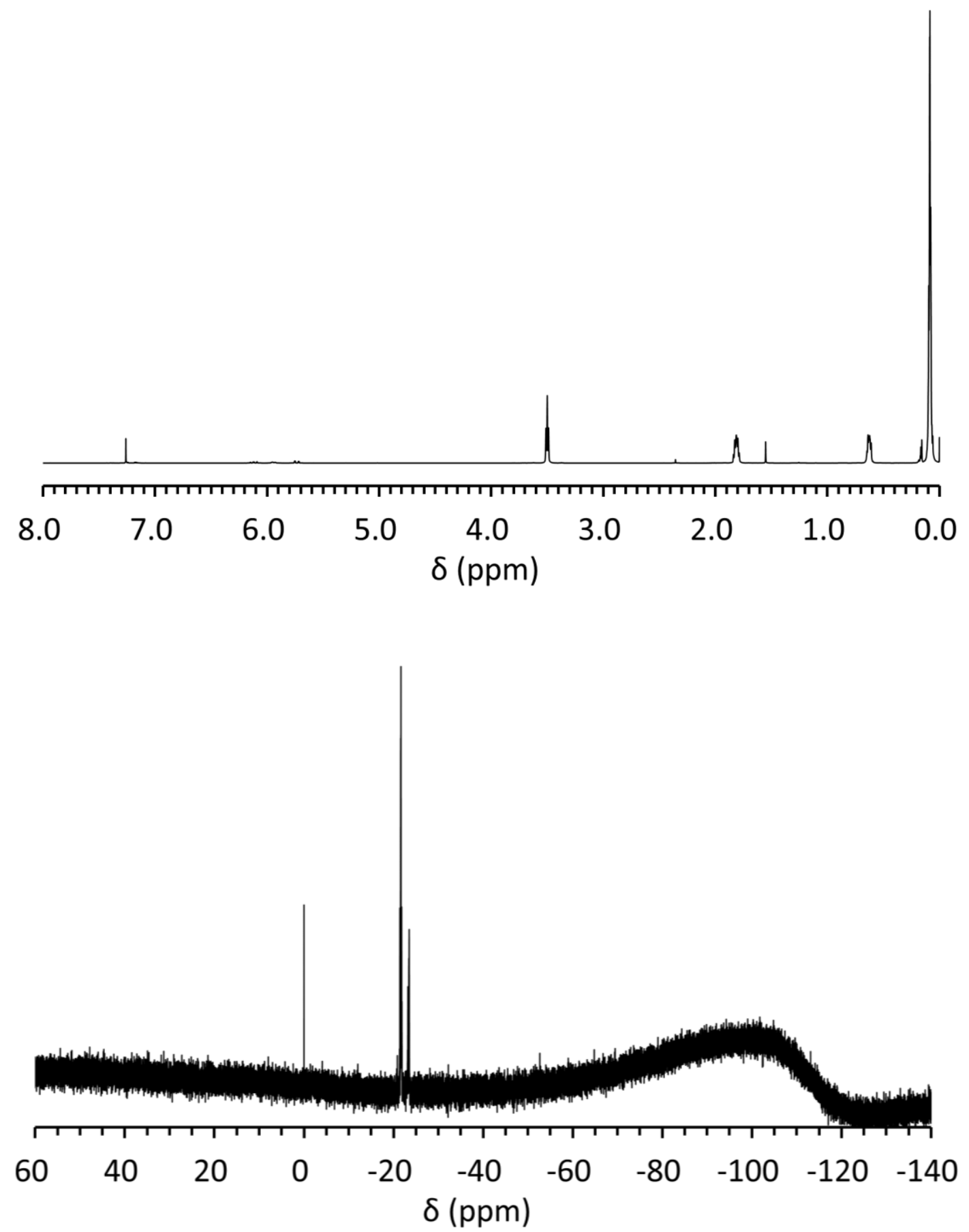

Figure S3. Full ${ }^{1} \mathrm{H}$ and ${ }^{29} \mathrm{Si}\left\{{ }^{1} \mathrm{H}\right\}$ NMR spectra of P(DMS-co-CIPMS) end-functionalized with dimethylvinylsilyl groups (Table 1, Entry 3, $M_{\mathrm{n}, \mathrm{NMR}}=8.87 \mathrm{kDa}, \bigoplus_{\mathrm{M}}=1.09_{4}$ ). 


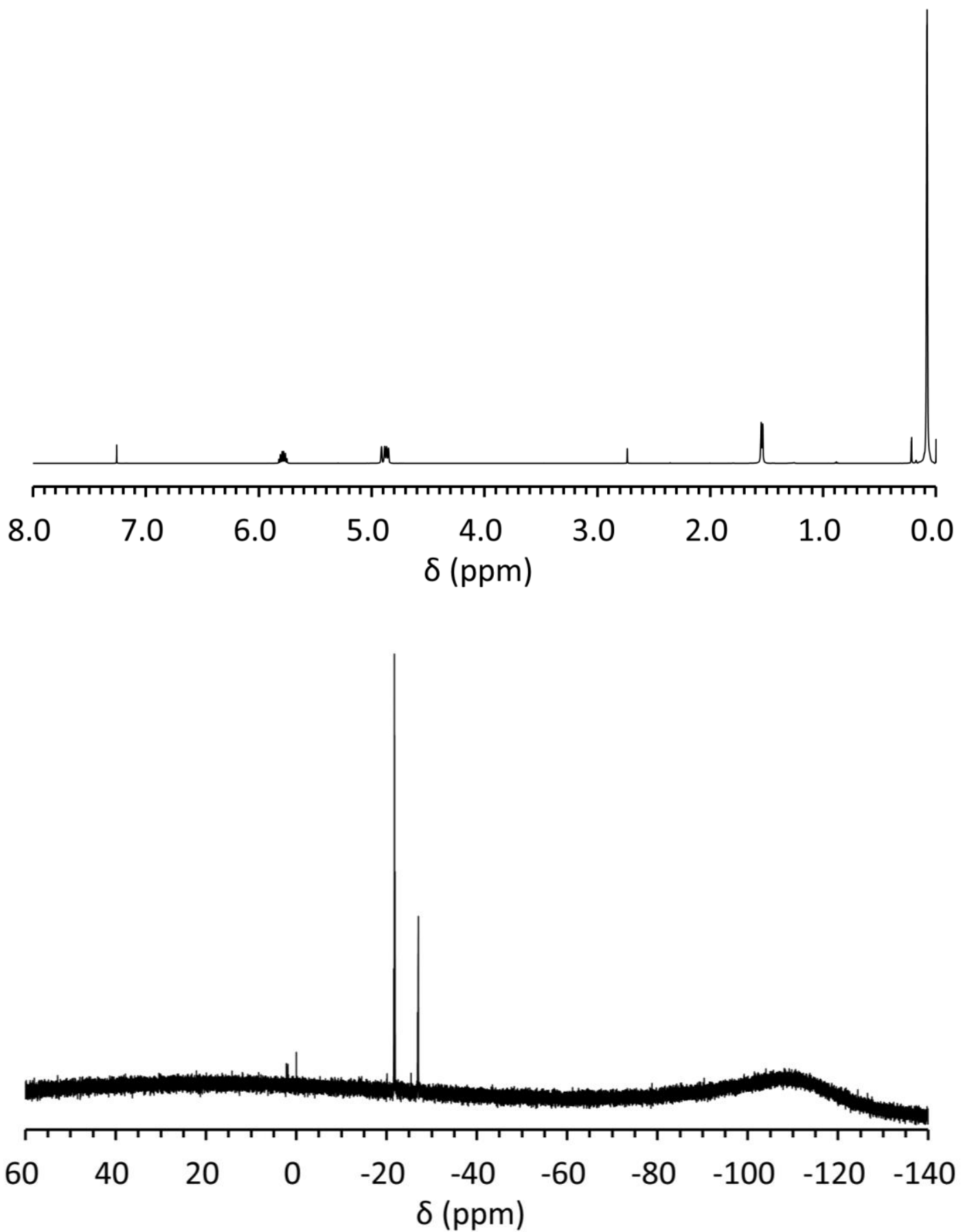

Figure S4. Full ${ }^{1} \mathrm{H}$ and ${ }^{29} \mathrm{Si}\left\{{ }^{1} \mathrm{H}\right\} \quad \mathrm{NMR}$ spectra of $\mathrm{P}(\mathrm{DMS}-\mathrm{co}-\mathrm{AMS})$ end-functionalized with (chloromethyl)dimethylsilyl groups (Table 1, Entry 6, $M_{\mathrm{n}, \mathrm{NMR}}=6.59 \mathrm{kDa}, \bigoplus_{\mathrm{M}}=1.11_{7}$ ). 


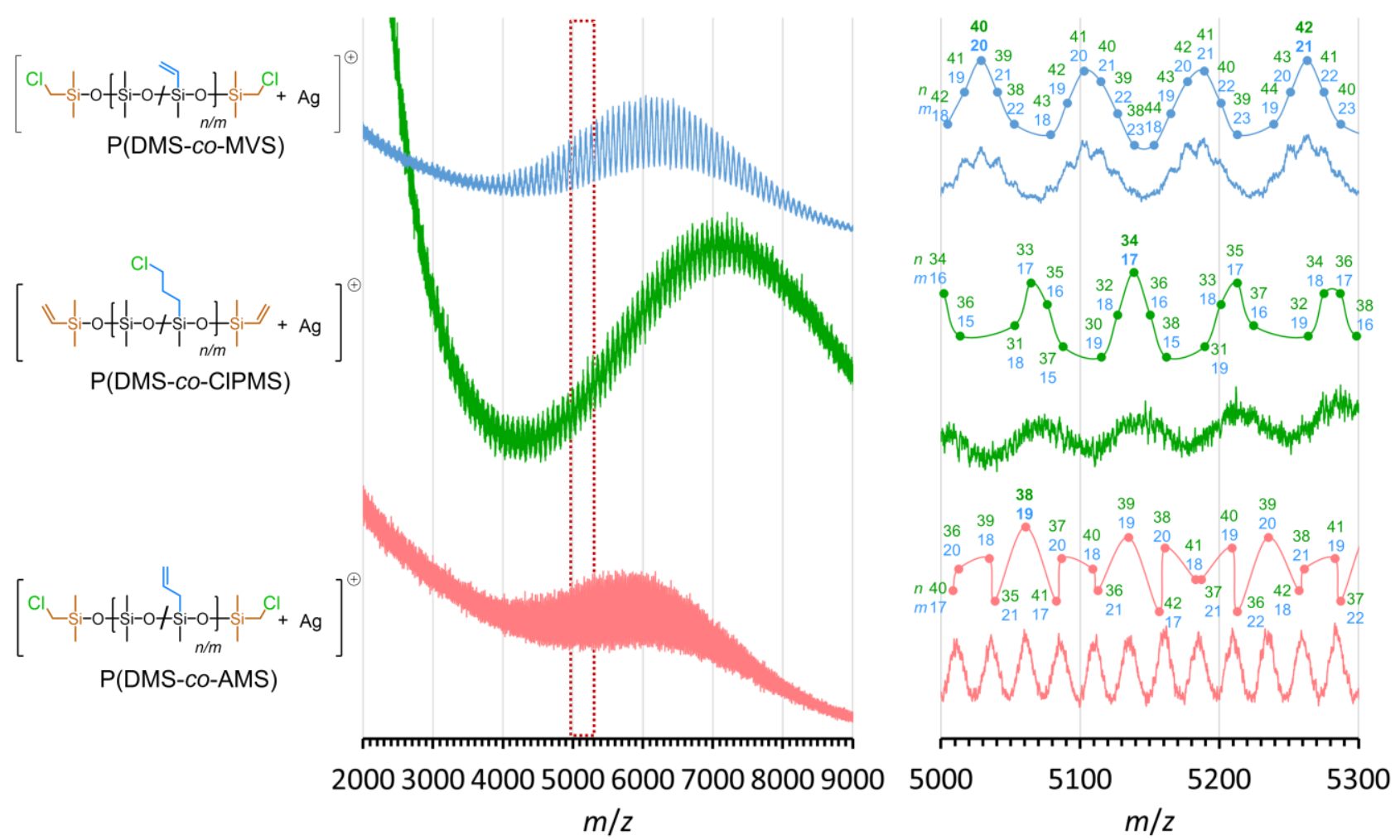

Figure S5. Positive-ion MALDI-TOF MS spectra of the obtained $\alpha, \omega$-bis[(chloromethyl)dimethylsilyl]terminated $\mathrm{P}(\mathrm{DMS}-\mathrm{co}-\mathrm{MVS}) \quad\left(\right.$ top, $\quad M_{\mathrm{n}, \mathrm{NMR}}=6.51 \mathrm{kDa} ; \emptyset_{\mathrm{M}}=1.08_{5} ;$ Table 1 , entry 2$), \alpha, \omega-$ bis[dimethyl(vinyl)silyl]-terminated P(DMS-co-ClPMS) (middle, $M_{\mathrm{n}, \mathrm{NMR}}=8.87 \mathrm{kDa} ; \bigoplus_{\mathrm{M}}=1.09_{4}$; Table 1 , entry 3), and $\alpha, \omega$-bis[(chloromethyl)dimethylsilyl]-terminated P(DMS-co-AMS) (bottom, $M_{\mathrm{n}, \mathrm{NMR}}=6.59 \mathrm{kDa} ; \bigoplus_{\mathrm{M}}=$ 1.117; Table 1, entry 6) measured in linear mode using a trans-2-[3-(4-tert-butylphenyl)-2-methyl-2propenylidene]malononitrile (DCTB) matrix and silver trifluoroacetate as the cationization agent. The circles in the right spectrum show the theoretical $\mathrm{m} / \mathrm{z}$ values for the polymers with degrees of polymerization of $n$ and $m$. The circles with lower deviation from $n / m=2 / 1$ are displayed at higher positions. 


\section{${ }^{1} \mathrm{H}$ NMR}
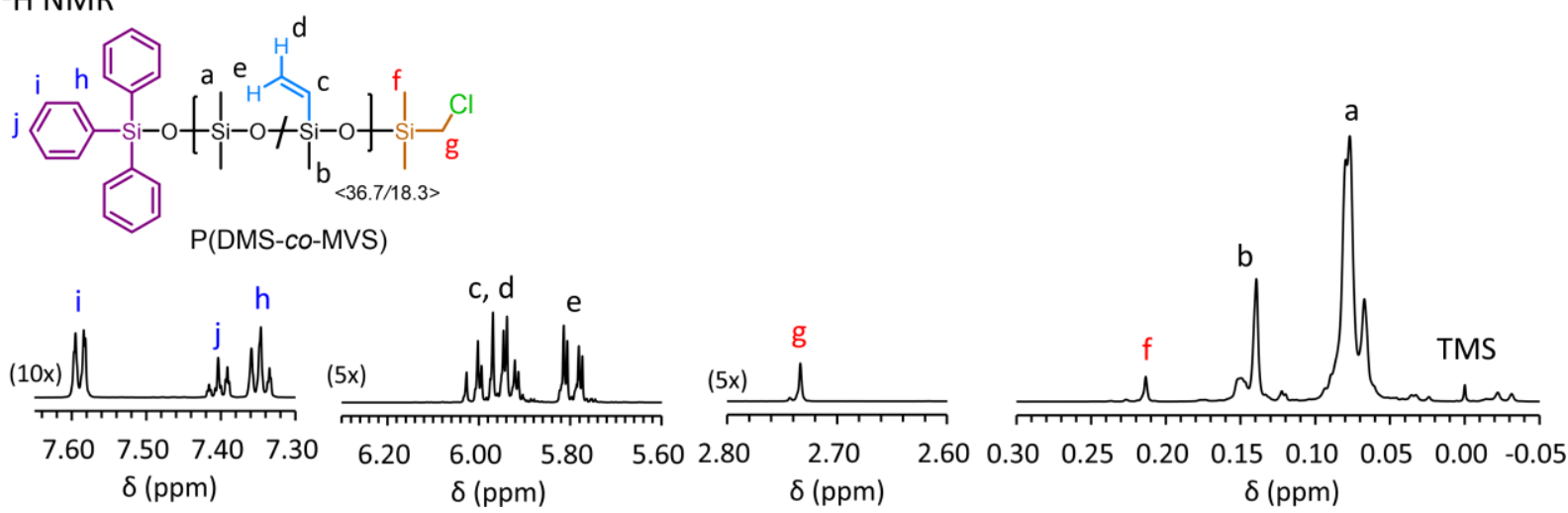

${ }^{29} \mathrm{Si}\left\{{ }^{1} \mathrm{H}\right\} \mathrm{NMR}$
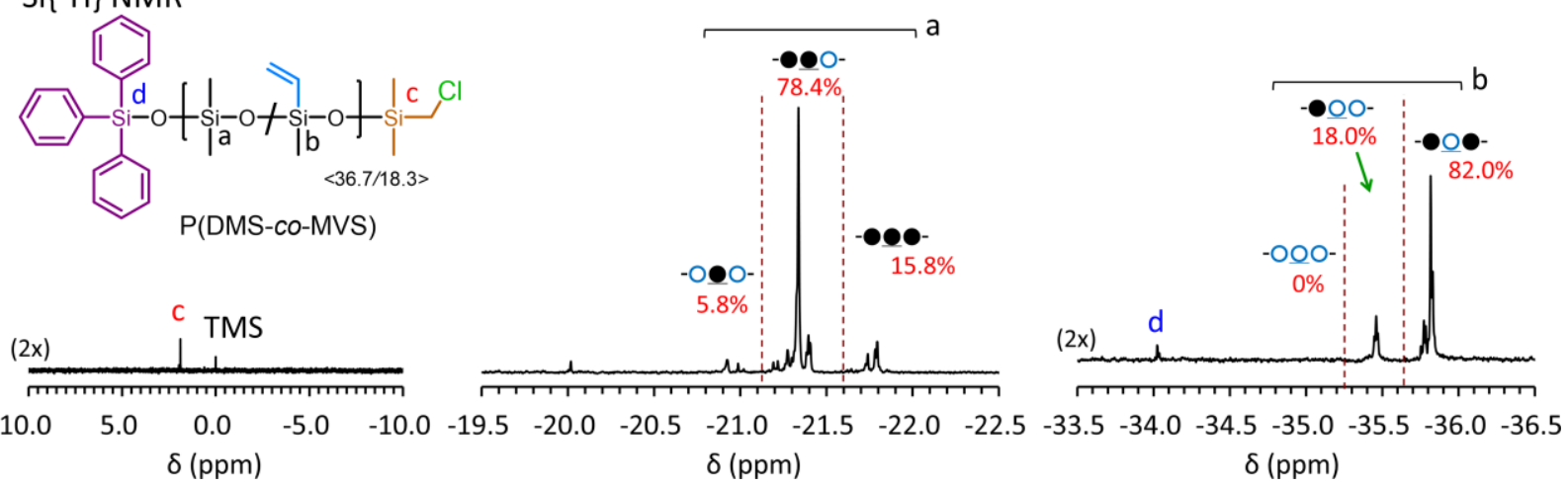

$\delta$ (ppm)

$\delta$ (ppm)

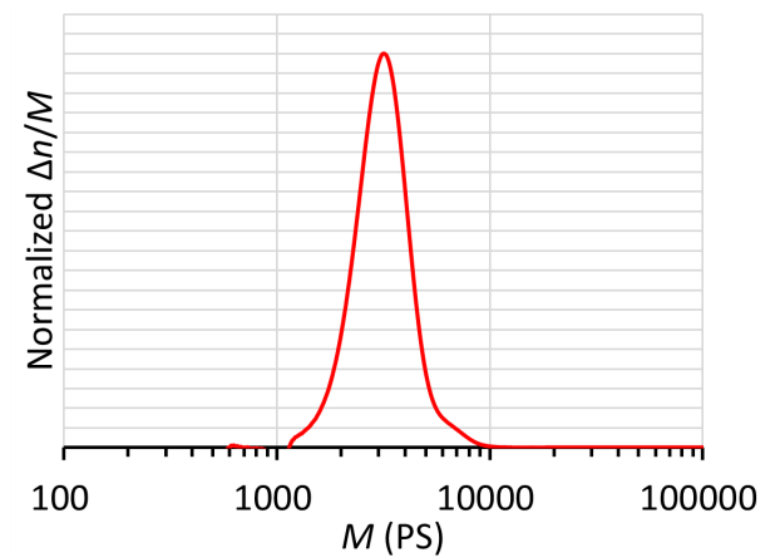

Figure S6. ${ }^{1} \mathrm{H}$ and ${ }^{29} \mathrm{Si}\left\{{ }^{1} \mathrm{H}\right\}$ NMR spectra and molar-mass distribution of $\mathrm{P}(\mathrm{DMS}-\mathrm{co}$-VMS) end-functionalized with a trimethylsilyl group and a (chloromethyl)dimethylsilyl group (Table 2, Entry 2, $M_{\mathrm{n}, \mathrm{NMR}}=4.88 \mathrm{kDa}, \bigoplus_{\mathrm{M}}=1.11_{7}$ ). 


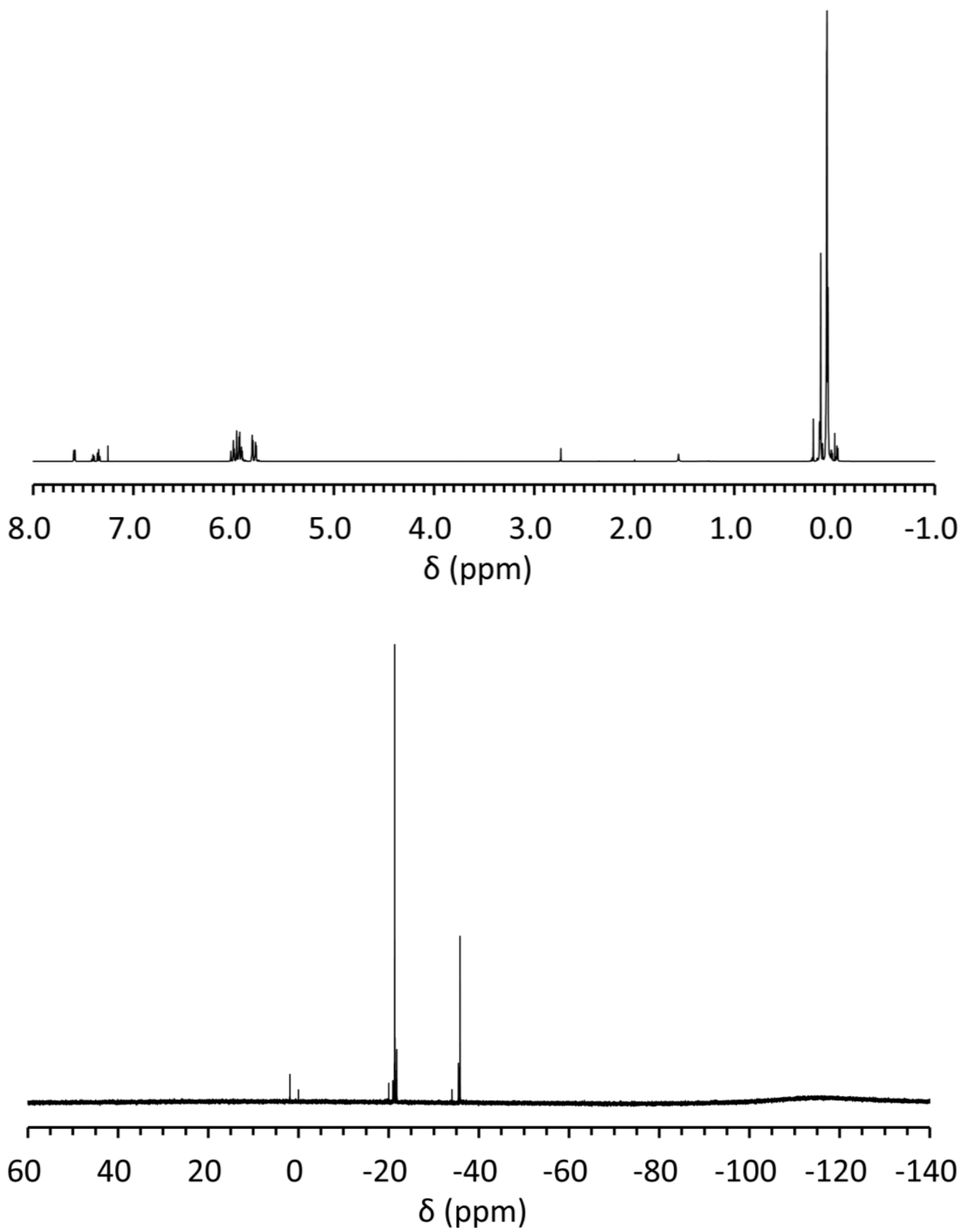

Figure S7. Full ${ }^{1} \mathrm{H}$ and ${ }^{29} \mathrm{Si}\left\{{ }^{1} \mathrm{H}\right\}$ NMR spectra of $\mathrm{P}(\mathrm{DMS}-\mathrm{co}$-VMS) end-functionalized with a trimethylsilyl group and a (chloromethyl)dimethylsilyl group (Table 2, Entry 2, $M_{\mathrm{n}, \mathrm{NMR}}=4.88 \mathrm{kDa}, \bigoplus_{\mathrm{M}}=1.11_{7}$ ). 

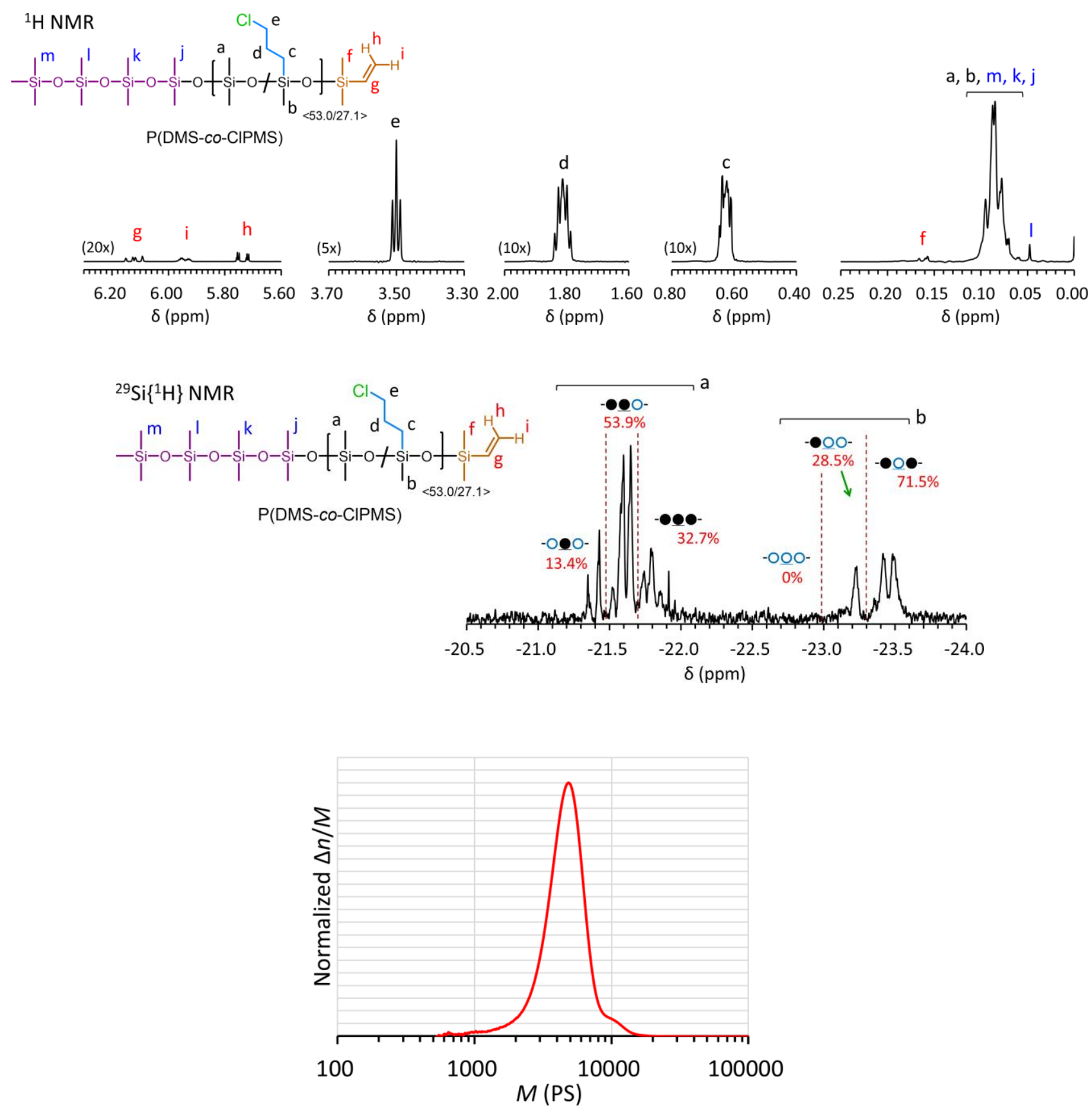

Figure S8. ${ }^{1} \mathrm{H}$ and ${ }^{29} \mathrm{Si}\left\{{ }^{1} \mathrm{H}\right\}$ NMR spectra and molar-mass distribution of $\mathrm{P}(\mathrm{DMS}-\mathrm{co}$-ClPMS) end-functionalized with a trimethylsilyl group and a dimethylvinylsilyl group (Table 2, Entry 3, $M_{\mathrm{n}, \mathrm{NMR}}=7.83 \mathrm{kDa}, \bigoplus_{\mathrm{M}}=1.13_{2}$ ). 

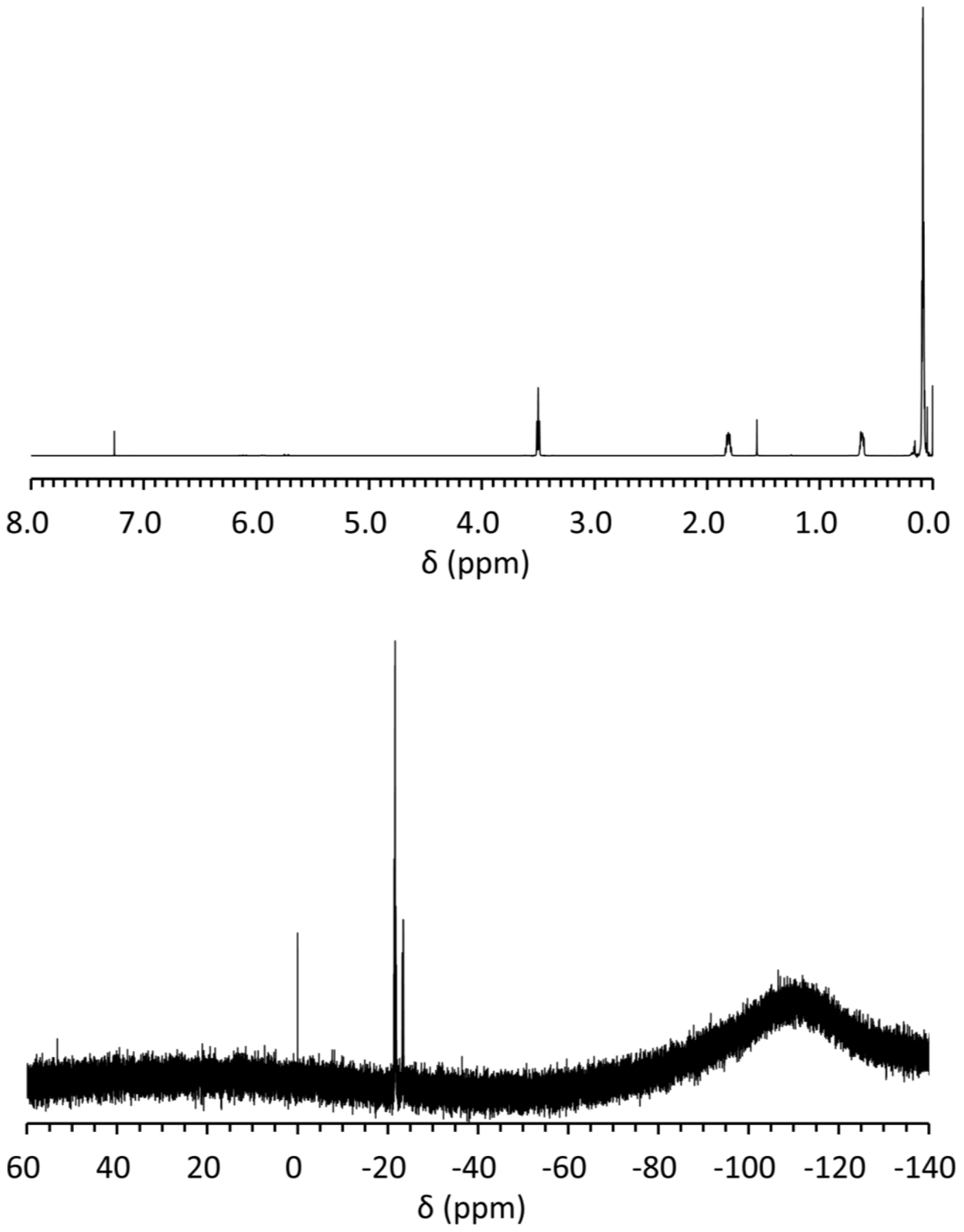

Figure S9. Full ${ }^{1} \mathrm{H}$ and ${ }^{29} \mathrm{Si}\left\{{ }^{1} \mathrm{H}\right\}$ NMR spectra of $\mathrm{P}(\mathrm{DMS}-\mathrm{co}$-ClPMS) end-functionalized with a trimethylsilyl group and a dimethylvinylsilyl group (Table 2, Entry $3, M_{\mathrm{n}, \mathrm{NMR}}=7.83 \mathrm{kDa}, \bigoplus_{\mathrm{M}}=1.13_{2}$ ). 


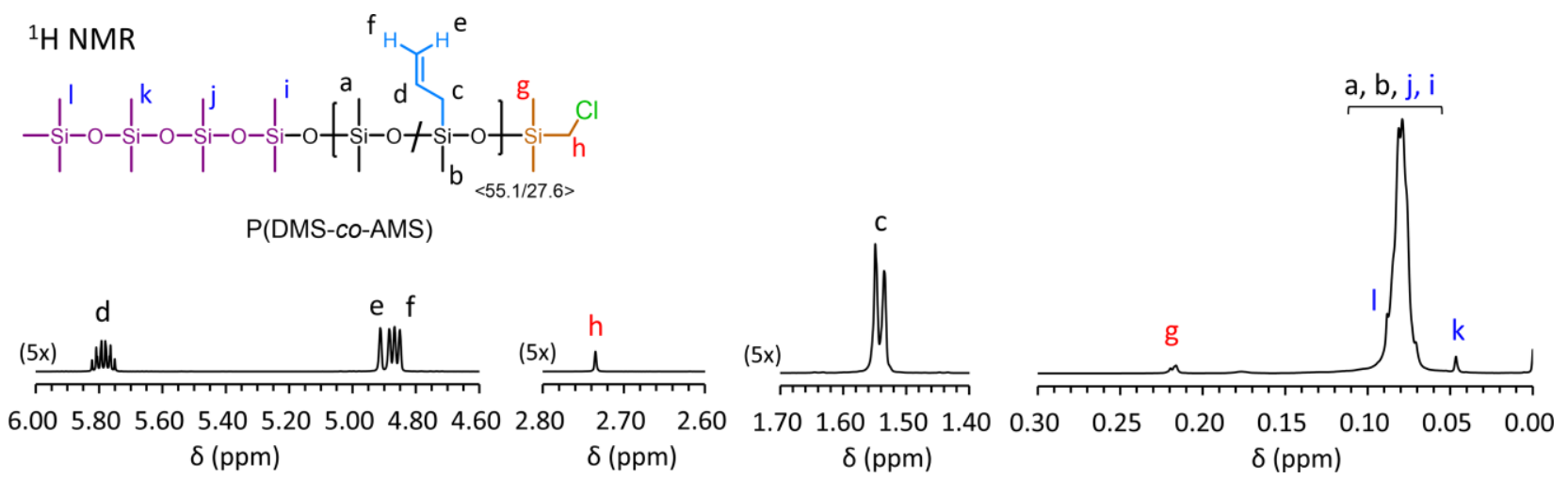

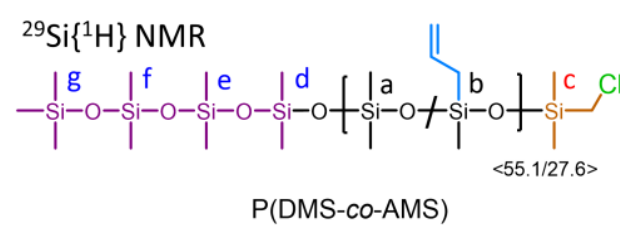

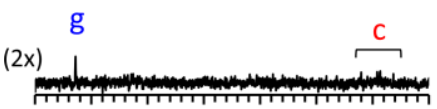

$\begin{array}{llllllllllllllllllllll}8.0 & 7.0 & 6.0 & 5.0 & 4.0 & 3.0 & 2.0 & 1.0 & -19.5 & -20.0 & -20.5 & -21.0 & -21.5 & -22.0 & -22.5 & -25.0 & -25.5 & -26.0 & -26.5 & -27.0 & -27.5 & -28.0\end{array}$ $\delta$ (ppm)
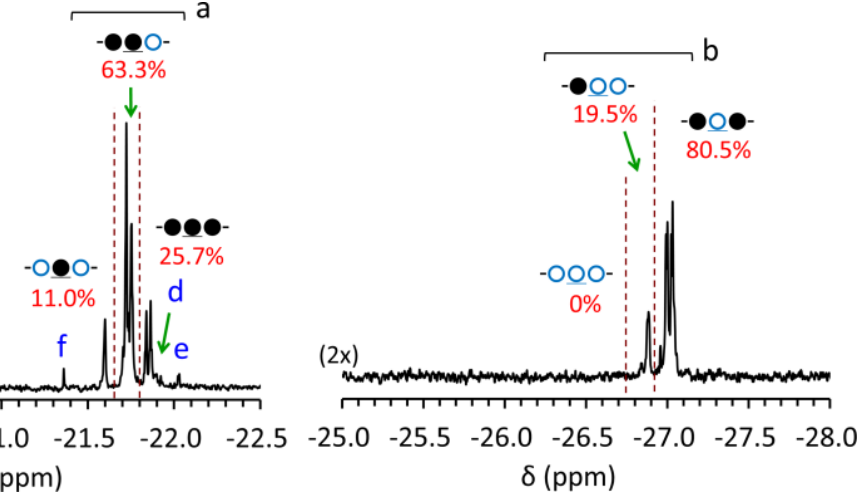

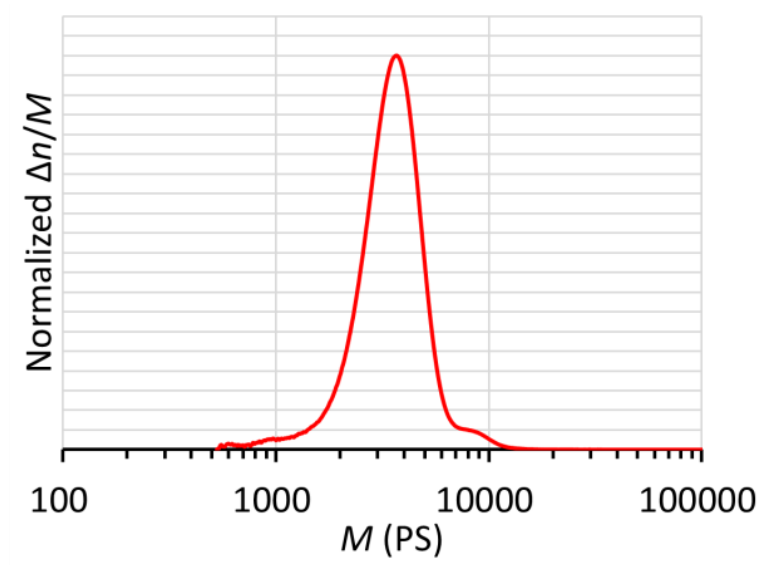

Figure S10. ${ }^{1} \mathrm{H}$ and ${ }^{29} \mathrm{Si}\left\{{ }^{1} \mathrm{H}\right\}$ NMR spectra and molar-mass distribution of $\mathrm{P}(\mathrm{DMS}-\mathrm{co}-\mathrm{AMS})$ end-functionalized with a trimethylsilyl group and a (chloromethyl)dimethylsilyl group (Table 2, Entry $6, M_{\mathrm{n}, \mathrm{NMR}}=7.27 \mathrm{kDa}, \bigoplus_{\mathrm{M}}=$ $\left.1.13_{8}\right)$. 

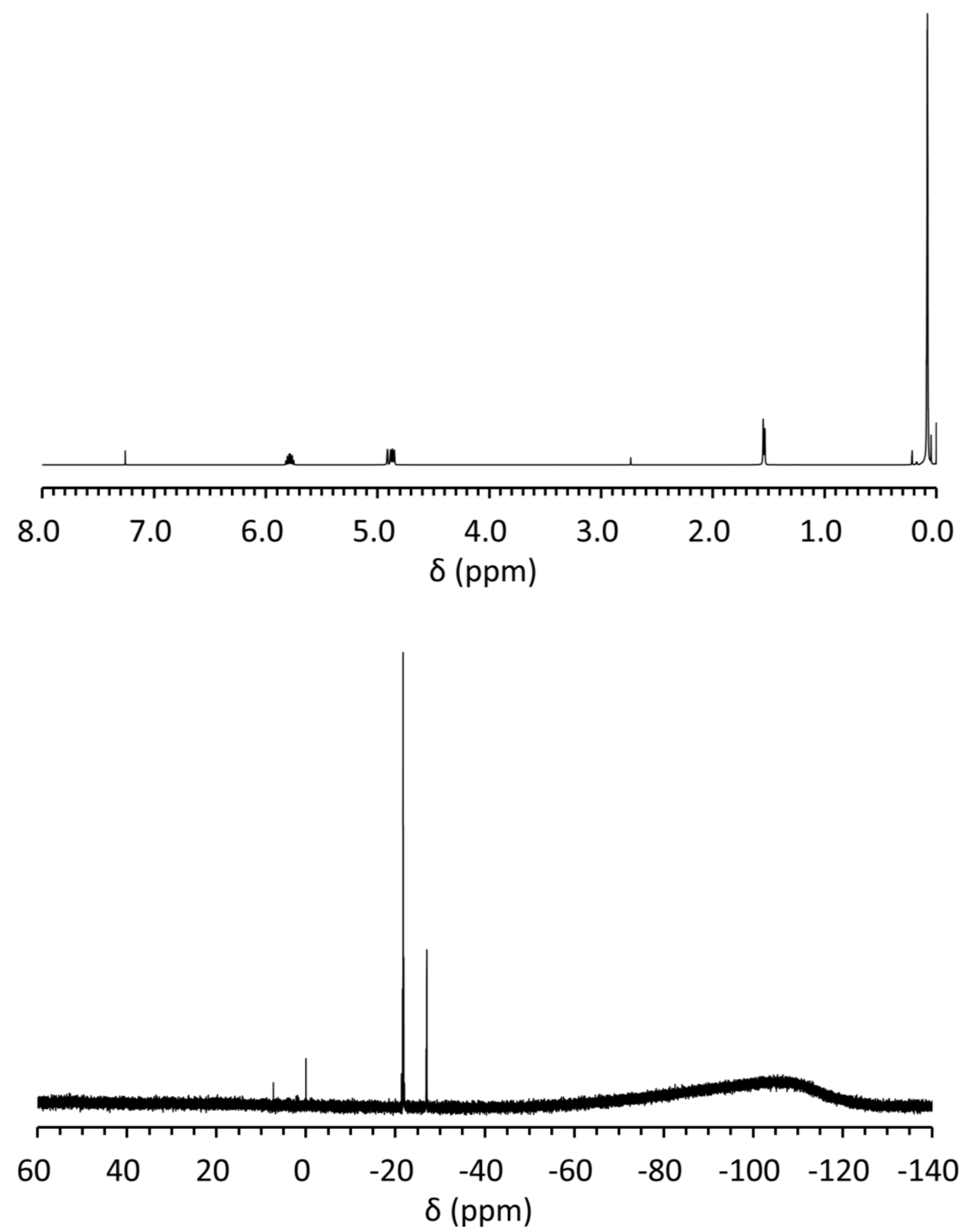

Figure S11. Full ${ }^{1} \mathrm{H}$ and ${ }^{29} \mathrm{Si}\left\{{ }^{1} \mathrm{H}\right\}$ NMR spectra of $\mathrm{P}(\mathrm{DMS}-\mathrm{co}-\mathrm{AMS})$ end-functionalized with a trimethylsilyl group and a (chloromethyl)dimethylsilyl group (Table 2, Entry 6, $M_{\mathrm{n}, \mathrm{NMR}}=7.27 \mathrm{kDa}, \biguplus_{\mathrm{M}}=1.13_{8}$ ). 

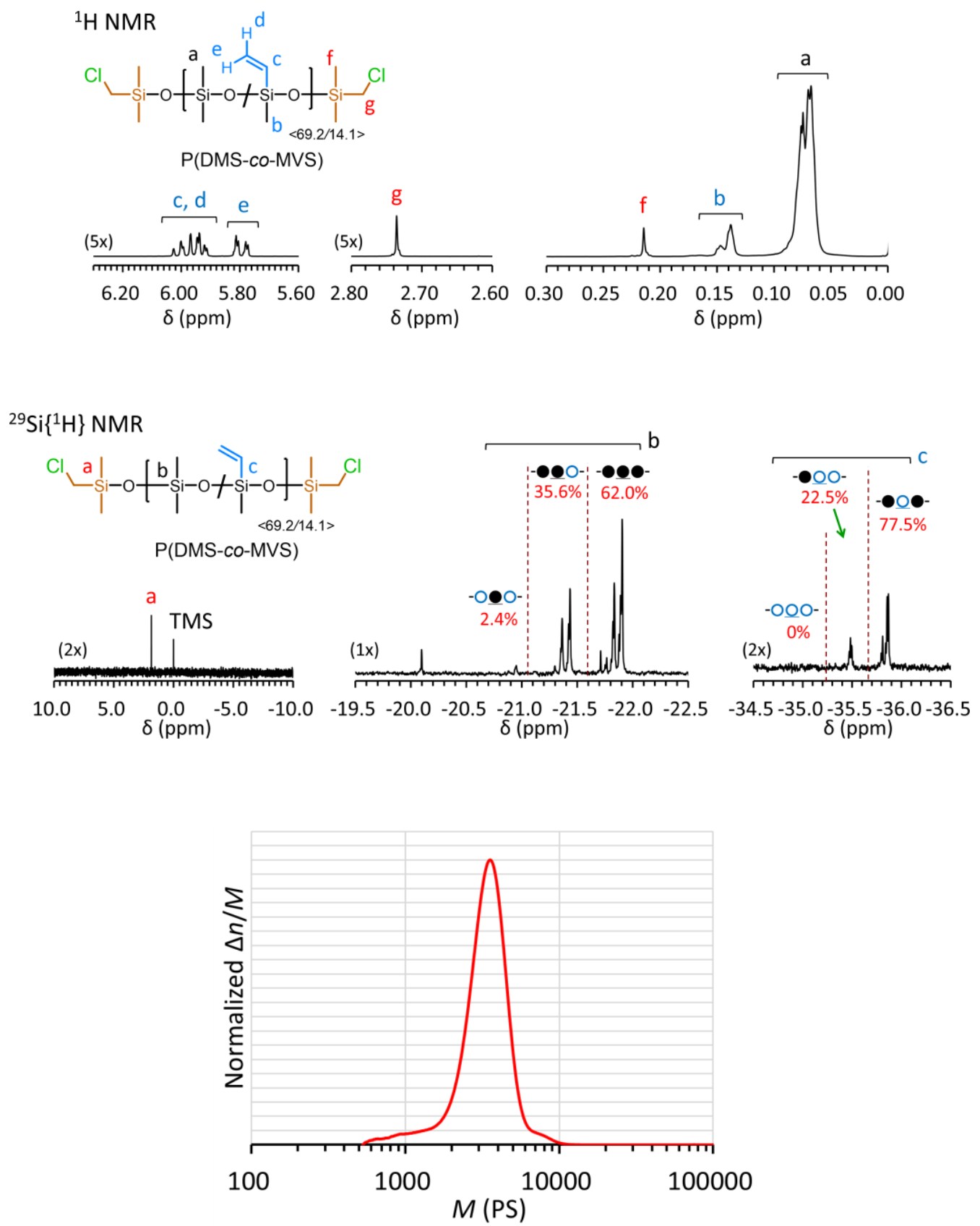

Figure S12. ${ }^{1} \mathrm{H}$ and ${ }^{29} \mathrm{Si}\left\{{ }^{1} \mathrm{H}\right\}$ NMR spectra and molar-mass distribution of $\mathrm{P}(\mathrm{DMS}-\mathrm{co}$-MVS) end-functionalized with (chloromethyl)dimethylsilyl groups (Table 3, Entry $1, M_{\mathrm{n}, \mathrm{NMR}}=7.29 \mathrm{kDa}, \bigoplus_{\mathrm{M}}=1.12_{1}$ ). 

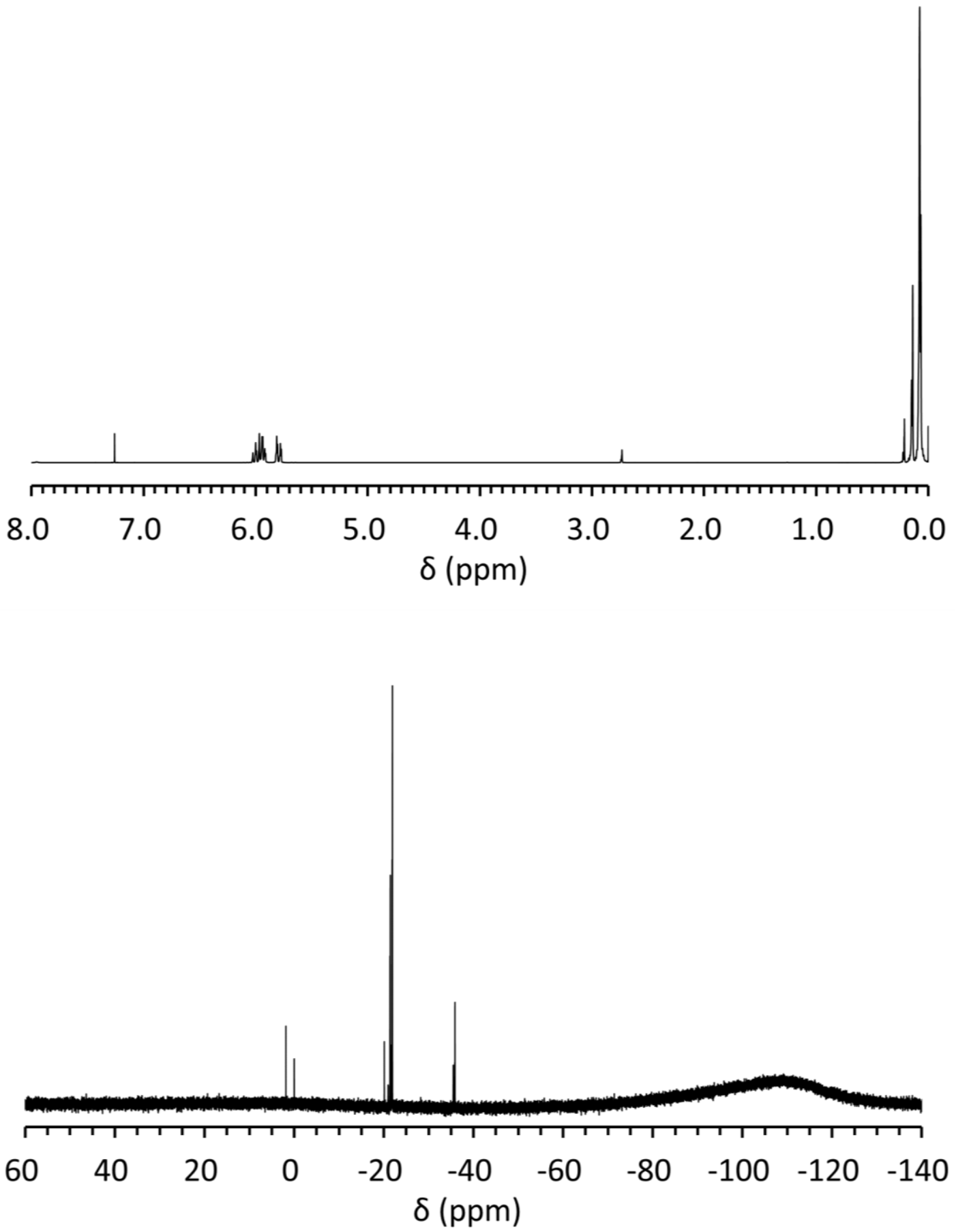

Figure S13. Full ${ }^{1} \mathrm{H}$ and ${ }^{29} \mathrm{Si}\left\{{ }^{1} \mathrm{H}\right\} \quad \mathrm{NMR}$ spectra of $\mathrm{P}(\mathrm{DMS}-\mathrm{co}-\mathrm{MVS})$ end-functionalized with (chloromethyl)dimethylsilyl groups (Table 3, Entry 1, $M_{\mathrm{n}, \mathrm{NMR}}=7.29 \mathrm{kDa}, \bigoplus_{\mathrm{M}}=1.12_{1}$ ). 


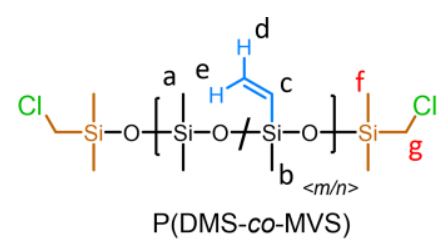

${ }^{1} \mathrm{H} \mathrm{NMR} \mathrm{(in} \mathrm{CDCl}_{3}$ )
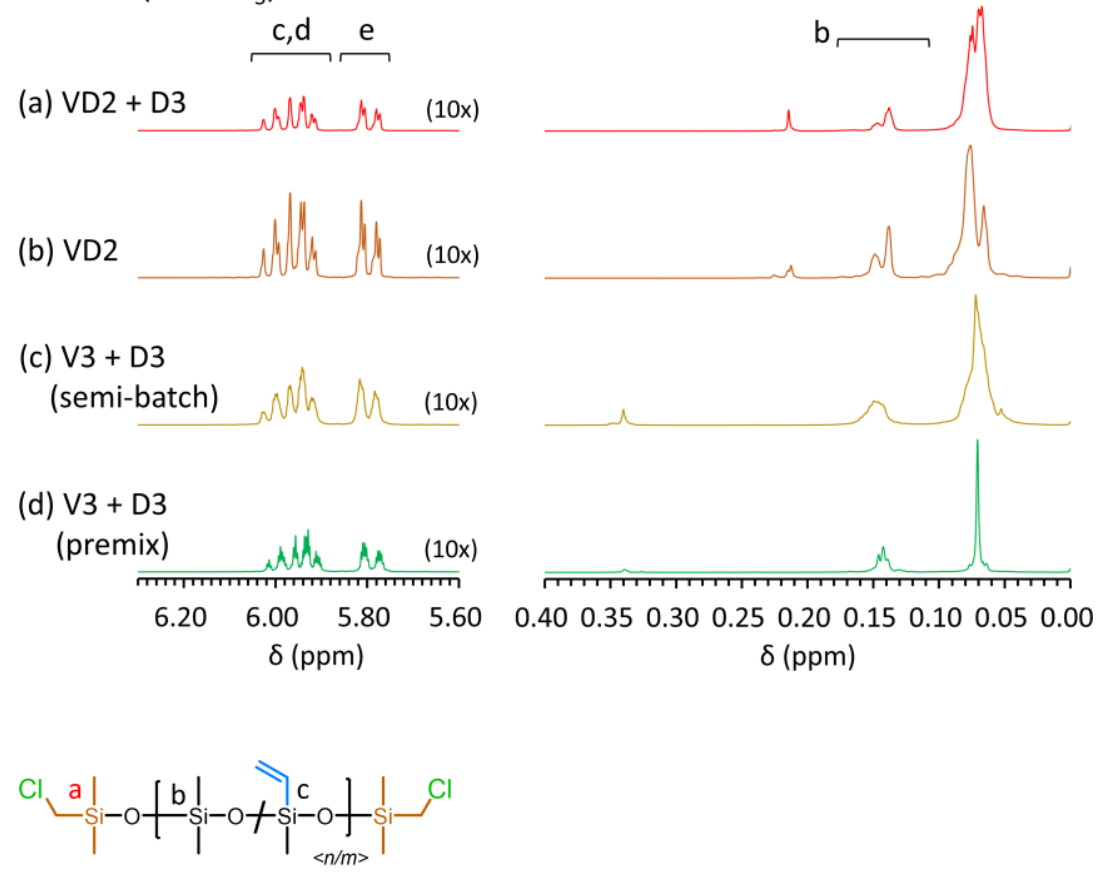

P(DMS-co-MVS)

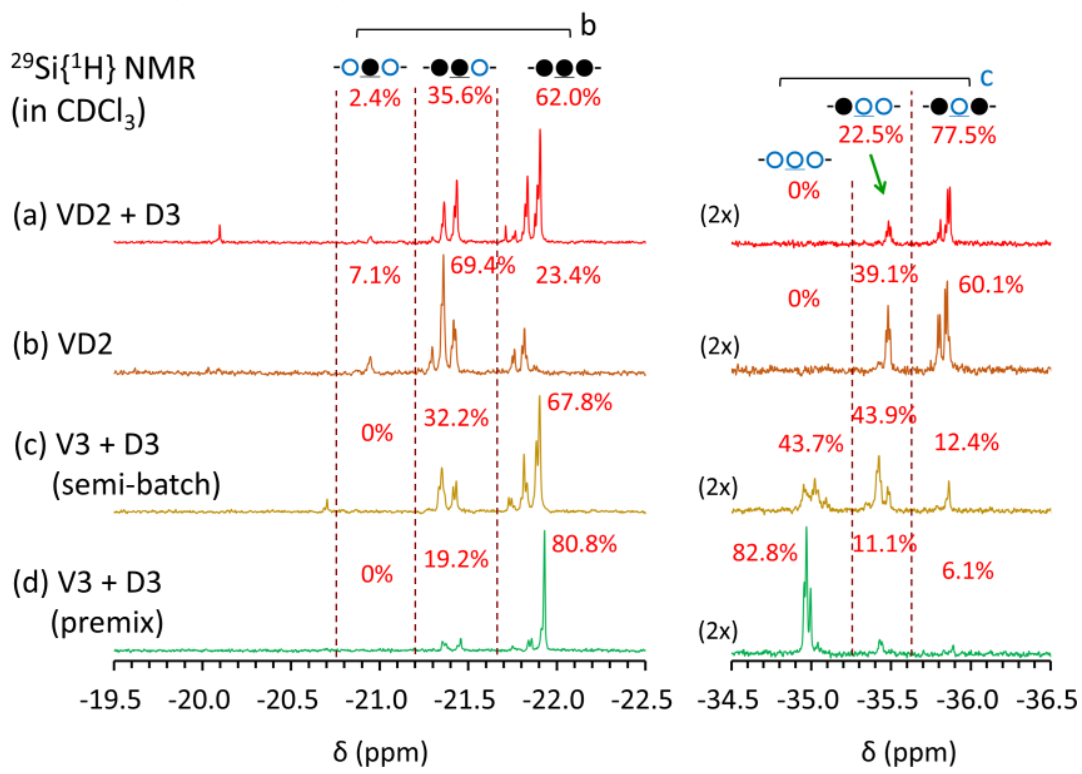

Figure S14. Comparison of ${ }^{1} \mathrm{H}$ and ${ }^{29} \mathrm{Si}\left\{{ }^{1} \mathrm{H}\right\}$ NMR spectra of $\mathrm{P}(\mathrm{DMS}-\mathrm{co}-\mathrm{MVS})$ synthesized with different procedures (measured in $\mathrm{CDCl}_{3}$ ). (a) $\mathrm{P}(\mathrm{DMS}-\mathrm{co}$-MVS) obtained from copolymerization of VD2 and D3 (Table 3, Entry $1, m / n=69.2 / 14.1, M_{\mathrm{n}, \mathrm{NMR}}=7.29 \mathrm{kDa}, \nexists_{\mathrm{M}}=1.12_{1}$ ), (b) the homopolymerization of VD2 (Table 1, Entry 2, $m / n=53.3 / 27.0, M_{\mathrm{n}, \mathrm{NMR}}=6.51 \mathrm{kDa}, \bigoplus_{\mathrm{M}}=1.08_{5}$ ), (c) the copolymerization of 1,3,5-trimethyl-1,3,5trivinylcyclotrisiloxane (V3) and D3 with the semi-batch method (Table 4, Entry $12, m / n=52 / 26, M_{\mathrm{n}, \mathrm{NMR}}=6.34$ $\left.\mathrm{kDa}, \oplus_{\mathrm{M}}=1.13\right),{ }^{\mathrm{S} 1}$ and $(\mathrm{d})$ the copolymerization of $\mathrm{V} 3$ and $\mathrm{D} 3$ with the premix method $\left(m / n=78 / 79, M_{\mathrm{n}, \mathrm{NMR}}=12.9\right.$ $\left.\mathrm{kDa}, \bigoplus_{\mathrm{M}}=1.37\right) .{ }^{\mathrm{S} 1}$ The polymerizations (c) and (d) were described in our previous article. ${ }^{\mathrm{S} 1}$ 

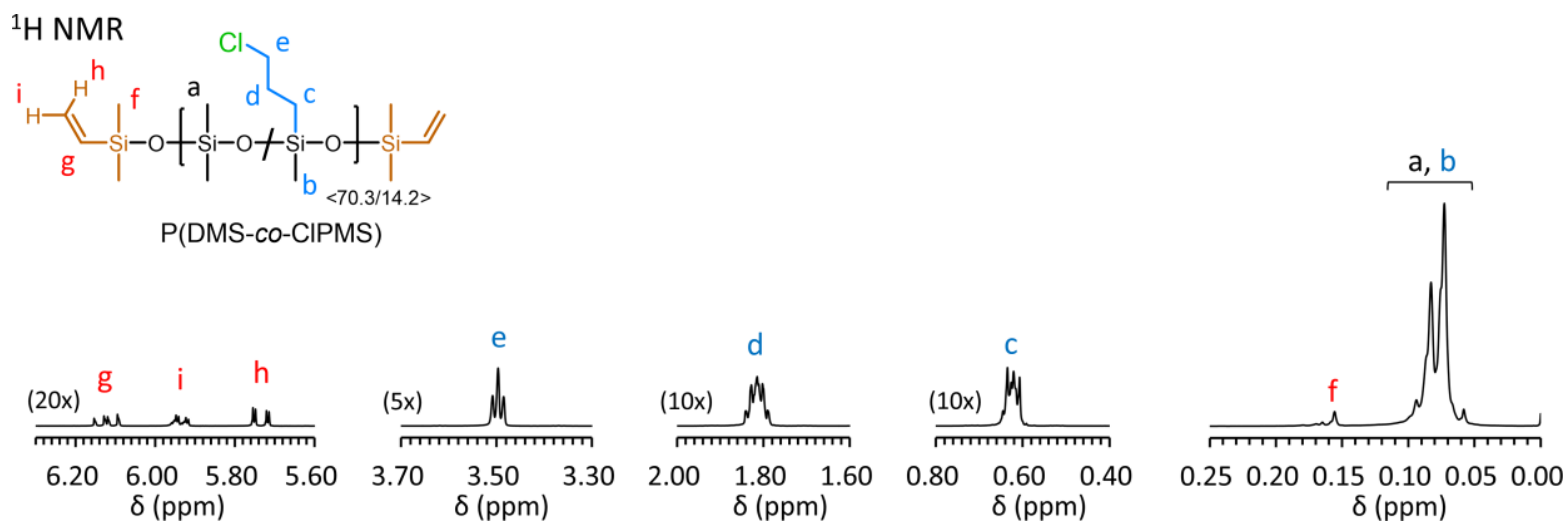

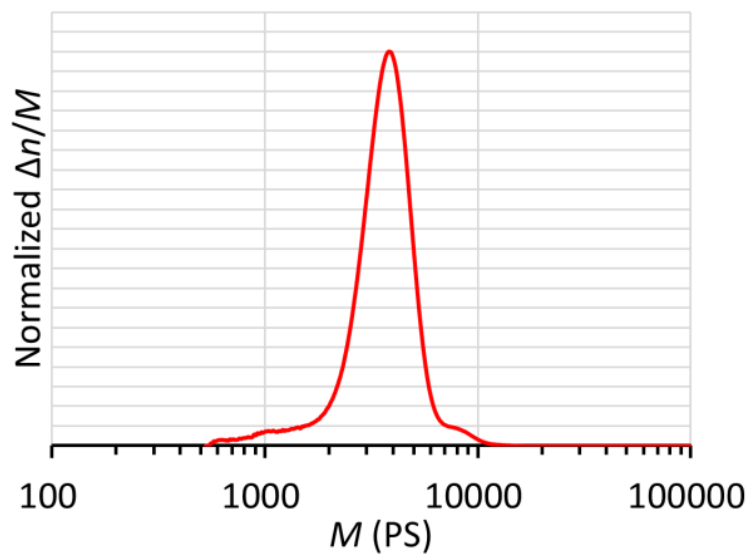

Figure S15. ${ }^{1} \mathrm{H}$ and ${ }^{29} \mathrm{Si}\left\{{ }^{1} \mathrm{H}\right\}$ NMR spectra and molar-mass distribution of P(DMS-co-ClPMS) end-functionalized with dimethylvinylsilyl groups (Table 3, Entry $2, M_{\mathrm{n}, \mathrm{NMR}}=7.34 \mathrm{kDa}, \emptyset_{\mathrm{M}}=1.11_{3}$ ). 

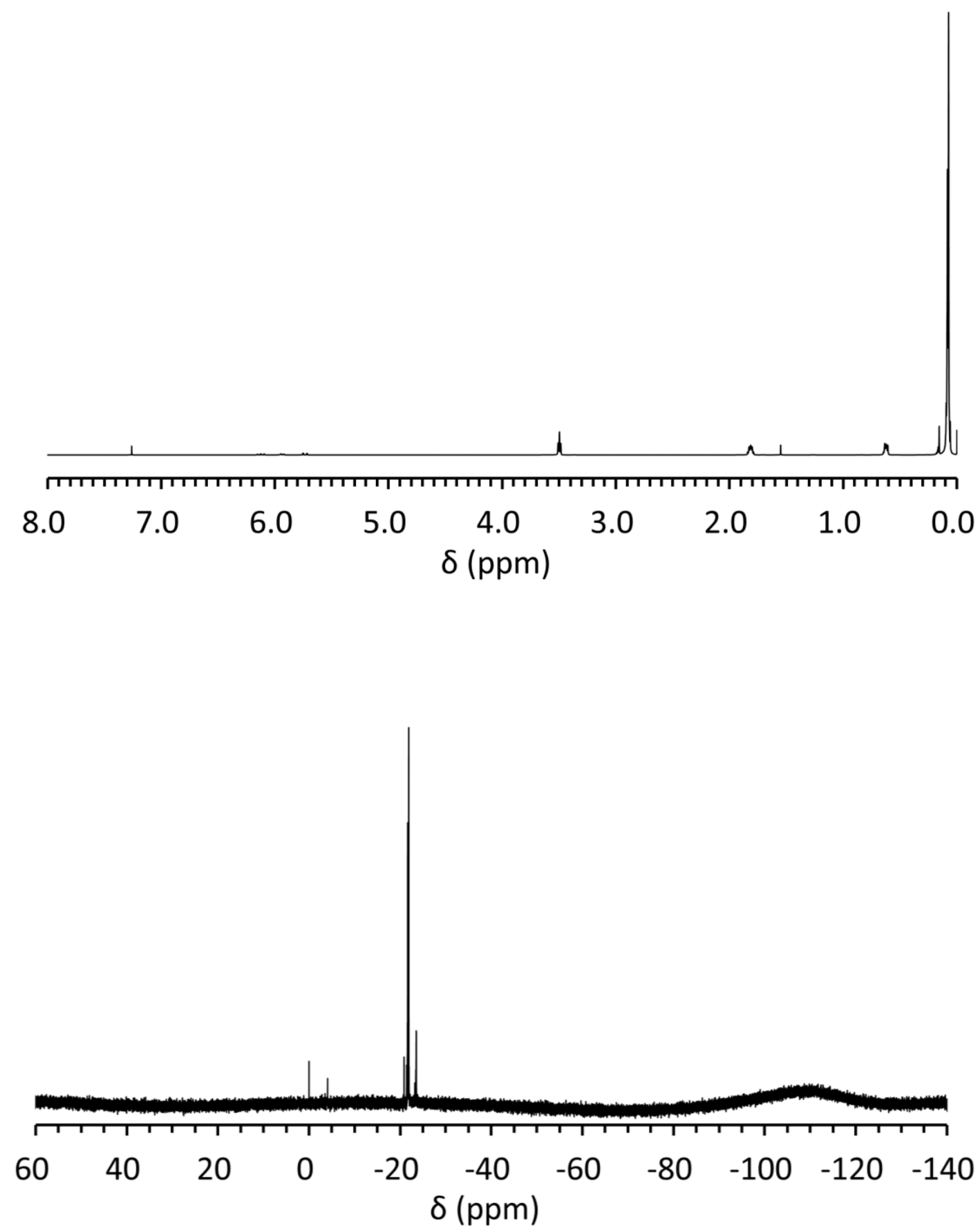

Figure S16. Full ${ }^{1} \mathrm{H}$ and ${ }^{29} \mathrm{Si}\left\{{ }^{1} \mathrm{H}\right\}$ NMR spectra of P(DMS-co-ClPMS) end-functionalized with dimethylvinylsilyl groups (Table 3, Entry 2, $M_{\mathrm{n}, \mathrm{NMR}}=7.34 \mathrm{kDa}, \nexists_{\mathrm{M}}=1.11_{3}$ ). 


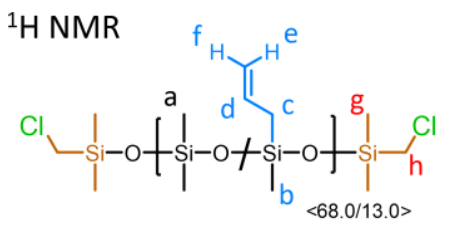

$\mathrm{P}$ (DMS-co-AMS)
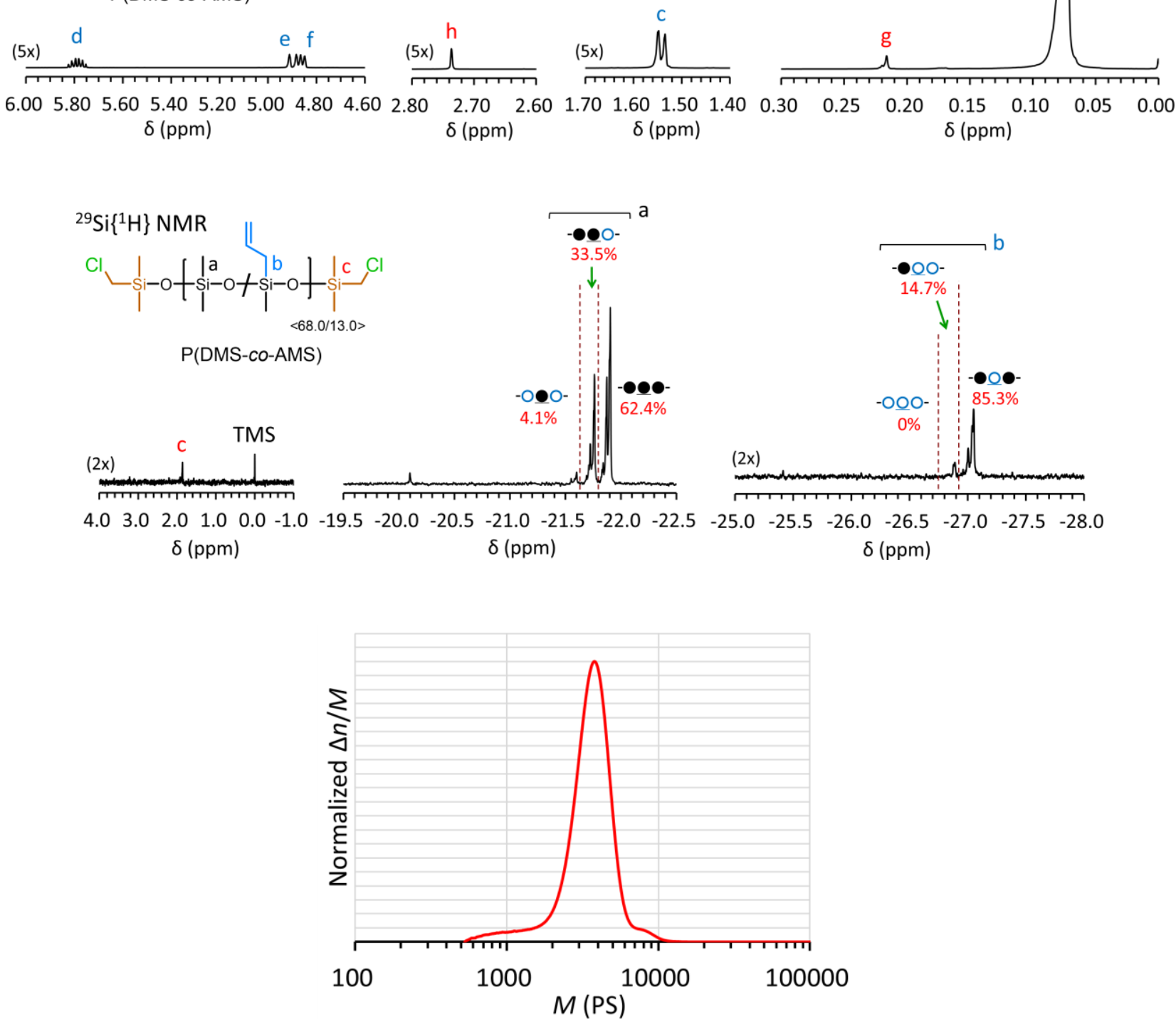

Figure S17. ${ }^{1} \mathrm{H}$ and ${ }^{29} \mathrm{Si}\left\{{ }^{1} \mathrm{H}\right\}$ NMR spectra and molar-mass distribution of $\mathrm{P}(\mathrm{DMS}-\mathrm{co}-\mathrm{AMS})$ end-functionalized with (chloromethyl)dimethylsilyl groups (Table 3, Entry 3, $M_{\mathrm{n}, \mathrm{NMR}}=6.57 \mathrm{kDa}, \bigoplus_{\mathrm{M}}=1.10_{9}$ ). 

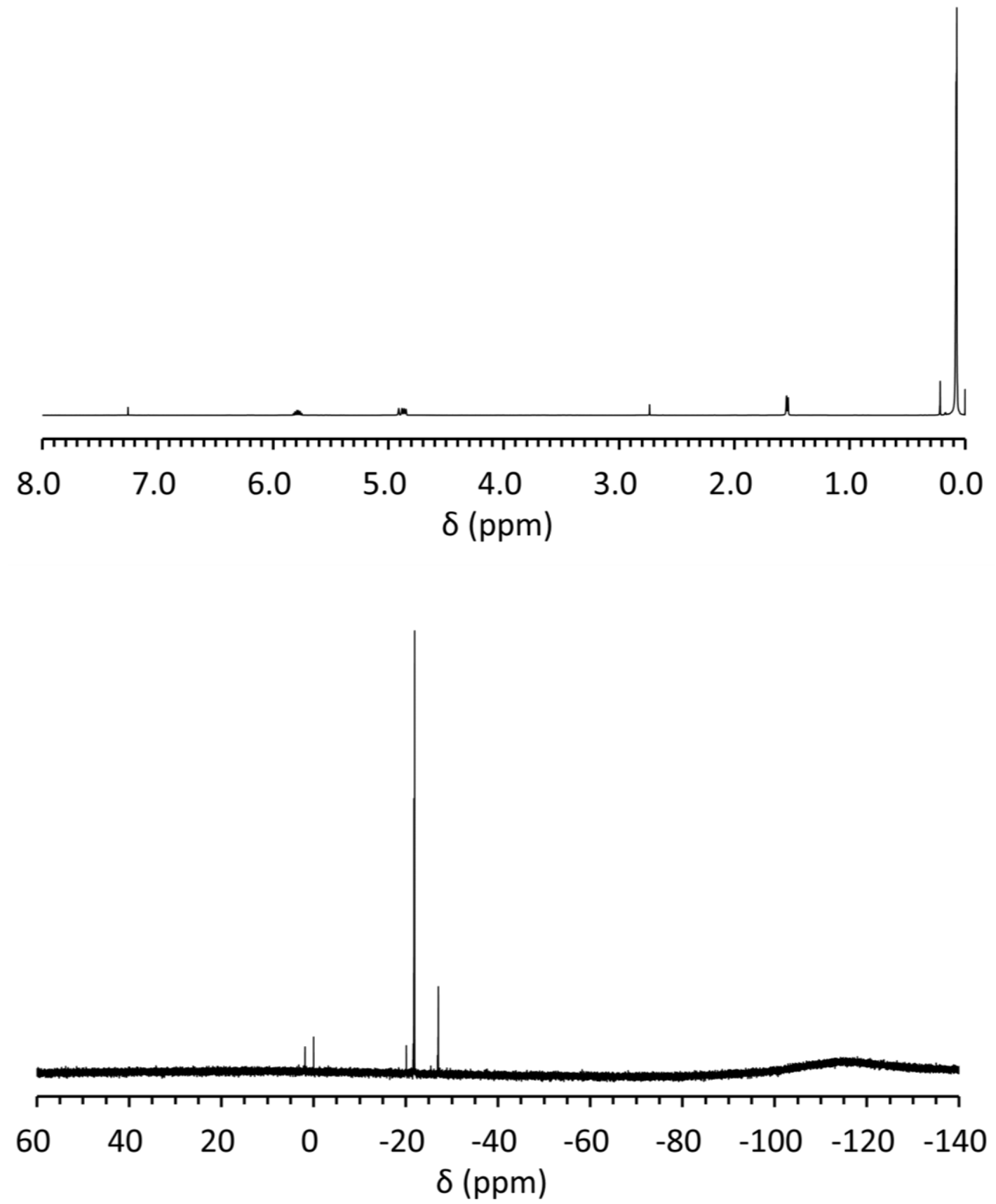

Figure S18. Full ${ }^{1} \mathrm{H}$ and ${ }^{29} \mathrm{Si}\left\{{ }^{1} \mathrm{H}\right\} \quad$ NMR spectra of $\mathrm{P}(\mathrm{DMS}-\mathrm{co}-\mathrm{AMS})$ end-functionalized with (chloromethyl)dimethylsilyl groups (Table 3, Entry 3, $M_{\mathrm{n}, \mathrm{NMR}}=6.57 \mathrm{kDa}, \bigoplus_{\mathrm{M}}=1.10_{9}$ ). 

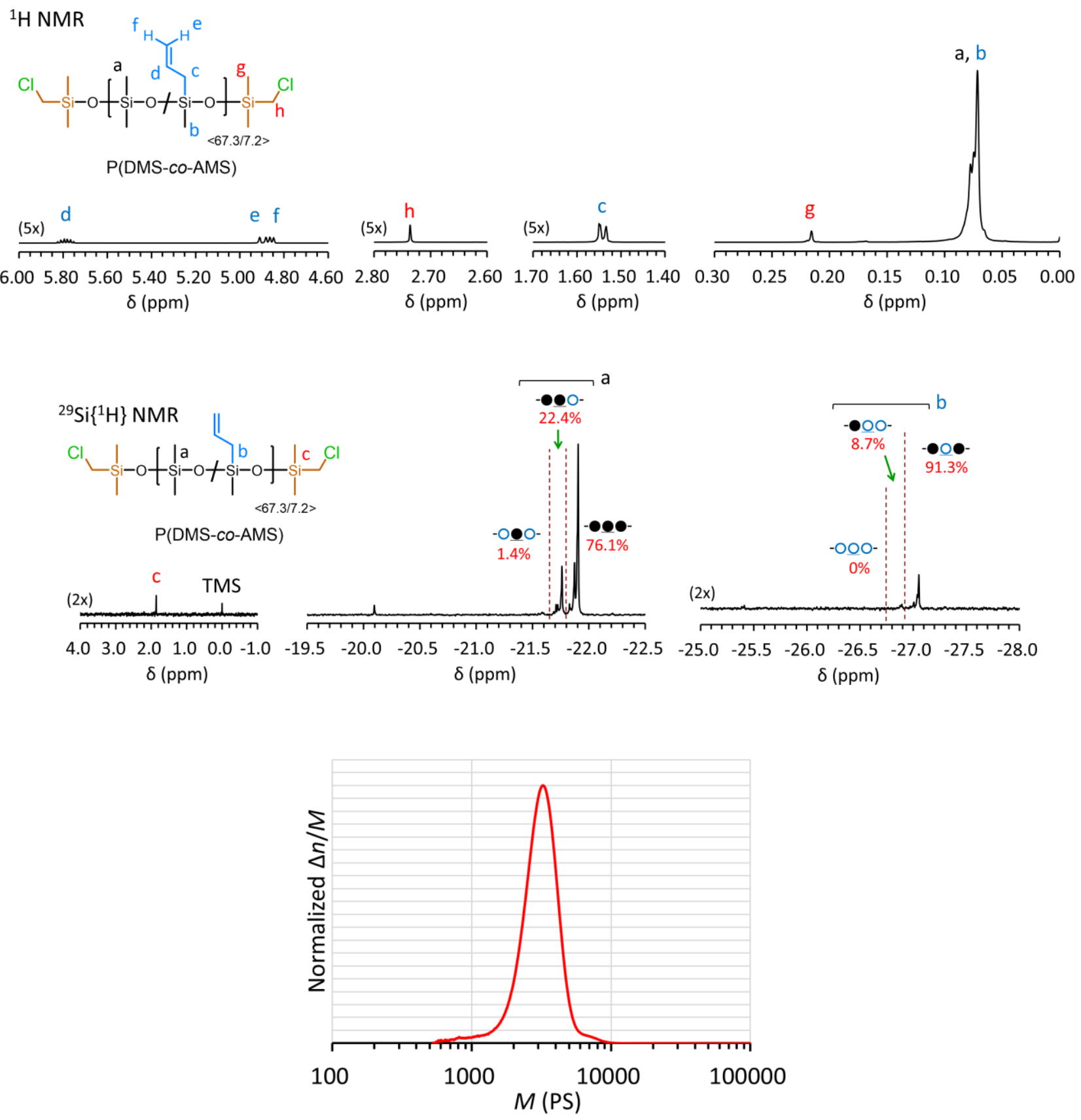

Figure S19. ${ }^{1} \mathrm{H}$ and ${ }^{29} \mathrm{Si}\left\{{ }^{1} \mathrm{H}\right\}$ NMR spectra and molar-mass distribution of P(DMS-co-AMS) end-functionalized with (chloromethyl)dimethylsilyl groups (Table 3, Entry 6, $M_{\mathrm{n}, \mathrm{NMR}}=5.95 \mathrm{kDa}, \bigoplus_{\mathrm{M}}=1.11_{3}$ ). 

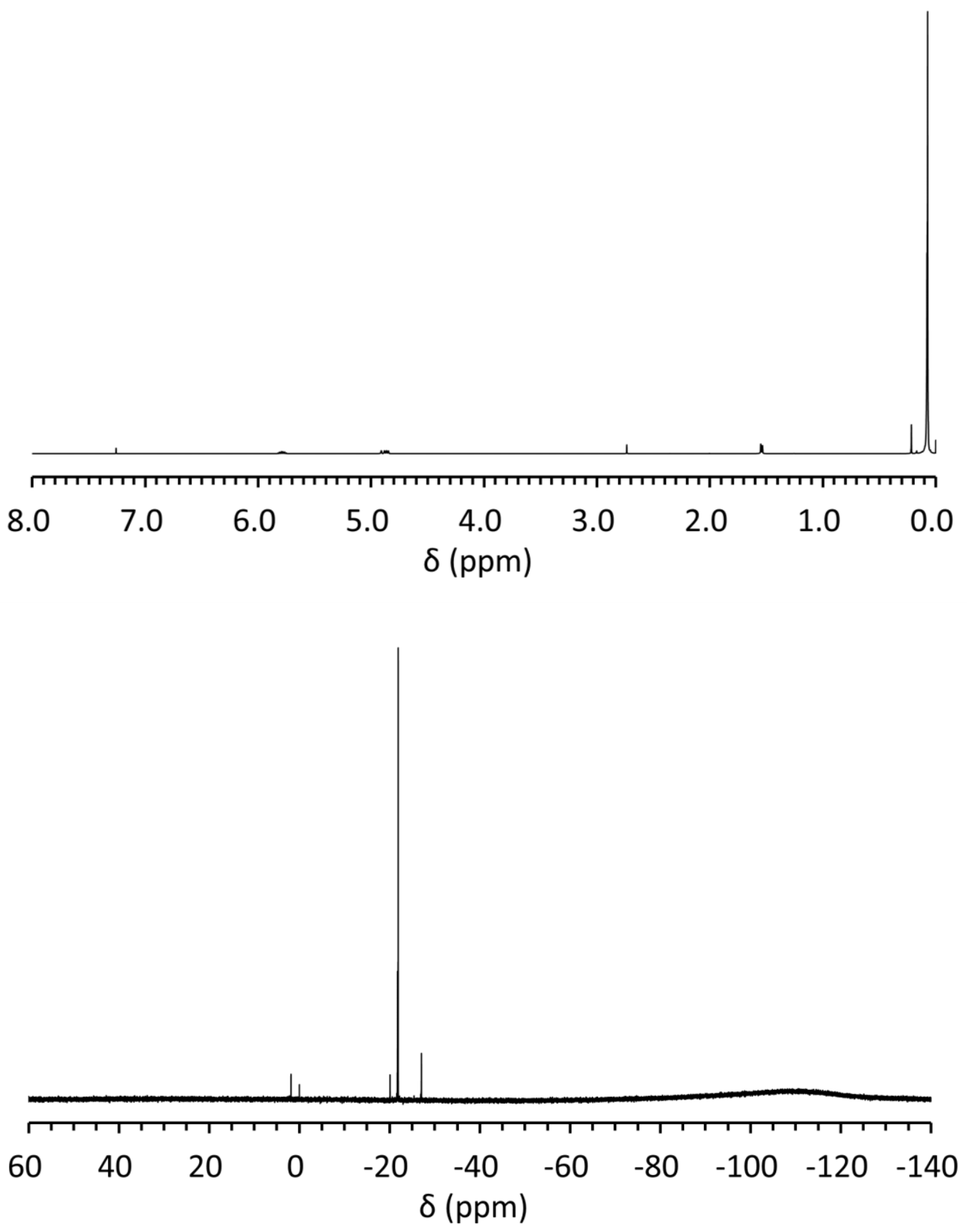

Figure S20. Full ${ }^{1} \mathrm{H}$ and ${ }^{29} \mathrm{Si}\left\{{ }^{1} \mathrm{H}\right\}$ NMR spectra and molar-mass distribution of P(DMS-co-AMS) endfunctionalized with (chloromethyl)dimethylsilyl groups (Table 3, Entry 6, $M_{\mathrm{n}, \mathrm{NMR}}=5.95 \mathrm{kDa}, \bigoplus_{\mathrm{M}}=1.11_{3}$ ). 

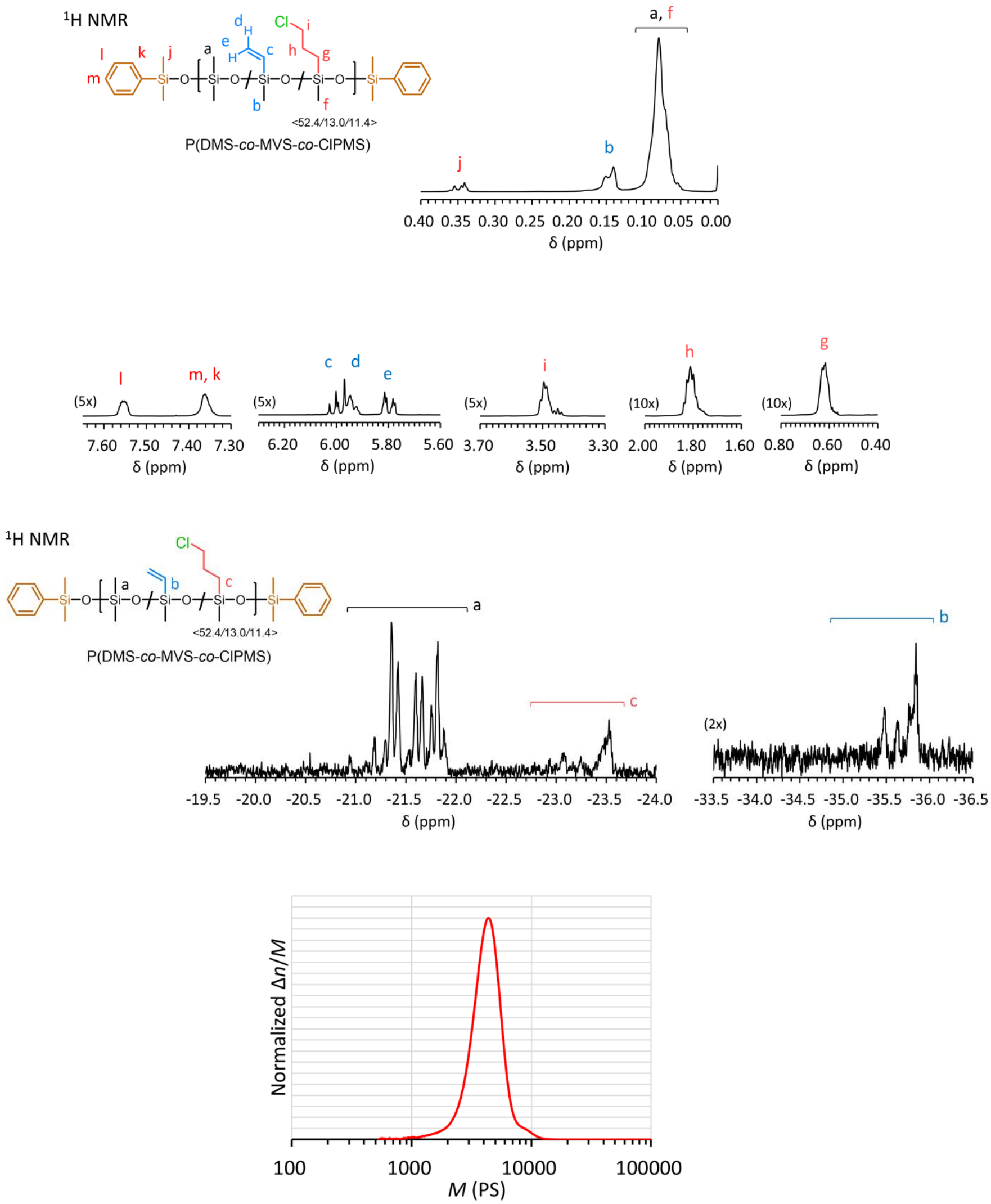

Figure S21. ${ }^{1} \mathrm{H}$ and ${ }^{29} \mathrm{Si}\left\{{ }^{1} \mathrm{H}\right\}$ NMR spectra and molar-mass distribution of P(DMS-co-MVS-co-ClPMS) endfunctionalized with (chloromethyl)dimethylsilyl groups (Table 3, Entry 4, $M_{\mathrm{n}, \mathrm{NMR}}=6.75 \mathrm{kDa}, \bigoplus_{\mathrm{M}}=1.10_{2}$ ). 

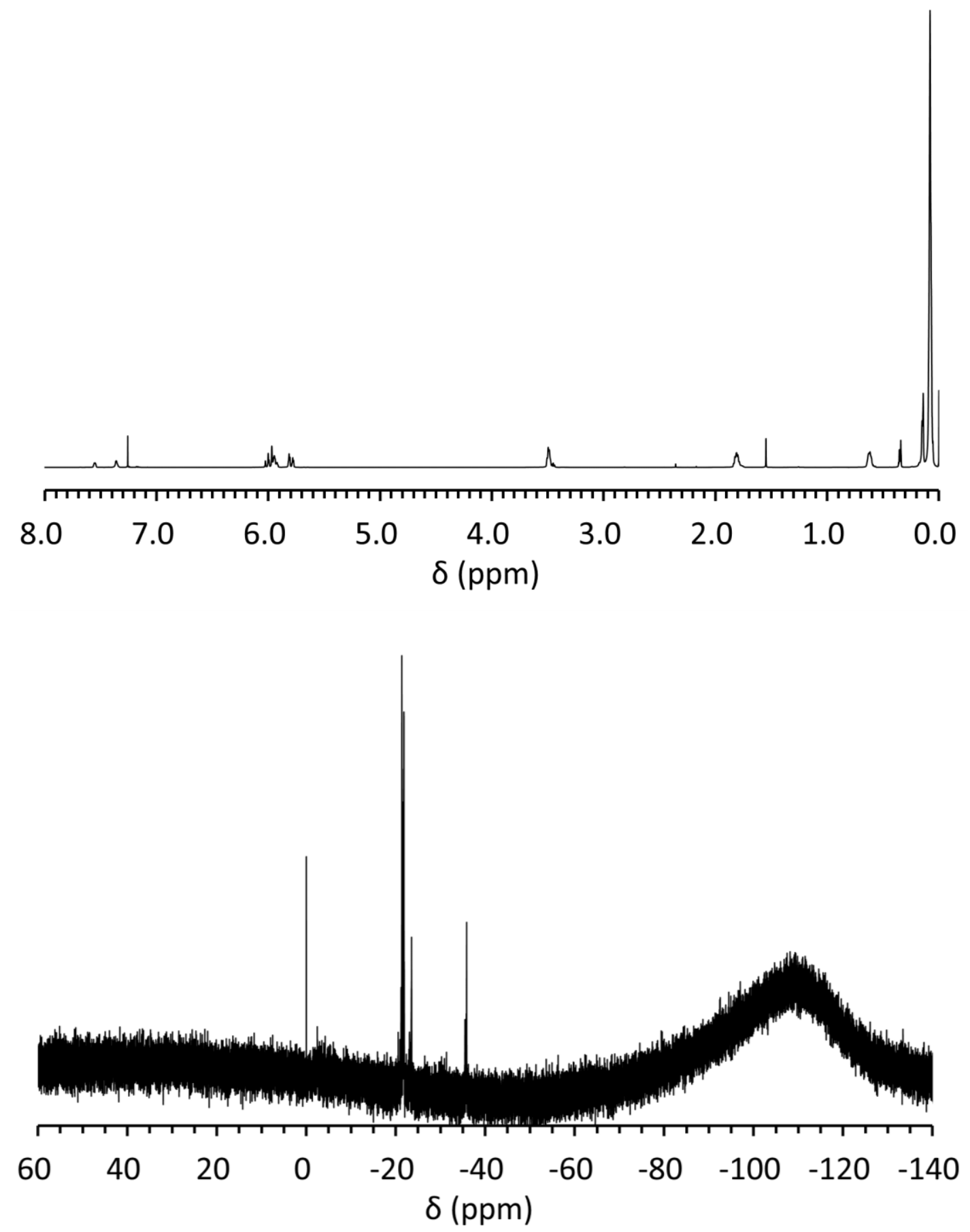

Figure S22. Full ${ }^{1} \mathrm{H}$ and ${ }^{29} \mathrm{Si}\left\{{ }^{1} \mathrm{H}\right\}$ NMR spectra of $\mathrm{P}(\mathrm{DMS}-c o-M V S-c o-C l P M S)$ end-functionalized with (chloromethyl)dimethylsilyl groups (Table 3, Entry 4, $M_{\mathrm{n}, \mathrm{NMR}}=6.75 \mathrm{kDa}, \bigoplus_{\mathrm{M}}=1.10_{2}$ ). 

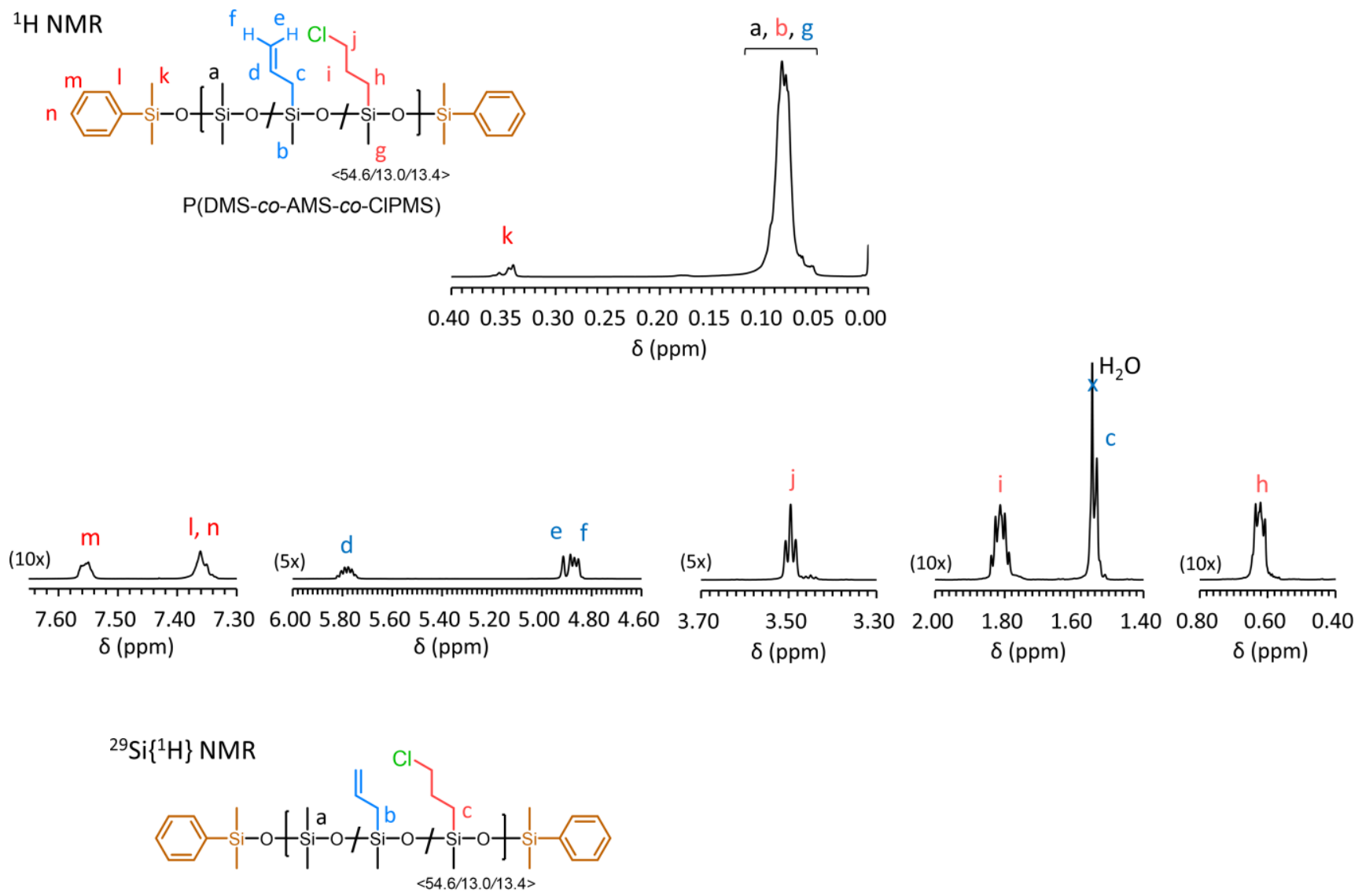
P(DMS-co-AMS-Co-CIPMS)
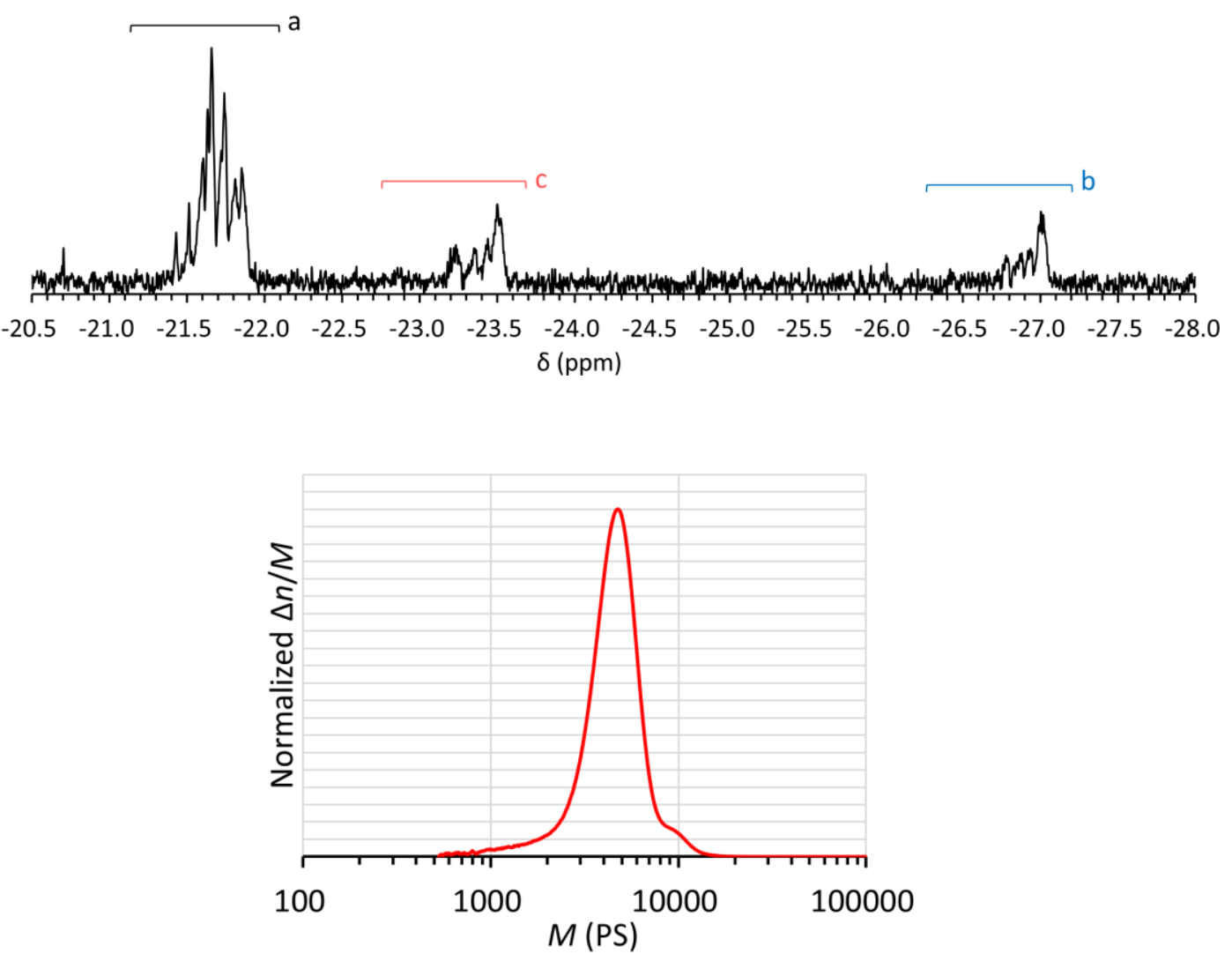

Figure S23. ${ }^{1} \mathrm{H}$ and ${ }^{29} \mathrm{Si}\left\{{ }^{1} \mathrm{H}\right\}$ NMR spectra and molar-mass distribution of P(DMS-co-AMS-co-ClPMS) endfunctionalized with (chloromethyl)dimethylsilyl groups (Table 3, Entry 5, $M_{\mathrm{n}, \mathrm{NMR}}=7.47 \mathrm{kDa}, \bigoplus_{\mathrm{M}}=1.13_{1}$ ). 

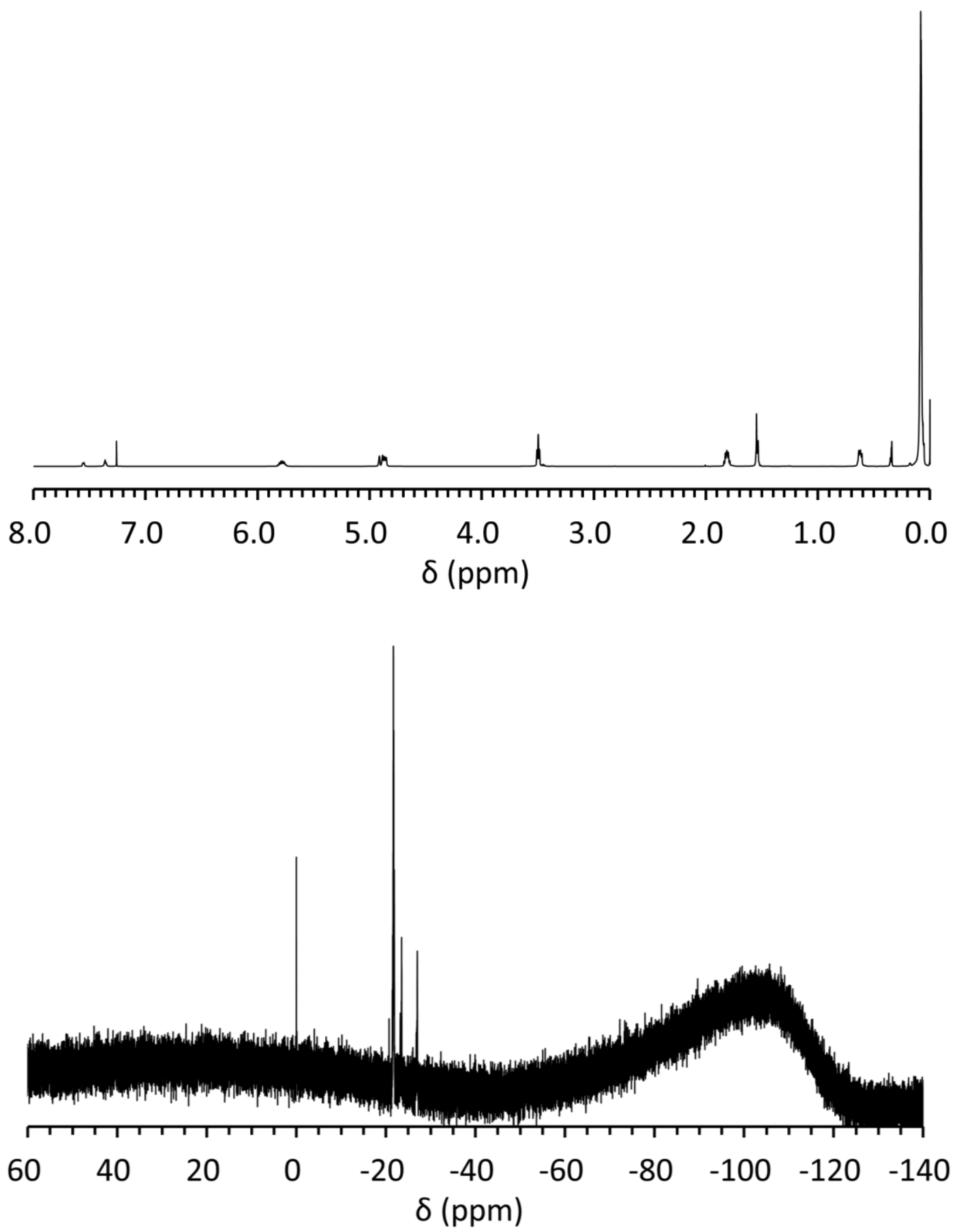

Figure S24. Full ${ }^{1} \mathrm{H}$ and ${ }^{29} \mathrm{Si}\left\{{ }^{1} \mathrm{H}\right\}$ NMR spectra of $\mathrm{P}(\mathrm{DMS}-c o-A M S-c o-C l P M S)$ end-functionalized with (chloromethyl)dimethylsilyl groups (Table 3, Entry 5, $M_{\mathrm{n}, \mathrm{NMR}}=7.47 \mathrm{kDa}, \bigoplus_{\mathrm{M}}=1.13_{1}$ ). 

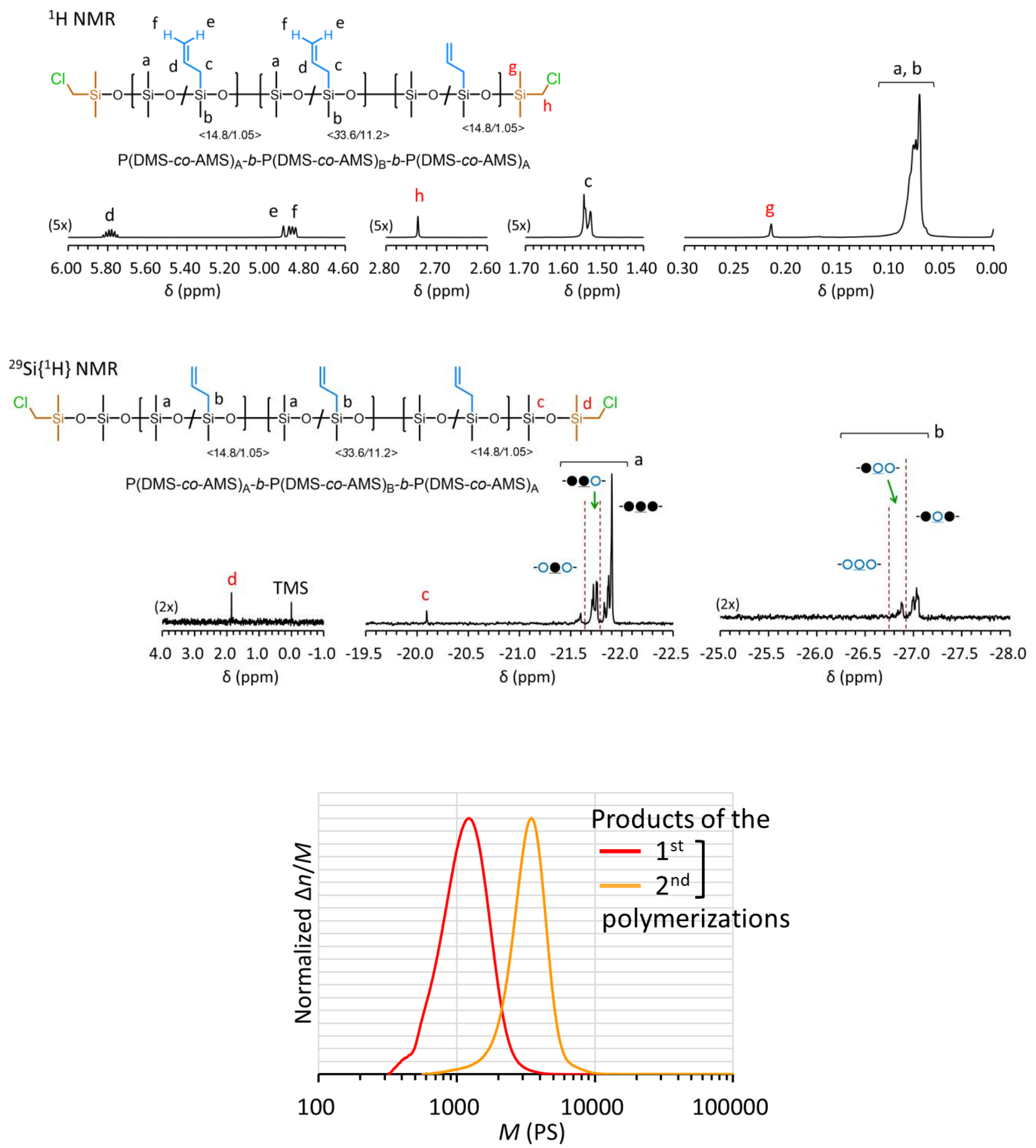

Figure S25. ${ }^{1} \mathrm{H}$ and ${ }^{29} \mathrm{Si}\left\{{ }^{1} \mathrm{H}\right\}$ NMR spectra and molar-mass distribution of triblock copolymer of P(DMS-coAMS $)_{\mathrm{A}}-b-\mathrm{P}(\mathrm{DMS}-c o-\mathrm{AMS})_{\mathrm{B}}-b-\mathrm{P}(\mathrm{DMS}-c o-\mathrm{AMS})_{\mathrm{A}}$ end-functionalized with (chloromethyl)dimethylsilyl groups (Table 3, Entry 7b, $M_{\mathrm{n}, \mathrm{NMR}}=6.21 \mathrm{kDa}, \emptyset_{\mathrm{M}}=1.09_{8}$ ). 

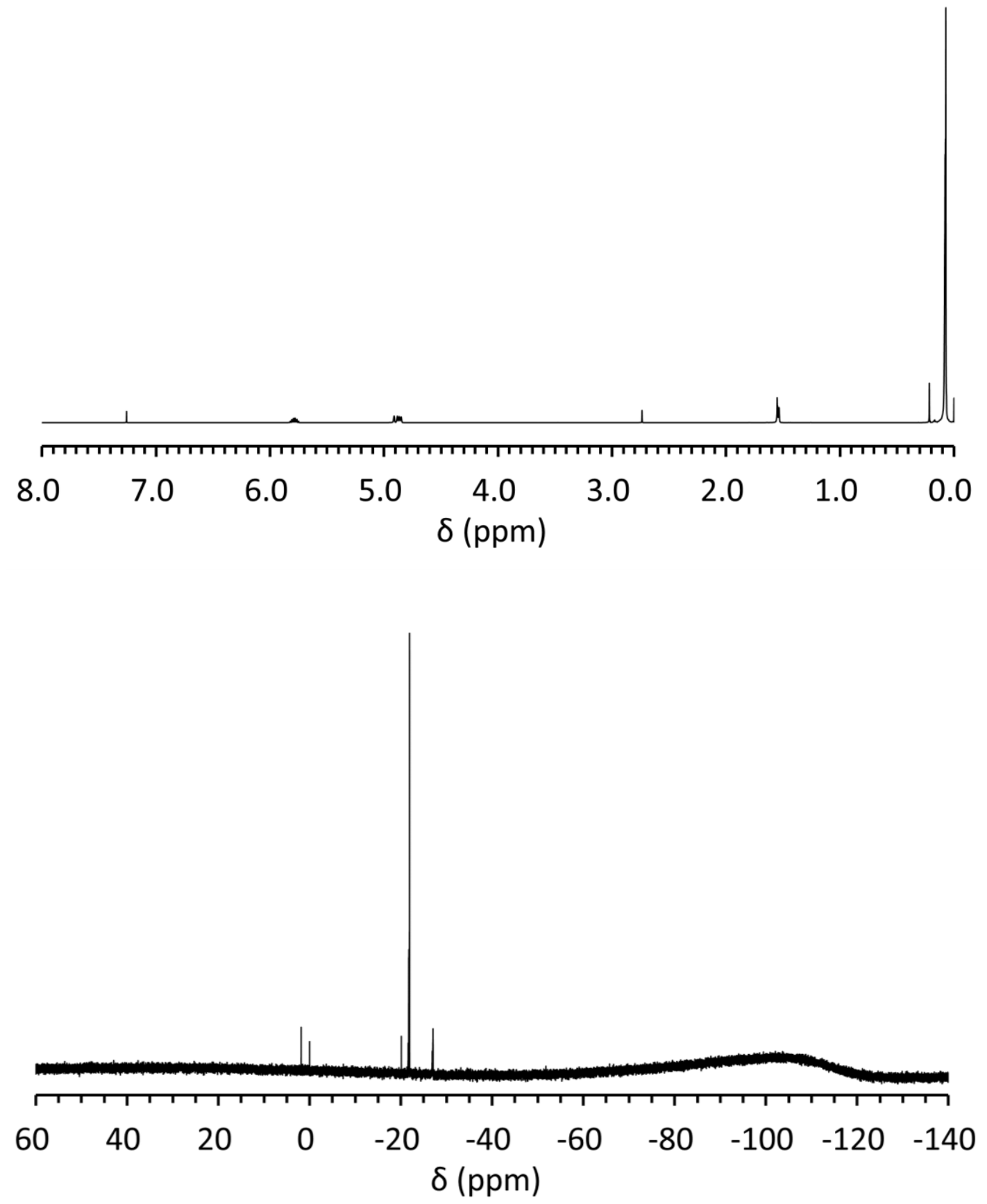

Figure S26. Full ${ }^{1} \mathrm{H}$ and ${ }^{29} \mathrm{Si}\left\{{ }^{1} \mathrm{H}\right\}$ NMR spectra of triblock copolymer of $\mathrm{P}(\mathrm{DMS}-c o-\mathrm{AMS})_{\mathrm{A}}-b-\mathrm{P}(\mathrm{DMS}-c o-\mathrm{AMS})_{\mathrm{B}}$ $b$-P(DMS-co-AMS) $)_{\mathrm{A}}$ end-functionalized with (chloromethyl)dimethylsilyl groups (Table 3, Entry 7b, $M_{\mathrm{n}, \mathrm{NMR}}=6.21$ $\left.\mathrm{kDa}, \oplus_{\mathrm{M}}=1.09_{6}\right)$. 


\section{Kinetics of the polymerizations}
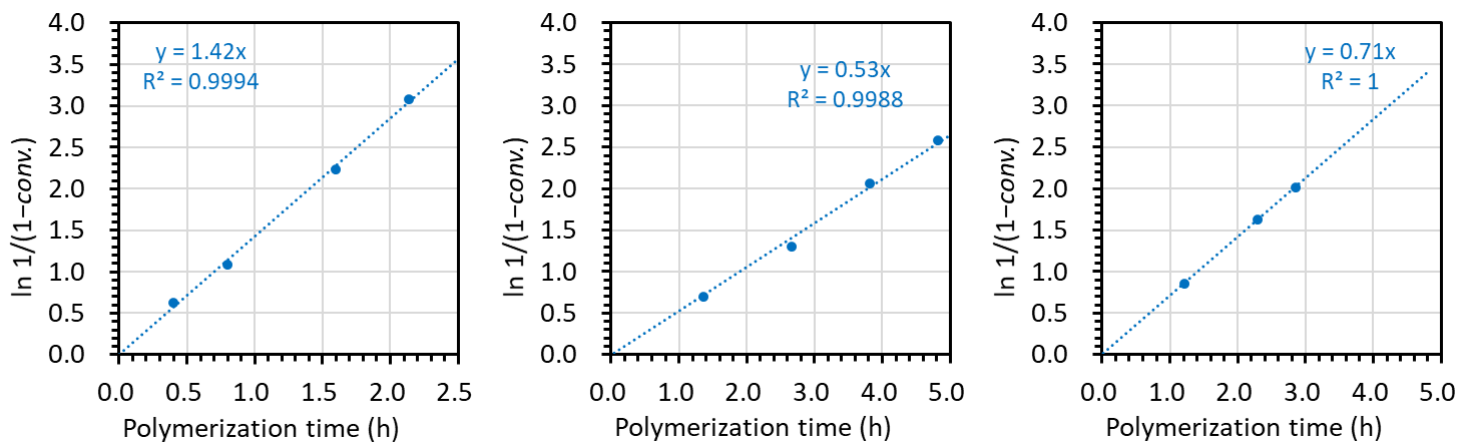

Figure S27. First-order kinetic plots for the polymerizations of VD2 (left, Table 1, Entry 2), ClPD2 (center, Table 1, Entry 3), and AD2 (right, Table 1, Entry 6) using water as an initiator and guanidine bases as catalysts.
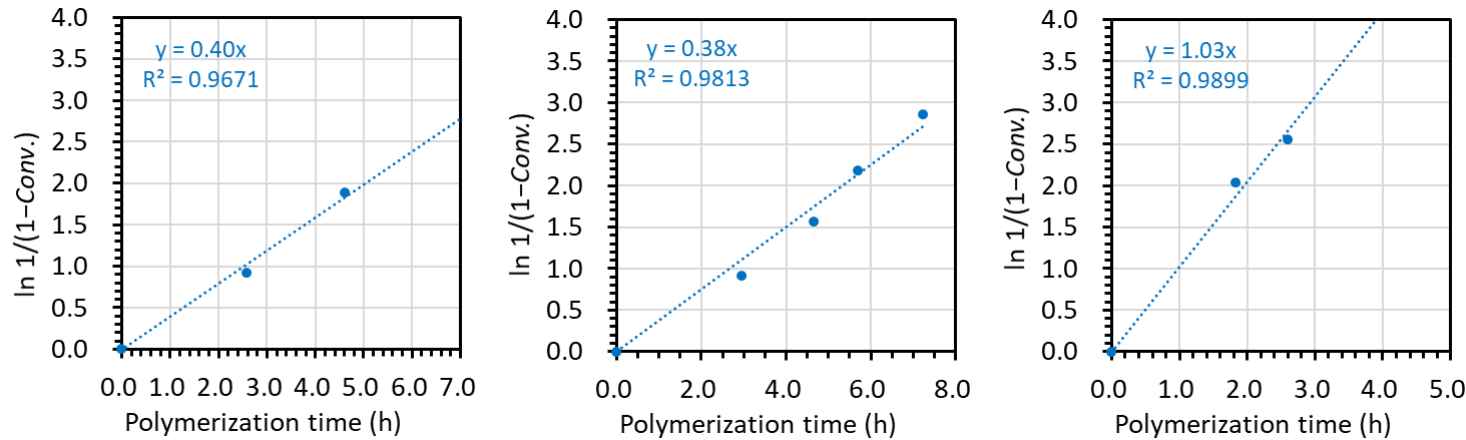

Figure S28. First-order kinetic plots for the polymerizations of VD2 (left, Table 2, Entry 2), CIPD2 (center, Table 2, Entry 3), and $\mathrm{AD} 2$ (right, Table 2, Entry 6) using $\mathrm{MeD} 4 \mathrm{OH}$ or $\mathrm{Ph}_{3} \mathrm{SiOH}$ as an initiator and guanidine bases as catalysts. 

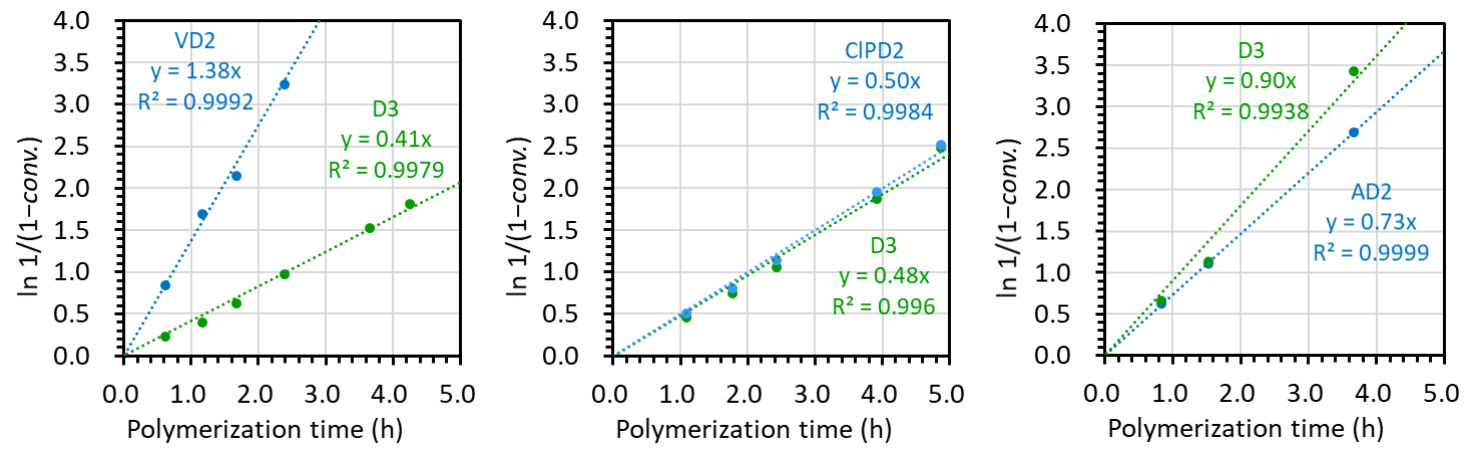

Figure S29. First-order kinetic plots for the copolymerizations of D3 and FnD2, i.e. VD2 (left, Table 3, Entry 1), CIPD2 (center, Table 3, Entry 2), and AD2 (right, Table 3, Entry 3) using water as an initiator and guanidine bases as catalysts.
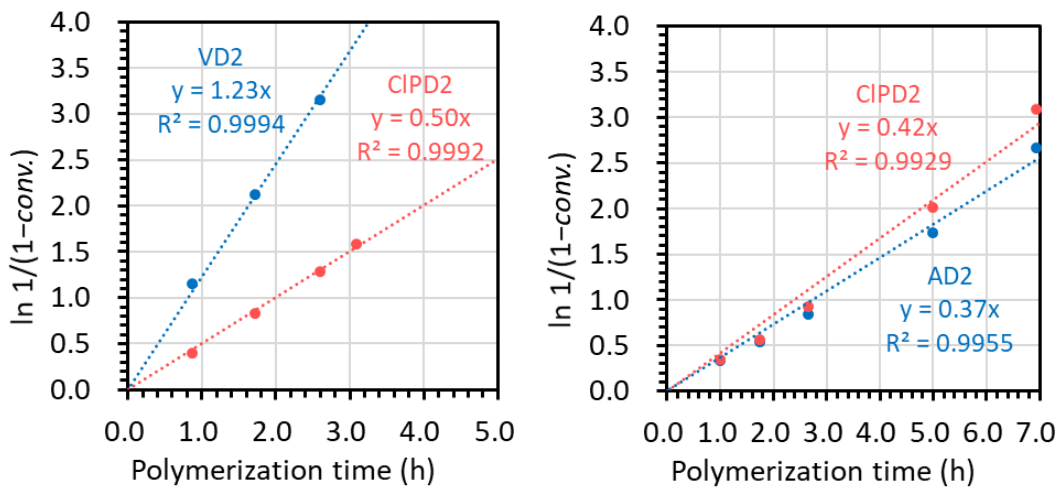

Figure S30. First-order kinetic plots for the copolymerizations of VD2 and ClPD2 (left, Table 3, Entry 4) as well as AD2 and CIPD2 (Table 3, Entry 5) using water as an initiator and guanidine bases as catalysts.
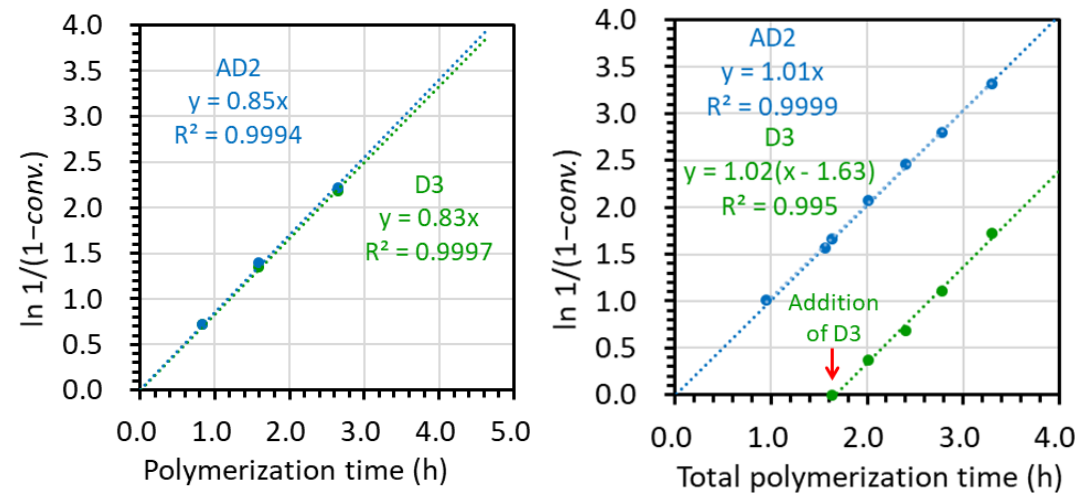

Figure S31. First-order kinetic plots for the copolymerizations of D3 and AD2 conducted using the premix method with $[\mathrm{AD} 2]_{0} /[\mathrm{D} 3]_{0} /\left[\mathrm{H}_{2} \mathrm{O}\right]_{0} /[\mathrm{TMMG}]_{0}=7.5 / 17.5 / 1 / 0.25$ (left, Table 3, Entry 6 ) as well as the copolymerizations of D3 and AD2 by the two-stage method (right, Table 3, Entry 7). 

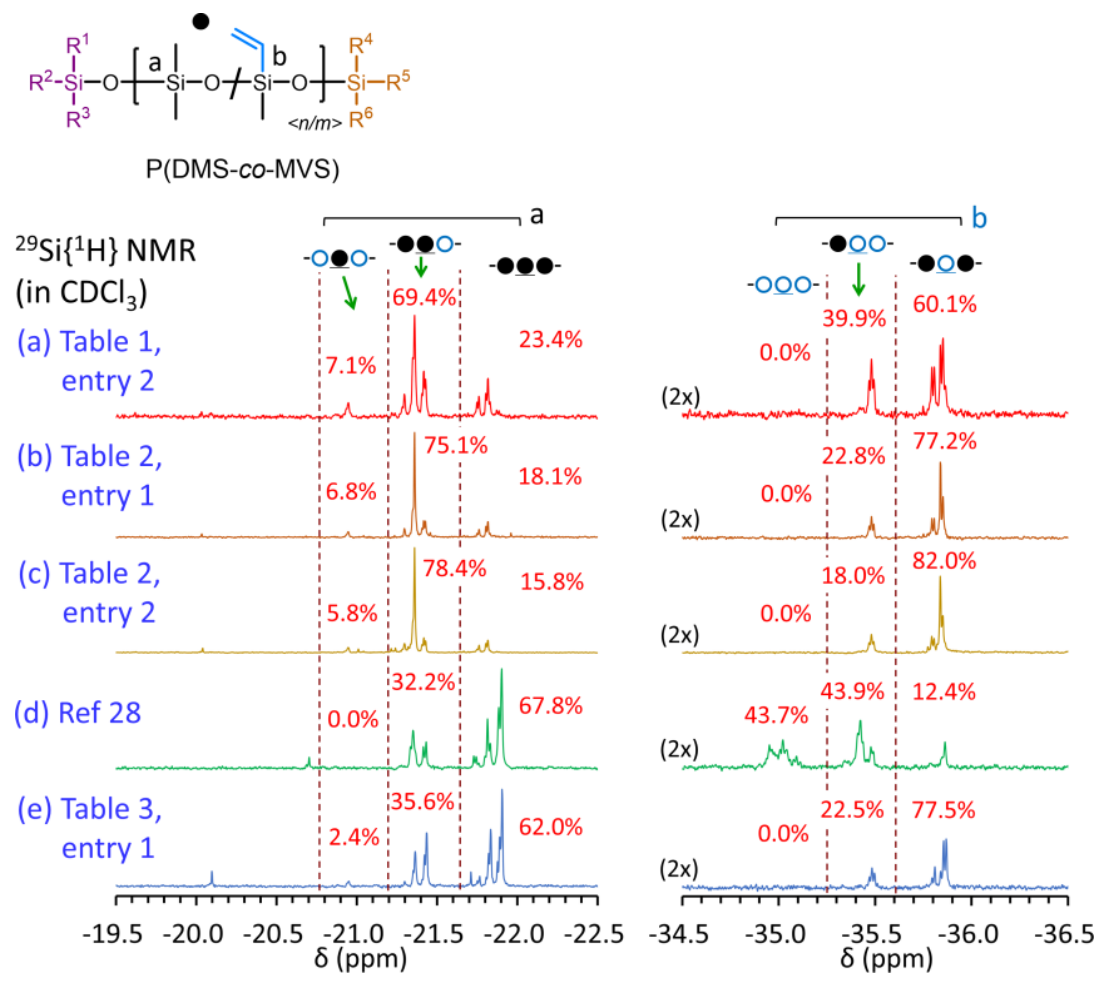

Figure S32. Comparison of ${ }^{29} \mathrm{Si}\left\{{ }^{1} \mathrm{H}\right\}$ NMR spectra of $\mathrm{P}(\mathrm{DMS}-\mathrm{co}$-MVS) synthesized with different procedures shown in Table 4 (measured in $\mathrm{CDCl}_{3}$ ).
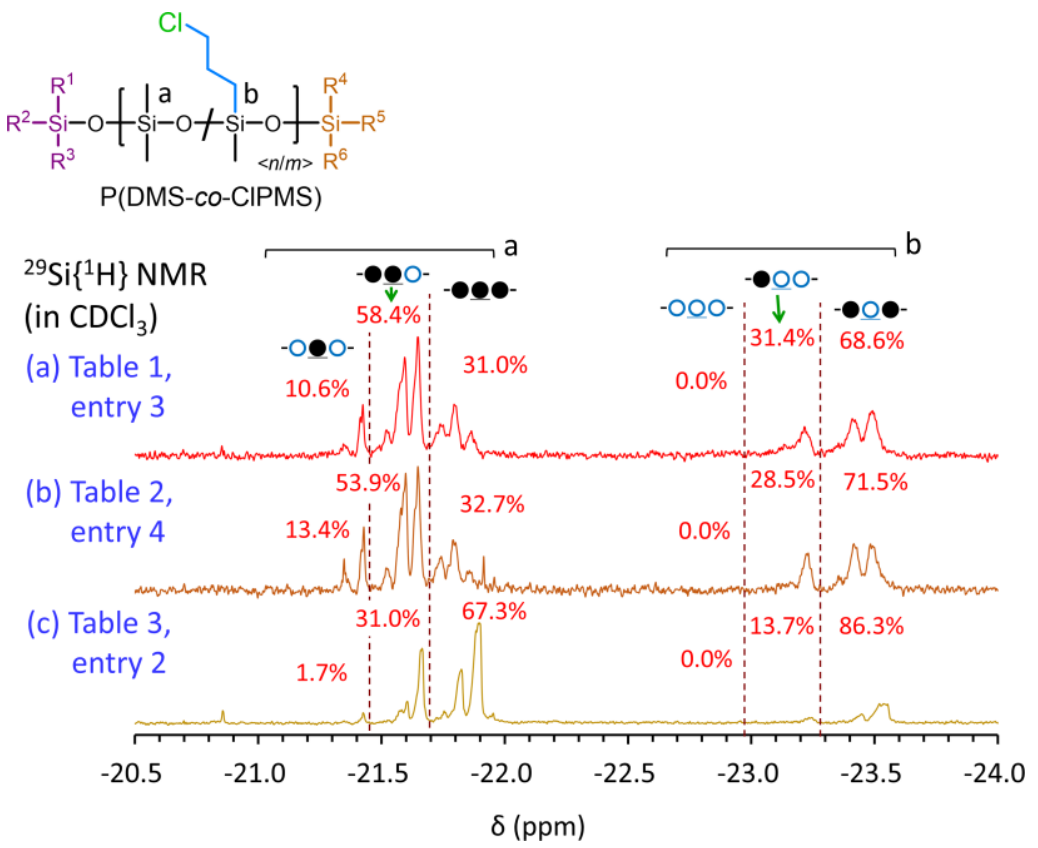

Figure S33. Comparison of ${ }^{29} \mathrm{Si}\left\{{ }^{1} \mathrm{H}\right\}$ NMR spectra of P(DMS-co-ClPMS) synthesized with different procedures shown in Table 4 (measured in $\mathrm{CDCl}_{3}$ ). 

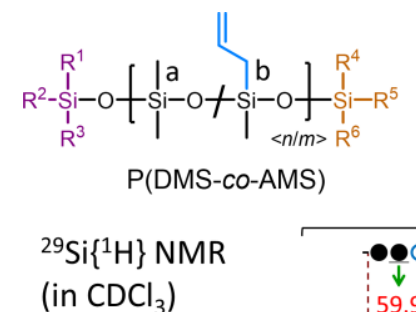

(a) Table 1 , entry 6

(b) Table 2, entry 6 (c) Table 3,
entry 3

(d) Table 3, entry 6

(e) Table 3, entry 7

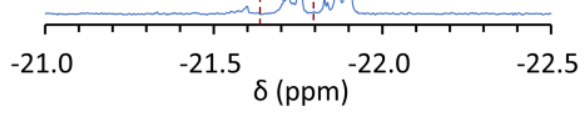

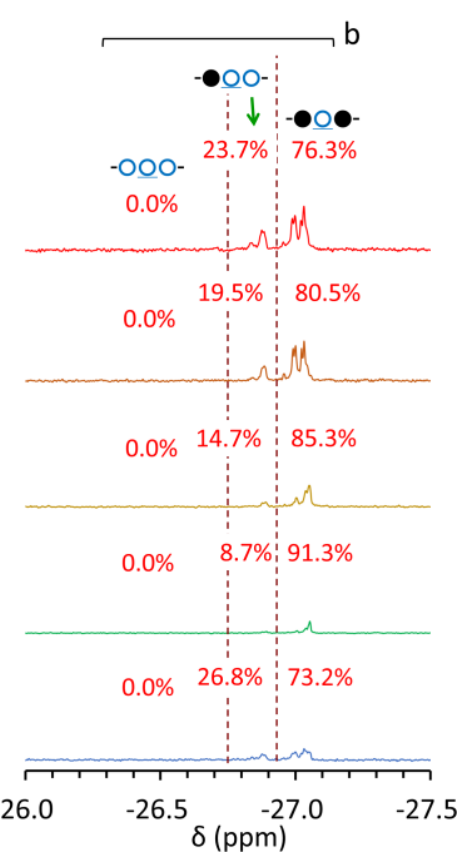

Figure S34. Comparison of ${ }^{29} \mathrm{Si}\left\{{ }^{1} \mathrm{H}\right\}$ NMR spectra of $\mathrm{P}(\mathrm{DMS}-\mathrm{co}-\mathrm{AMS})$ synthesized with different procedures shown in Table 4 (measured in $\mathrm{CDCl}_{3}$ ). 


\section{Sequences of monomeric units}

Mode of propagation reaction

Three possible modes of regio-selective propagation

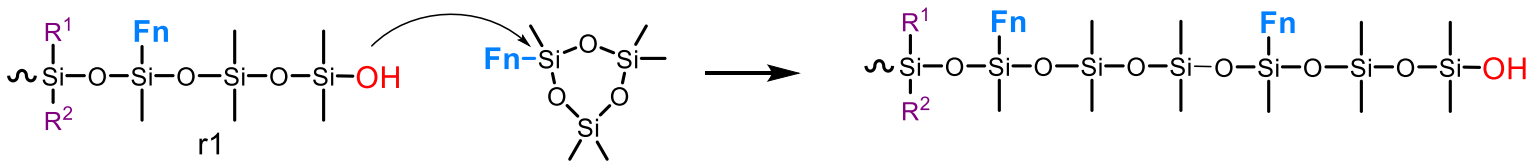

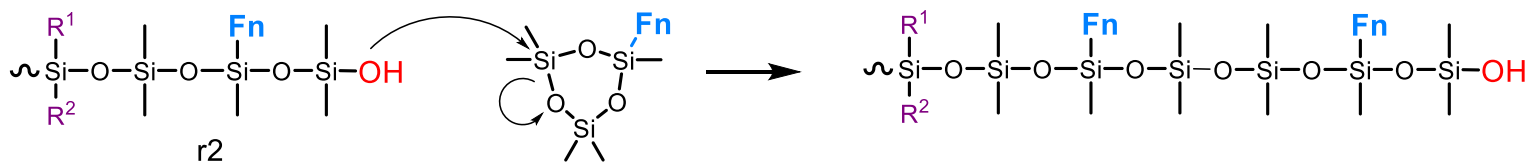

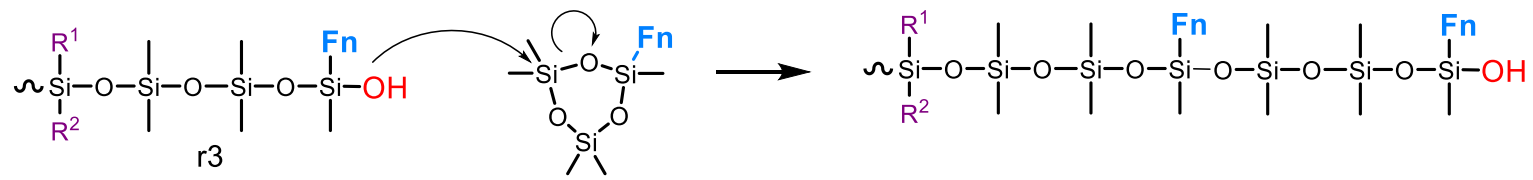

\section{Statistical propagation}
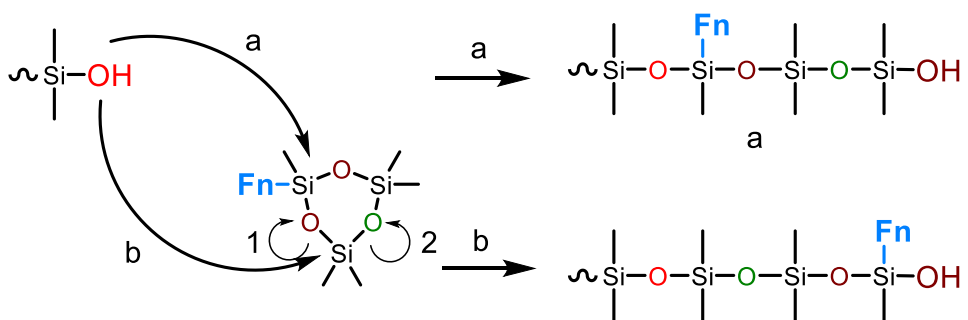

a
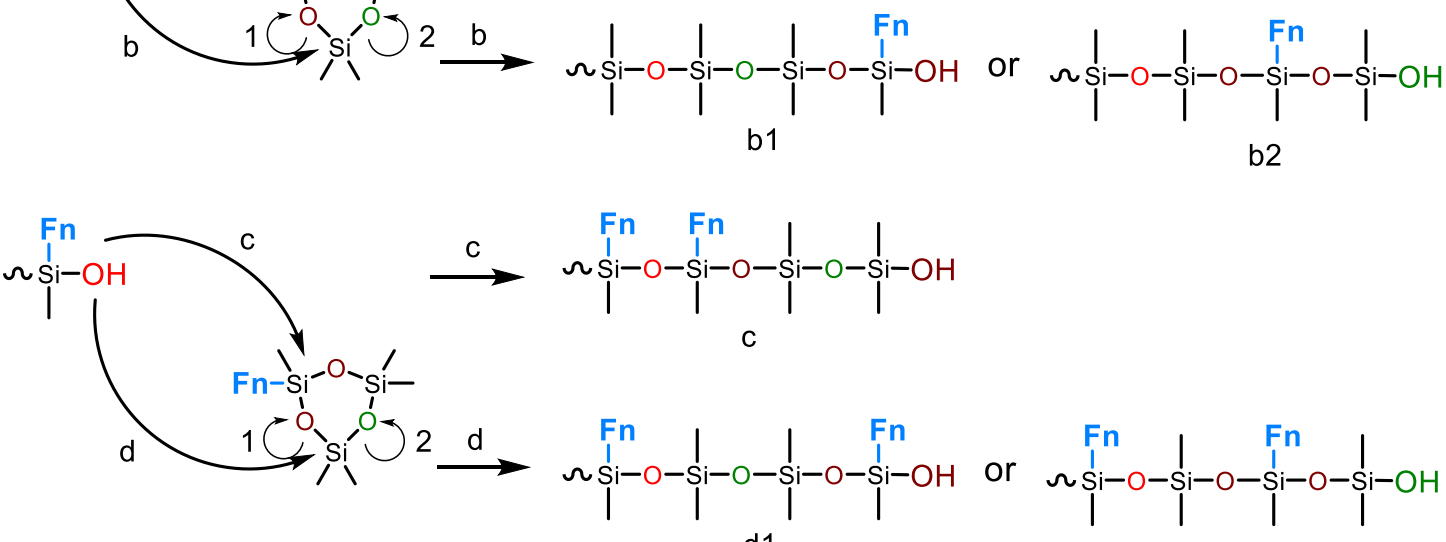

d1

d2

Theoretically, assuming perfect statistical propagation, the propagation reaction of FnD2 via a, b1, and $\mathrm{b} 2$, as well as that via $\mathrm{c}, \mathrm{d} 1$, and $\mathrm{d} 2$ with equal probability.

Figure S35. Comparison of the regio-selective propagation and the statistical propagation in the ROP of monofunctional cyclotrisiloxanes. 
(a) Initiation

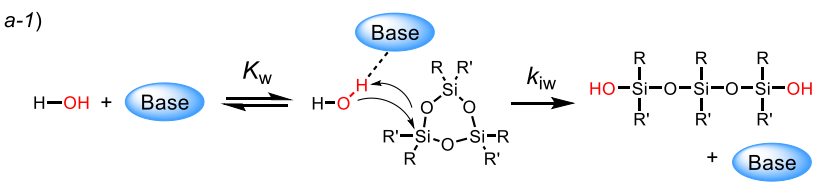

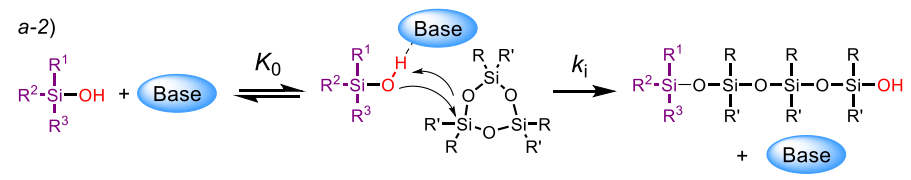

(b) Propagation

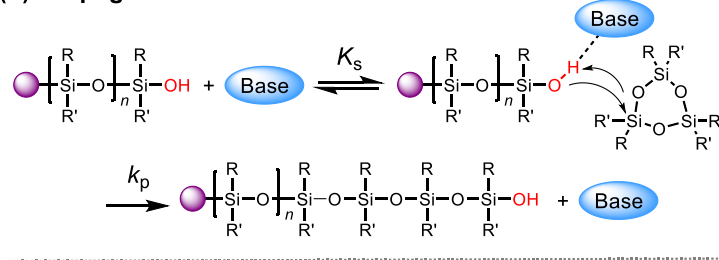

(c) Intermolecular transfer of a terminal hydroxysilyl group (disproportionation, allowable side-reaction)

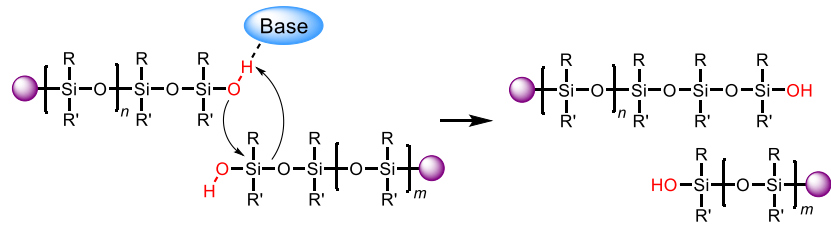

(d) Condensation (undesired side-reaction)

$d-1)$

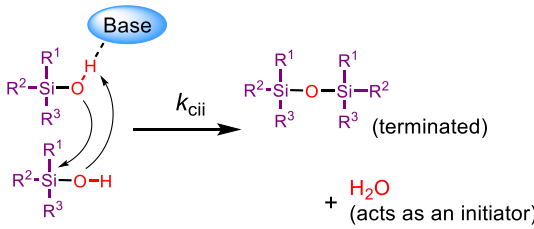

$d-2$

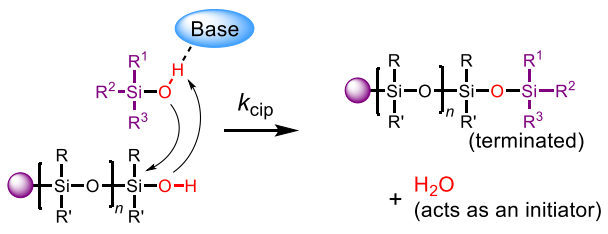

$d-3$
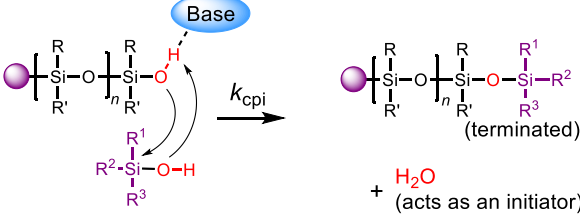

$+\mathrm{H}_{2} \mathrm{O}$

(acts as an initiator)

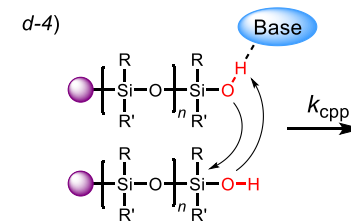

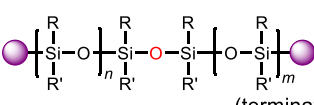

(terminated)

$+\mathrm{H}_{2} \mathrm{O}$

$\mathrm{H}_{2} \mathrm{O}$
(acts as an initiator)

(e) Backbiting (depolymerization, undesired side-reaction)

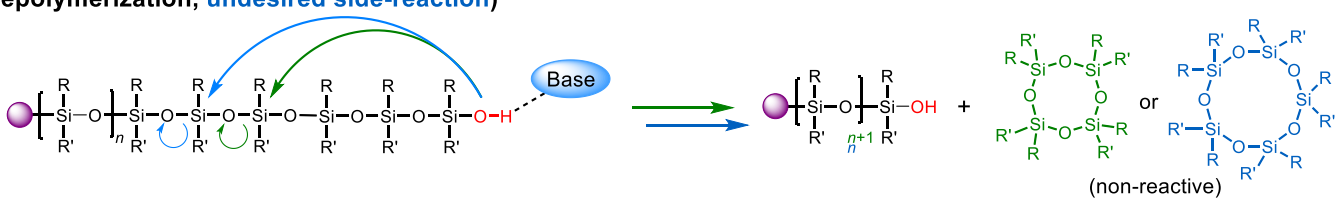

Scheme S1. Possible and plausible elementary reactions in the polymerization of cyclotrisiloxanes using a water or a silanol as an initiator and a strong organic base as a catalyst. 
Method to simulate the monomeric unit sequences and chain-length distributions of the side-chainfunctionalized polysiloxanes

\section{Simulation A) for the products obtained via the homopolymerization of FnD2}

This simulation uses the experimentally determined $M_{\mathrm{n}, \mathrm{NMR}}, \bigoplus_{\mathrm{M}}$, and molar ratios of the six possible monomer triads of P(DMS-co-FnMS), i.e., DDD/DDFn/FnDFn and FnFnFn/FnFnD/DFnD. The symbols D and Fn indicate a dimethylsiloxy unit and a methyl(organofunctional)siloxy unit, i.e. a methyl(vinyl)siloxy, a 3chloropropyl(methyl)siloxy unit, and an allyl(methyl)siloxy unit.

- $\quad$ Ten polymer chains are generated.

- The numbers of monomeric units, $X_{1} \ldots X_{10}$, for each polymer chain were determined from the normalized Gaussian distribution (Eq 1) using $\mu=\left[M_{\mathrm{n}, \mathrm{NMR}}-(\right.$ molar mass of terminal structure) $\left.]\right) / M_{\mathrm{AV}}, M_{\mathrm{AV}}=($ numberaverage molar mass of monomeric units in the polymer), and $\sigma=M_{\mathrm{n}, \mathrm{NMR}} / M_{\mathrm{AV}} \times\left(\bigoplus_{\mathrm{M}}-1\right)^{1 / 2}$. For P(DMS-coMVS) with $<X_{\mathrm{n}, \mathrm{D}}>=53.3$ and $<X_{\mathrm{n}, \mathrm{V}}>=27.0, M_{\mathrm{AV}}=\left(74.154<X_{\mathrm{n}, \mathrm{D}}>+86.165<X_{\mathrm{n}, \mathrm{V}}>\right) /\left(<X_{\mathrm{n}, \mathrm{D}}>+<X_{\mathrm{n}, \mathrm{V}}>\right)$.

$$
f(x)=\frac{1}{\sqrt{2 \pi} \sigma} \exp \left(\frac{-(x-\mu)^{2}}{2 \sigma^{2}}\right)
$$

- $\quad X_{n}$ was determined from the value that fulfills Eq 2:

$$
\int_{0}^{X_{n}} f(x)=\frac{n}{11}(n=1,2,3,4,5,6,7,8,9, \text { and } 10)
$$

$X_{n}$ was then rounded to the closest integer.

- $\quad$ First, two monomeric units were chosen for the 10 polymers. The probability of choosing each of the monomeric unit pairs $P(\mathrm{DD}), P(\mathrm{DFn}), P(\mathrm{FnD})$, and $P(\mathrm{FnFn})$ was calculated from the experimentally determined values of FnDFn/DDFn/DDD and FnFnFn/FnFnD/DFnD.

For example, for FnDFn/DDFn/DDD = 0.071/0.695/0.234 and FnFnFn/FnFnD/DFnD = 0.000/0.399/0.601 (Table 4, Entry 6), the six values were calculated to be $P(\mathrm{DDD})=0.234 /(2 / 3)=0.156, P(\mathrm{DDFn})=0.695 /(2 / 3)$ $=0.463_{3}, P($ FnDFn $)=0.071 /(2 / 3)=0.0473, P($ FnFnFn $)=0.000 /(1 / 3)=0.000, P($ FnFnD $)=0.399 /(1 / 3)=0.133$, and $P(\mathrm{DFnD})=0.601 /(1 / 3)=0.200_{3}$.

The first dyad sequence (DD/DFn/FnD/FnFn) was selected by comparing the following probabilities and a randomized number $R N D$ in the range of $[0,1)$ :

$$
\begin{aligned}
& P(\mathrm{DD})=P(\mathrm{DDD})+P(\mathrm{DDFn}) / 2=0.387_{65} \\
& P(\mathrm{DFn})=P(\mathrm{DFnD})+P(\mathrm{FnFnD}) / 2=0.266_{8} \\
& P(\mathrm{FnD})=P(\mathrm{DDFn}) / 2+P(\mathrm{FnDFn})=0.278_{95} \\
& P(\mathrm{FnFn})=P(\mathrm{FnFnD}) / 2+P(\mathrm{FnFnFn})=0.066_{5}
\end{aligned}
$$

- A single monomeric unit was repeatedly added to the previously generated sequences of monomeric units until the length of the polymer chain reached $X_{1} \ldots X_{10}$ monomeric units.

For the simulation of the polymerizations using water as an initiator, monomeric units were added to the left and right of the generated monomeric sequence. For those using a silanol as an initiator, a monomeric unit was only added to the right. The monomeric unit was selected by comparing the following probabilities and a randomized number in the range of $[0,1)$ : 
Combination of terminal dyad and Probability

an incoming monomeric unit

$\begin{array}{ll}\ldots . . \mathrm{DD}+\mathrm{D} & P(\mathrm{DDD}) \times(2 / 3) \\ \ldots \mathrm{DD}+\mathrm{Fn} & P(\mathrm{DDFn}) / 2 \times(2 / 3) \\ \ldots \mathrm{DFn}+\mathrm{D} & P(\mathrm{DFnD}) \times(1 / 3) \\ \ldots \mathrm{DFn}+\mathrm{Fn} & P(\mathrm{FnFnD}) / 2 \times(1 / 3) \\ \ldots \mathrm{FnD}+\mathrm{D} & P(\mathrm{DDFn}) / 2 \times(2 / 3) \\ \ldots \mathrm{FnD}+\mathrm{Fn} & P(\mathrm{FnDFn}) / 2 \times(2 / 3) \\ \ldots \mathrm{FnFn}+\mathrm{D} & P(\mathrm{FnFnD}) / 2 \times(1 / 3) \\ \ldots \mathrm{FnFn}+\mathrm{Fn} & P(\mathrm{FnFnFn}) \times(1 / 3)\end{array}$

- The results of simulation A are shown in Figures S36-S38. The monomeric units of D and Fn are shown as

and $\bigcirc$, respectively.

\section{Simulation B) for the products in the copolymerizations}

- The simulation uses the following parameters:

(1) $X_{\mathrm{M} 1}$ and $X_{\mathrm{M} 2}$, which are the initial molar ratios of the two monomers, $\mathrm{M}_{1}(=\mathrm{FnD} 2)$ and $\mathrm{M}_{2}$ (= D3 or Fn'D2), relative to the initiator;

(2) $k_{\mathrm{p} \text {,app }}$ and $\bigoplus_{\mathrm{M}}$, which are experimentally determined;

(3) $t_{\exp }$, which is the polymerization time in the actual experiments.

- Ten polymer chains were generated.

- The propagation reaction of the polymer chains was simulated. Condensation and intermolecular transfer of a terminal siloxy group (Scheme S1) were ignored in this simulation.

- For example, the values $X_{\mathrm{M} 1}=7.5, X_{\mathrm{M} 2}=17.5, k_{\text {p,app_M1 }}=0.83, k_{\text {p,app_M2 }}=0.85, \bigoplus_{\mathrm{M}}=1.095$, and $t_{\text {exp }}=2.6[\mathrm{~h}]$ were used for the simulation of the copolymerization of AD2 (M1) and D3 (M2) shown in Table 3, Entry 6.

- The values of the expected numbers of monomeric units, $X_{1} \ldots X_{10}$, in each polymer chain were determined from 
Eq 1 and Eq 2 using $\mu=X_{\mathrm{M} 1} \times\left[1-\exp \left(-k_{\text {p,app_M1 }} \times t_{\text {exp }}\right)\right]+X_{\mathrm{M}_{2}} \times\left[1-\exp \left(-k_{\text {p,app_M2 }} \times t_{\text {exp }}\right)\right]$ and $\sigma=\mu\left(\bigoplus_{\mathrm{M}}\right.$ $-1)^{1 / 2}$.

- The overall polymerization was divided into $Y$ stages. The propagation reactions in each stage were simulated for each polymer chain to generate sequences of monomeric units. This process was repeated $Y$ times. The initial value of the time, $t$, was set to 0 . After one round of the process, $t_{\text {step }}\left(=t_{\exp } / Y\right)$ was added to $t$ for the next round. A $Y$ value of 20 was used in this study.

- The following equations gave the numbers of monomers reacting with each polymer between $t$ and $t+t_{\text {step }}$ :

$$
\begin{aligned}
& N_{\mathrm{M} 1}=X_{n} \times\left[X_{\mathrm{M} 1} /\left(X_{\mathrm{M} 1}+X_{\mathrm{M} 2}\right)\right] \times\left[\left\{1-\exp \left[-k_{\mathrm{p}, \text { app } \_\mathrm{M} 1} \times\left(t+t_{\text {step }}\right)\right]\right\}-\left[1-\exp \left(-k_{\mathrm{p}, \text { app } \_\mathrm{M} 1} \times t\right)\right]\right] \\
& N_{\mathrm{M} 2}=X_{n} \times\left[X_{\mathrm{M} 2} /\left(X_{\mathrm{M} 1}+X_{\mathrm{M} 2}\right)\right] \times\left[\left\{1-\exp \left[-k_{\mathrm{p}, \text { app } \_\mathrm{M} 2} \times\left(t+t_{\text {step }}\right)\right]\right\}-\left[1-\exp \left(-k_{\mathrm{p}, \text { app } \_\mathrm{M} 2} \times t\right)\right]\right]
\end{aligned}
$$

- Additionally, the following values were calculated:

$N_{\text {total }}=N_{\mathrm{M} 1}+N_{\mathrm{M} 2}+N_{\text {residual }}$

( $N_{\text {residual }}$ is the decimal part of $N_{\text {total }}$ in the previous round of the process. Zero is used for $N_{\text {residual }}$ in the first round of the process.)

$r_{\mathrm{M} 2}=N_{\mathrm{M} 2} /\left(N_{\mathrm{M} 1}+N_{\mathrm{M} 2}\right)$

$N_{\text {total_int }}$ was calculated by rounding off $N_{\text {total }}$.

- $\quad$ If $N_{\text {total }} \geq 1$, the polymer chain reacts with M1 or M2 $N_{\text {total_int }}$ times. M1 or M2 was selected by comparing $r_{\mathrm{M} 2}$ and a randomized number, $R N D$, within the range of $[0,1)$. Namely, if $R N D<r_{\mathrm{M} 2}$, a triad sequence was randomly selected from among FnDD (○○), DFnD (○○), or DDFn (○○). The selected triad was used as the first triad sequence of the polymer chain or randomly added to the left or the right of the already generated polymer chain. If $R N D \geq r_{\mathrm{M} 2}$ and $\mathrm{M} 2$ was $\mathrm{D} 3$, a triad sequence from D3, i.e., DDD ( $)$ ), was used as the first triad sequence or randomly added to the left or right of the already generated polymer chain. If M2 was Fn'D2, a triad sequence was randomly selected from among Fn'DD ( $\triangle \bigcirc)$, DFn'D $(\triangle \triangle)$, or $\operatorname{DDFn}^{\prime}(\bigcirc)$ instead of DDD.

- The decimal part of $N_{\text {total }}$ was used as $N_{\text {residual }}$ for the next round of the process.

- Triad sequences were randomly selected in this simulation because we found that statistical propagation was predominant in the actual polymerization experiments.

- The results of simulation A are shown in Figures S36-S39. The monomeric units D, Fn, and Fn' are shown as $\bigcirc$, and $\triangle$, respectively. 
copolymerizations of FnD2 and D3 proceeding via statistical propagation.

- The values shown in Table 4, Entries 4 and 5 were determined by the following process.

- A sufficiently long sequence of (=D) and $\bigcirc$ (= Fn) was randomly generated by combining the four possible triad sequences, i.e., determined from the molar ratio of $\mathrm{D} 3$ and $\mathrm{FnD} 2$ used in the polymerization.

- For example, in a polymerization using $\mathrm{D} 3 / \mathrm{FnD} 2=5 / 5$, the ratio of the four triad sequences would be:

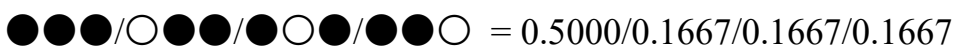

- In a polymerization using $\mathrm{D} 3 / \mathrm{FnD} 2=3 / 7$, the ratio of the four triad sequences would be:

$\bullet \bullet / \bigcirc \bullet \bullet \odot \bullet / \bullet \bullet ○=0.7 / 0.1 / 0.1 / 0.1$

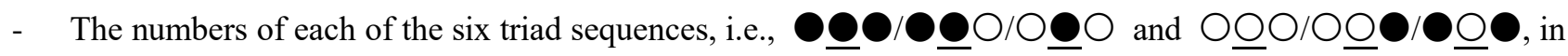
the resultant sequence were counted to determine the theoretical ratio. 
$P(D M S-c o-M V S)$
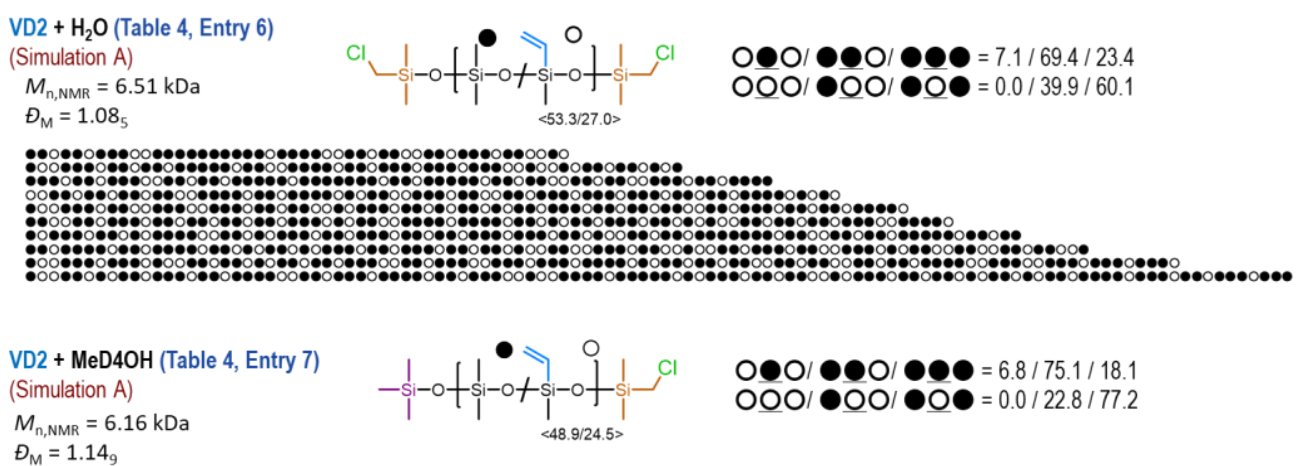

$\Theta_{\mathrm{M}}=1.14_{9}$
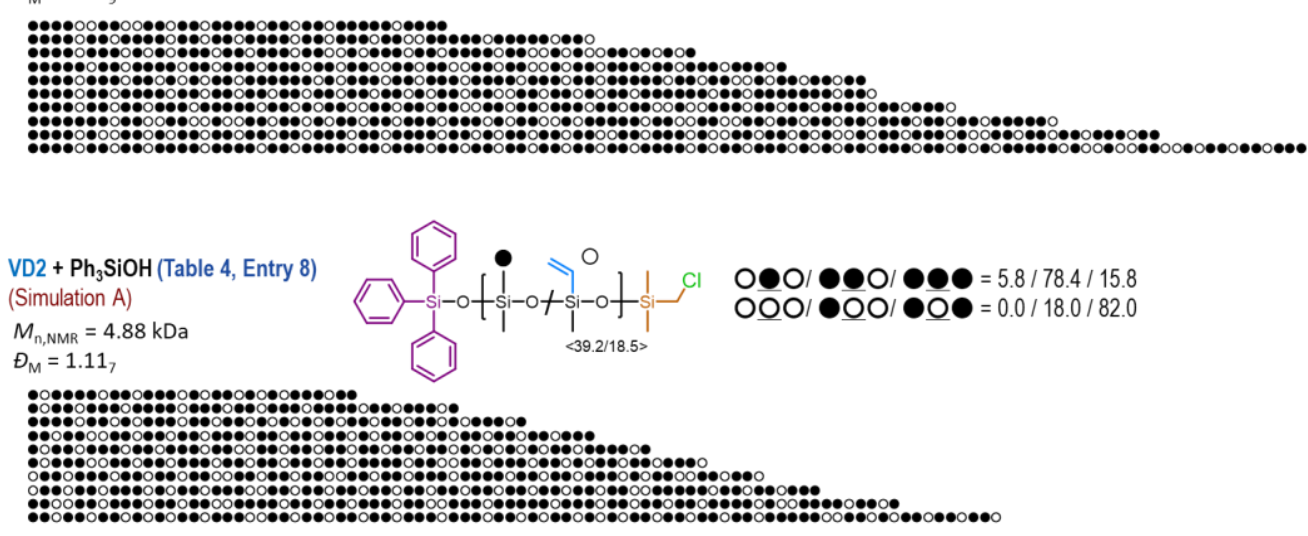

$\mathrm{V} 3+\mathrm{D} 3+\mathrm{H}_{2} \mathrm{O}$ (Semi-batch, Table 4, Entry 12)
$($ Simulation A)
$M_{\mathrm{n}, \mathrm{NMR}}=6.34 \mathrm{kDa}$
$\Theta_{\mathrm{M}}=1.12_{6}$

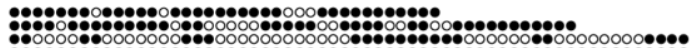

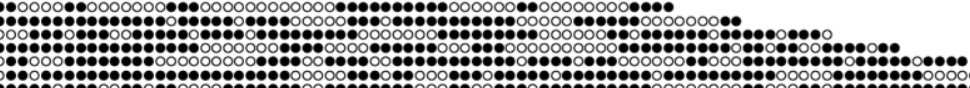

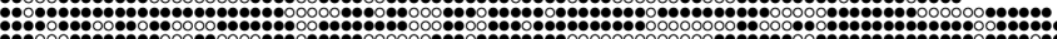

$\mathrm{V} 3+\mathrm{D} 3+\mathrm{H}_{2} \mathrm{O}$ (Premix, Ref 18$)$

(Simulation B)

$k_{\mathrm{p}, \text { app }}(\mathrm{V} 3)=3.86$

$k_{\mathrm{D}, \mathrm{ap}}(\mathrm{D} 3)=0.17$

$X_{\mathrm{v} 3} / X_{\mathrm{D} 3}=25 / 25$

$\Theta_{\mathrm{M}}=1.15_{2}, t_{\text {exp }}=9.0 \mathrm{~h}$
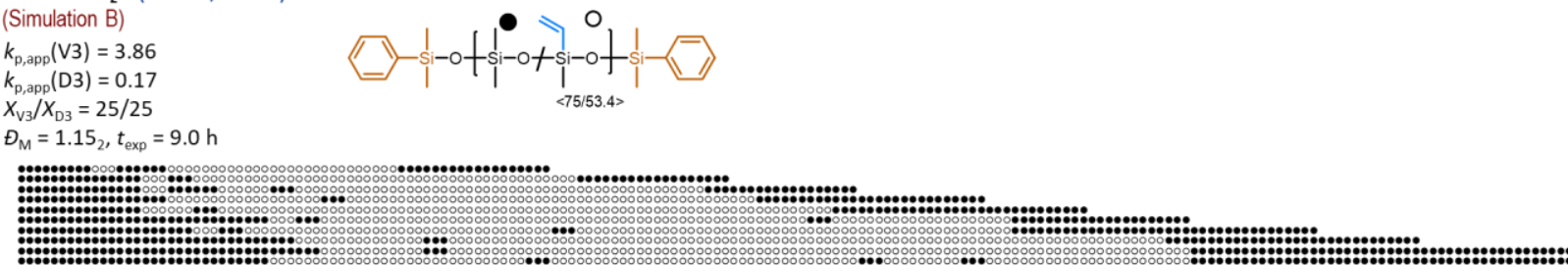

VD2 + D3 + $\mathrm{H}_{2} \mathrm{O}$ (Table 4, Entry 13)

(Simulation B)

$k_{\mathrm{p}, \text { app }}(\mathrm{VD} 2)=1.38$

$k_{\mathrm{p}, \mathrm{ppp}}(\mathrm{D} 3)=0.41$

$X_{\mathrm{VD} 2} / X_{\mathrm{D} 3}=12.5 / 12.5$

$\Theta_{\mathrm{M}}=1.12_{1}, t_{\exp }=4.0 \mathrm{~h}$
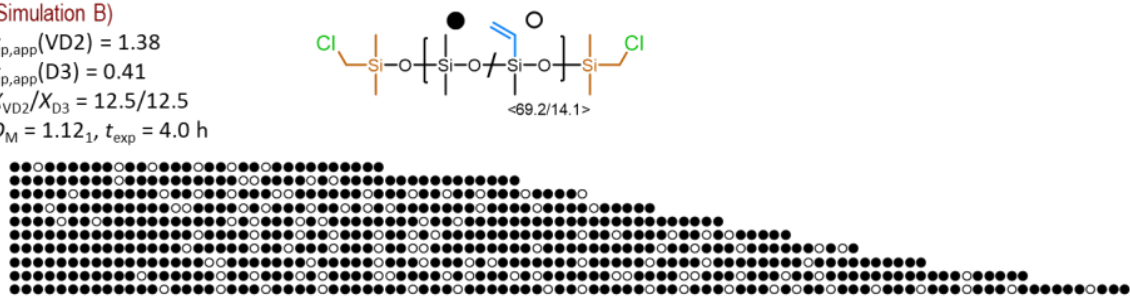

Figure S36. Simulated results for the sequence of monomeric units and distribution of chain length of P(DMS-coMVS) synthesized with different methods. The parameters used for each polymer are indicated in the figures. The first, second, and sixth data are also shown in Figure 1. 
$P(D M S-c o-C l P M S)$
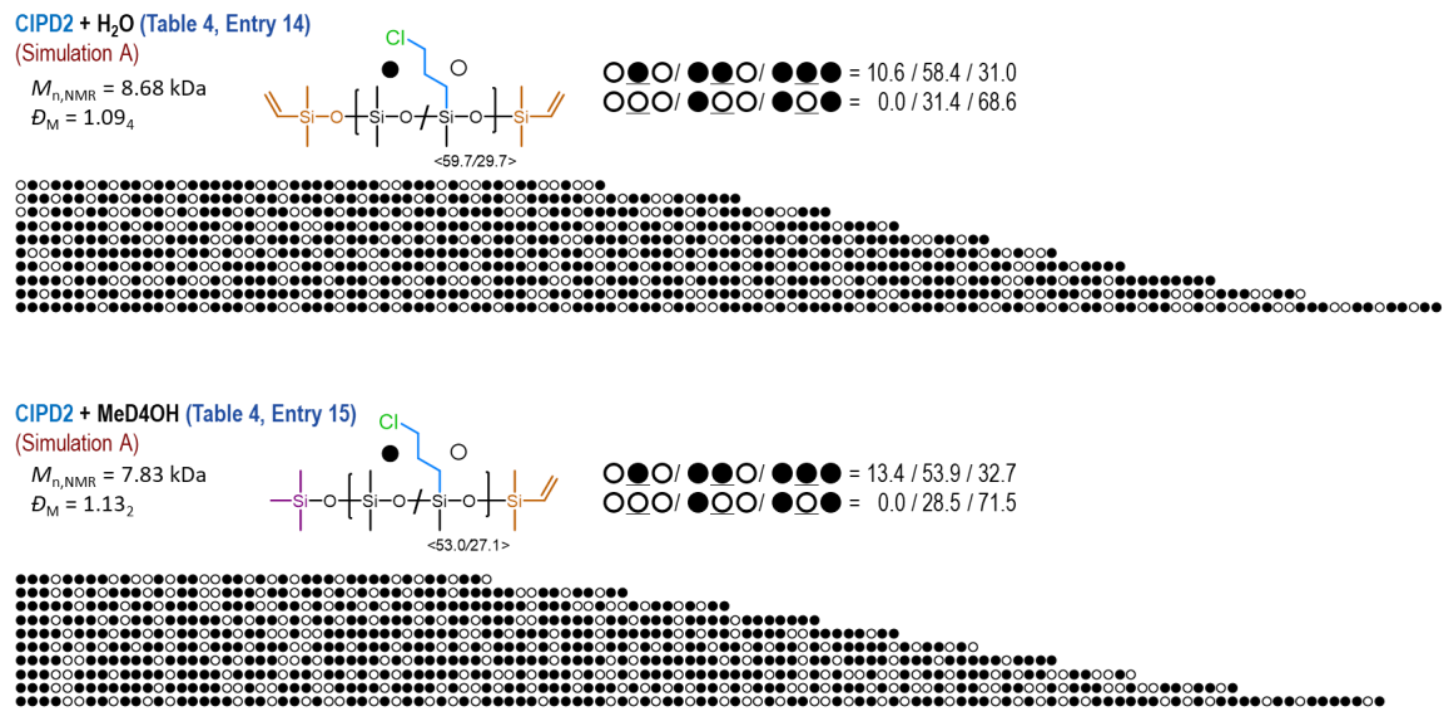

$\mathrm{CIPD} 2+\mathrm{D} 3+\mathrm{H}_{2} \mathrm{O}$ (Table 4, Entry 17)
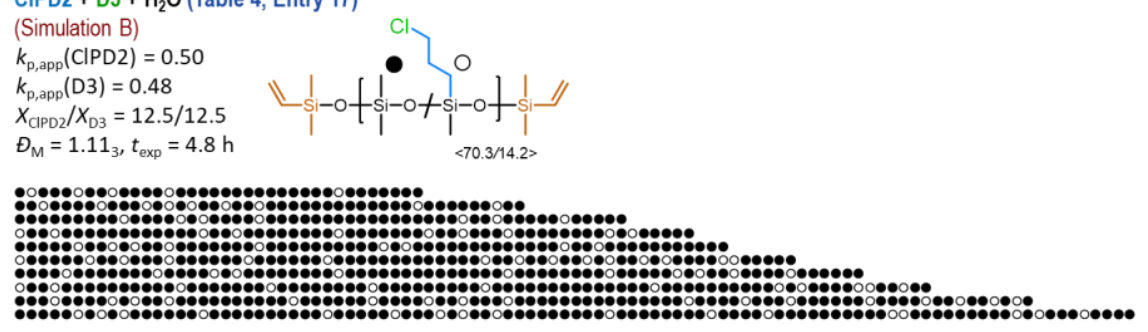

Figure S37. Simulated results for the sequence of monomeric units and distribution of chain length of P(DMS-coCIPMS) synthesized with different methods. The parameters used for each polymer are indicated in the figures. 
$P(D M S$-co-AMS)
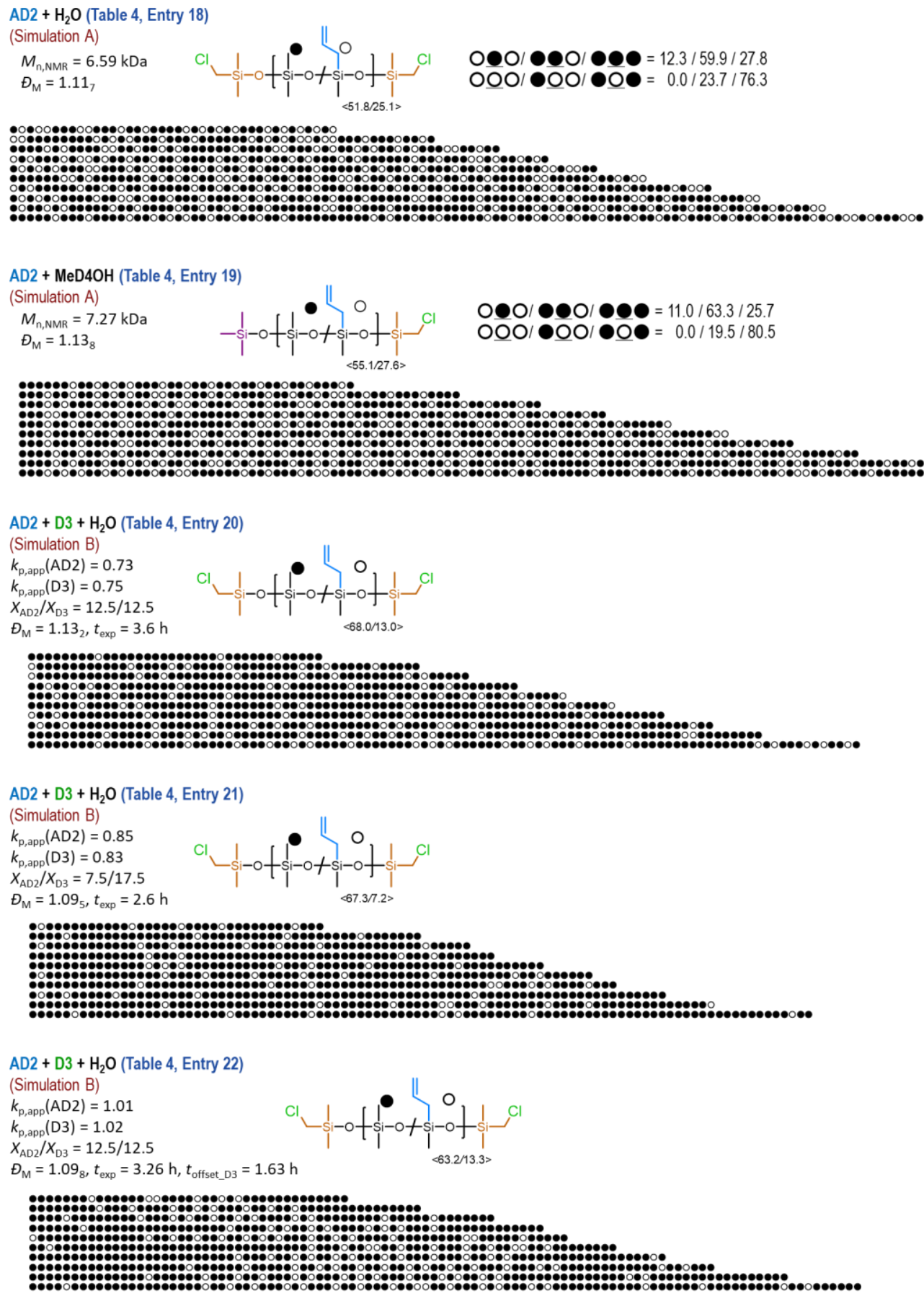

Figure S38. Simulated results for the sequence of monomeric units and distribution of chain length of P(DMS-coAMS) synthesized with different methods. The parameters used for each polymer are indicated in the figures. 
$\mathrm{VD2}+\mathrm{CIPD} 2+\mathrm{H}_{2} \mathrm{O}$ (Table 3, Entry 4)

(Simulation B)

$k_{\mathrm{p}, \mathrm{app}}(\mathrm{VD2})=1.23$

$k_{\mathrm{p}, \text { app }}(\mathrm{ClPD} 2)=0.50$

$X_{\mathrm{VD} 2} / X_{\mathrm{CIPD} 2}=12.5 / 12.5$

$\Theta_{\mathrm{M}}=1.10_{2}, t_{\exp }=3.1 \mathrm{~h}$

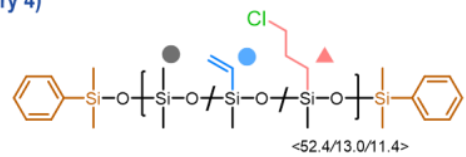

:०A
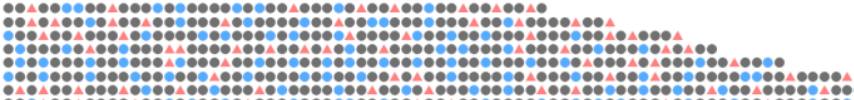

$\mathrm{AD2}+\mathrm{CIPD} 2+\mathrm{H}_{2} \mathrm{O}($ Table 3 , Entry 5$)$

(Simulation B)

$k_{\mathrm{p}, \text { app }}(\mathrm{AD2})=0.37$

$k_{\mathrm{p}, \text { app }}(\mathrm{ClPD} 2)=0.42$

$X_{\mathrm{AD2}} / X_{\mathrm{CIPD} 2}=12.5 / 12.5$

$\theta_{\mathrm{M}}=1.13_{1}, t_{\mathrm{exp}}=6.9 \mathrm{~h}$
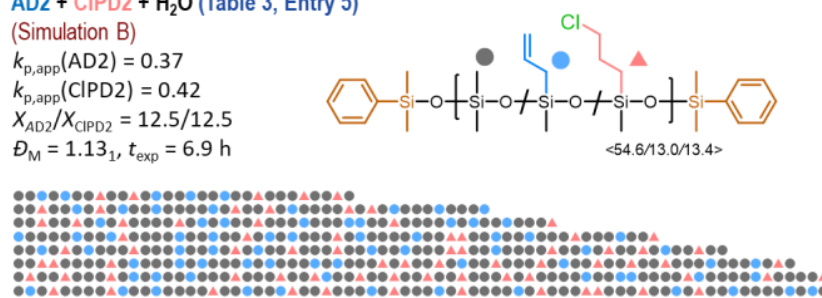

Figure S39. Simulated results for the sequence of monomeric units and distribution of chain length of P(DMS-coMVS-co-ClPMS) and P(DMS-co-AMS-co-ClPMS) synthesized with different methods. The parameters used for each polymer are indicated in the figures. 


\section{References}

(S1) Fuchise, K.; Igarashi, M.; Sato, K.; Shimada, S. Organocatalytic controlled/living ring-opening polymerization of cyclotrisiloxanes initiated by water with strong organic base catalysts. Chem. Sci. 2018, 9, 2879-2891.

(S2) Kreshkov, A. P.; Karateev, D. A.; Fyurst, V. I. Reaction of Organosilicon Compounds Containing Vinyl Groups Directly Linked to Silicon Atoms with Boric and Phosphoric Acids and with Phosphoric Anhydride. J. Appl. Chem. USSR 1961, 34, 2564-2567.

(S3) Andrianov, K. A.; Zhdanov, A. A.; Rodionova, E. F.; Vasilenko, E. G. Synthesis of Organocyclosiloxanes with a 2-Siloxanylethyl Group on One Silicon Atom. J. Gen. Chem. USSR 1975, 45, 2401-2403.

(S4) Hempenius, M. A.; Lammertink, R. G. H.; Vancso, G. J. Side-Chain Liquid-Crystalline Polysiloxanes via Anionic Polymerization: (n-Undecyloxy)arenecarboxylic Acid Mesogens Linked to Poly(dimethylsiloxane-comethylvinylsiloxane). Macromolecules 1997, 30, 266-272.

(S5) Fortuniak, W.; Chojnowski, J.; Sauvet, G. Controlled Synthesis of Siloxane Polymers and Siloxane-Siloxane Block Copolymers with 3-Chloropropyl Groups Pendant to the Siloxane Chain. Macromol. Chem. Phys. 2001, 202, 2306-2313.

(S6) Frisch, K. C.; Goodwin, P. A.; Scott, R. E. Hydrolysis and Separation of Unsaturated Chlorosilanes. J. Am. Chem. Soc. 1952, 74, 4584-4585.

(S7) Fuchise, K.; Kobayashi, T.; Sato, K.; Igarashi, M. Organocatalytic ring-opening polymerization of cyclotrisiloxanes using silanols as initiators for the precise synthesis of asymmetric linear polysiloxanes. Polym.

Chem. 2020, 11, 7626-7635. 